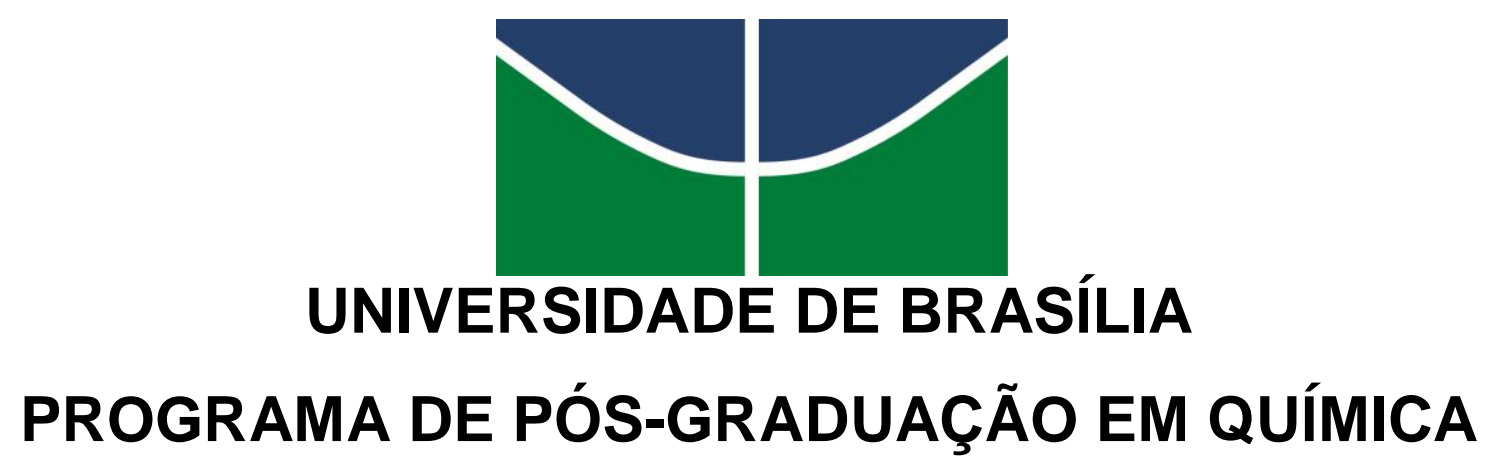

\author{
DISSERTAÇÃO DE MESTRADO
}

\title{
AVALIAÇÃO DOS PROCESSOS FENTON E FOTO- FENTON NO TRATAMENTO DA ÁGUA DE LAVAGEM DO BIODIESEL DE SOJA
}

Gabriel Ferreira da Silva Brito

Orientadora: Profa. Dra. Fernanda Vasconcelos de Almeida Coorientadora: Profa. Dra. Ingrid Távora Weber

$$
\begin{gathered}
\text { Brasília - DF } \\
2015
\end{gathered}
$$




\section{AVALIAÇÃO DOS PROCESSOS FENTON E FOTO-FENTON NO TRATAMENTO DA ÁGUA DE LAVAGEM DO BIODIESEL DE SOJA}

Dissertação apresentada ao Instituto de Química da Universidade de Brasília como requisito parcial para obtenção do título de Mestre em Química.

Área de concentração: Química Analítica

Orientadora: Profa. Dra. Fernanda Vasconcelos de Almeida

Coorientadora: Profa. Dra. Ingrid Távora Weber

\section{Brasília - DF}




\section{FOLHA DE APROVAÇÃO}

Comunicamos a aprovação da Defesa de Dissertação de Mestrado do (a) aluno (a) Gabriel Ferreira da Silva Brito, matrícula no 13/0163309, intitulada "Avaliação dos processos Fenton e foto-Fenton no tratamento da água de lavagem do biodiesel de soja", apresentada no (a) Auditório Verde do Instituto de Química (IQ) da Universidade de Brasília (UnB) em 9 de dezembro de 2015.

\section{Profa Dra Fernanda Vasconcelos de Almeida \\ Presidente de Banca (IQ/UnB)}

Prof. Dr. José Joaquín Linares León

Membro Titular (IQ/UnB)

Dra Kaline Amaral Wanderley

Membro Titular (UFPE)

Profa Dra Marly Eiko Osugi

Membro Suplente (IQ/UnB)

Em 9 de dezembro de 2015. 
Dedico este estudo a minha mãe, que sempre me apoiou e me deu todos os recursos necessários a minha formação. 


\section{AGRADECIMENTOS}

A Deus.

A minha mãe Valmira por ser quem mais me dá forças e quem jamais deixará de estar ao meu lado.

Aos meus irmãos Daniel, Jaqueline e Juninho, que são grandes inspirações e fonte de força de vontade para mim.

Aos meus amigos Daniel, Gleison, James e Wesley, por tornarem divertidos os meus dias e fazerem deles dias mais felizes, além de me fazerem acreditar no meu potencial.

Aos meus amigos Ana Cândida, Cristiane Silva, Elder Romão, Ídio Filho, Karolyne Vilela, pelo apoio e por serem essas pessoas maravilhosas que eles são.

Aos meus amigos de laboratório que estiveram comigo durante esse tempo de estudos e também de risadas no laboratório, Tati, Carla, Nancy, Victor, Thiago.

Aos meus ilustríssimos Professores Doutores do AQQUA, Fernanda Vasconcelos, Fernando Sodré, Jez Willian, Valéria Regina, Ana Cristi, e Alexandre Fonseca pela paciência e prontidão em ensinar, ajudar e aconselhar.

Ao laboratório LIMA pela disponibilidade e auxílio nas análises de COT e também por compartilhar conhecimento em nossas reuniões semanais.

Às Profas Dra Fernanda Vasconcelos e Ingrid Távora, pela excelente orientação prestada, pela compreensão, pelos puxões de orelha e pelos ensinamentos que serão levados para o resto de minha vida.

Aos membros da banca examinadora por aceitarem estar presentes e dividir seus conhecimentos para contribuir com o aperfeiçoamento do meu trabalho.

Aos amigos e professores Rhaul e César, do LABGEN do instituto de biologia da UnB pelo apoio e colaboração prestados para a realização deste trabalho. 
A todos os estudantes e professores do IQ, que direta ou indiretamente colaboraram para a realização deste trabalho, bem como para o meu desenvolvimento pessoal.

À professora Marly Osugi e ao professor José Joaquim, por ser mais que professores, sempre colaborando com o desempenho do meu trabalho.

À Capes, à FAP e ao INCTAA pelo auxílio financeiro prestado e colaborações para que essa pesquisa pudesse ser realizada.

À UnB, ao Instituto de Química e ao PPGQ pela experiência.

Muito obrigado a todos! 
"Por vezes sentimos que aquilo que fazemos não é senão uma gota de água no mar. Mas o mar seria menor se Ihe faltasse uma gota."

Madre Teresa de Calcutá 
BRITO, G. F. S. Avaliação dos processos Fenton e foto-Fenton no tratamento da água de lavagem do biodiesel de soja. Dissertação (Mestrado em Química) - Universidade de Brasília, Brasília, 2015.

O processo de produção do biodiesel merece atenção quanto à geração de resíduos. A etapa de purificação do biodiesel é geradora de grandes volumes de água de lavagem, numa proporção de até 1:3 biodiesel:água de lavagem. Considerando o crescimento atual na produção de biodiesel e consequentemente o volume gerado da água de lavagem, é de grande importância o eficiente tratamento deste resíduo impedindo que ele chegue aos corpos hídricos na sua forma bruta. Devido ao seu baixo custo e elevada taxa de degradação de compostos orgânicos em soluções aquosas, os processos oxidativos avançados Fenton e foto-Fenton apresentam-se como boas alternativas para o tratamento da água de lavagem do biodiesel e, por este motivo foram avaliados neste trabalho. As amostras de água de lavagem foram obtidas em escala laboratorial e caracterizadas. Apresentaram teor de COT de $40700 \pm 570 \mathrm{mg} \mathrm{L}^{-1}$; TOG de $2237 \pm 204 \mathrm{mg} \mathrm{L}^{-1} ;$ DQO de $24210 \pm 265 \mathrm{mg} \mathrm{L}^{-1} \mathrm{e}$ valor de $\mathrm{CL}_{50}$ para o teste FET de 0,118 $\% \mathrm{em} \mathrm{pH}$ 7. Foram avaliadas as melhores concentrações de $\mathrm{Fe}(\mathrm{II})$ e $\mathrm{H}_{2} \mathrm{O}_{2}$ pelo processo Fenton, que foi realizado utilizando como fonte de ferro o $\mathrm{FeSO}_{4} \cdot 7 \mathrm{H}_{2} \mathrm{O}$, para obter uma concentração de $\mathrm{Fe}^{2+}$ de $20 \mathrm{mg} \mathrm{L}^{-1}$ e $250 \mu \mathrm{L}$ de volume de peróxido de hidrogênio $30 \%$ $\mathrm{v} / \mathrm{v}$ adicionado a cada $15 \mathrm{~min}$ em $100 \mathrm{~mL}$ de amostra sob agitação constante, devido ao seu desempenho e menor impacto ambiental. $O$ processo foto-Fenton foi realizado utilizando as mesmas concentrações para o Fenton, porém dentro de um reator caseiro sob irradiação de uma lâmpada de vapor de mercúrio de média pressão de potência de $125 \mathrm{~W}$ sem o bulbo. Para avaliar a influência da luz e do peróxido, os processos UV e $\mathrm{UV} / \mathrm{H}_{2} \mathrm{O}_{2}$ também foram avaliados. Amostras foram coletadas periodicamente para avaliação do COT até 300 min para o Fenton e 480 min para os demais processos. $O$ processo Fenton não reduziu de forma significativa os compostos orgânicos do resíduo e por esta razão foi descontinuado em 300 min. No entanto, no período de 480 min, nenhum processo foi suficiente para remover $100 \%$ dos contaminantes orgânicos da água de lavagem. O foto-Fenton apresentou o melhor desempenho reduzindo $93,8 \%$ do COT. Embora apresente remoção satisfatória do COT, o processo foto-Fenton não é suficiente para enquadrar o efluente, dentro do tempo proposto, na norma para lançamento de efluentes para águas salobras ou águas salinas (CONAMA 430/2011), nem tampouco reduzir a toxicidade do efluente, que aumenta após o tratamento.

Palavras-chave: Água de lavagem, Biodiesel, Fenton, foto-Fenton. 
BRITO, G. F. S. Evaluation of Fenton and foto-Fenton processes in treatment of soybean biodiesel wastewater. Thesis (Chemistry Master's Degree) - University of Brasília, Brasília, 2015.

Biodiesel production process need some attention of the residue generation. The purification step generate a lot amount of biodiesel wastewater up in a 1:3 biodiesel: wastewater proportion. Considering the current growth in biodiesel production and, consequently, the wastewater volume, the treatment of this residue is important to prevent that it get in a water bodies in raw form. Due his low cost and high organic compounds degradation rates, the advanced oxidation processes Fenton and photo-Fenton are good alternatives for the treatment of biodiesel wastewater and that is the reason why they were used in this work. Biodiesel wastewater samples were obtained in a laboratory scale and characterized by TOC $\left(40700 \pm 204 \mathrm{mg} \mathrm{L}^{-1}\right)$, Oil \& Grease $\left(2237 \pm 204 \mathrm{mg} \mathrm{L}^{-1}\right)$, COD $\left(24210 \pm 265 \mathrm{mg} \mathrm{L}^{-1}\right)$ and LC $50(0,118 \% \mathrm{in} \mathrm{pH} 7)$ for the FET. The best concentration from $\mathrm{Fe}(\mathrm{II})$ and $\mathrm{H}_{2} \mathrm{O}_{2}$ were evaluated to Fenton process, that used $\mathrm{FeSO}_{4} \cdot 7 \mathrm{H}_{2} \mathrm{O}$ as iron source to obtain a $\left[\mathrm{Fe}^{2+}\right]=20 \mathrm{mg} \mathrm{L}^{-1}$ and $250 \mu \mathrm{L}$ of $\mathrm{H}_{2} \mathrm{O}_{2} 30 \% \mathrm{v} / \mathrm{v}$ add each $15 \mathrm{~min}$ in $100 \mathrm{~mL}$ of sample under constant stirring, due his performance and low environmental impact. Photo-Fenton process was carried out using same concentrations of Fenton but inside a homemade reactor under irradiation of a $125 \mathrm{~W}$ mercury mid-pressure lamp without bulb. To evaluate the light and the peroxide influence, the processes UV and $U V / \mathrm{H}_{2} \mathrm{O}_{2}$ were carried out too. Samples were collected periodically until $300 \mathrm{~min}$ for Fenton and $480 \mathrm{~min}$ for the other processes for TOC measures. Fenton did not reduce significantly the organic compounds and for that reason was stopped in $300 \mathrm{~min}$. However, no one reduce $100 \%$ of organic contaminants of the biodiesel wastewater. The photo-Fenton showed the best performance and reduced approximately $93.2 \%$ of COT, but was not enough to put the residue accord legislation (CONAMA 430/2011) and nor reduced the toxicity of effluent.

Keywords: Biodiesel, wastewater, washwater, Fenton, photo-Fenton. 
Figura 1. Produção de biodiesel acumulada mensalmente entre 2012 e agosto de 2015 (Fonte: MME, 2015). .7

Figura 2. Esquema de conversão de um triacilglicerol em biodisel via alcóolise... .8

Figura 3. Etapas reacionais envolvidas na transesterificação de triacilglicerídeos (Meneghetti e Colaboradores, 2013). 9

Figura 4. Classificação dos processos oxidativos (adaptado de Poyatos e colaboradores, 2010). 19

Figura 5. Níveis energéticos dos materiais (Adaptado de Teixeira \& Jardim, 2004). .....20

Figura 6. Etapas de produção e coleta da água de lavagem do biodiesel de soja. A alcóolise; B - decantação da glicerina e C - lavagem (Fotografias de arquivo do autor).

Figura 7. Sistema reator para realização de foto-ensaio para degradação da água de lavagem do biodiesel. A - Interior do reator e B - Exterior (Fotografias do arquivo do autor).

Figura 8. Esquema dos testes de toxicidade em embriões de peixe-zebra (adaptada de OECD, 2013).

Figura 9. Da esquerda para direita. a- Glicerina bruta; b- Biodiesel; c- Primeira fração da água de lavagem; d-Segunda fração da água de lavagem (Fotografia do arquivo do autor).

Figura 10. Curvas de dose resposta para o zebrafish após o quarto dia do teste com água de lavagem de biodiesel. .38

Figura 11. Ensaio preliminar com duração de 180 minutos (proporção $\mathrm{Fe}^{2+}: \mathrm{H}_{2} \mathrm{O}_{2} \mathrm{em} \mathrm{mgL}$ $\left.{ }^{1}\right)$. O eixo vertical foi iniciado em $70 \%$ para efeitos de melhor visualização.

Figura 12. Gráfico de degradação de COT por processo Fenton (100 mL de amostra; $\left[\mathrm{Fe}^{2+}\right]=20 \mathrm{mg} \mathrm{L}^{-1}$ e $\left.\left[\mathrm{H}_{2} \mathrm{O}_{2}\right]=1000 \mathrm{mg} \mathrm{L}^{-1}\right)$ da água de lavagem de biodiesel de soja. ...42 
Figura 13. Gráfico de degradação de COT pelo processo foto-Fenton (100 mL de amostra; $\lambda=254 \mathrm{~nm} ;\left[\mathrm{Fe}^{2+}\right]=20 \mathrm{mg} \mathrm{L}^{-1}$ e $\left.\left[\mathrm{H}_{2} \mathrm{O}_{2}\right]=1000 \mathrm{mg} \mathrm{L}^{-1}\right)$.

Figura 14. Gráfico de degradação de COT por processo foto-Fenton (100 mL de amostra; $\lambda=254 \mathrm{~nm} ;\left[\mathrm{Fe}^{2+}\right]=20 \mathrm{mg} \mathrm{L}^{-1}$ e $\left.\left[\mathrm{H}_{2} \mathrm{O}_{2}\right]=1000 \mathrm{mg} \mathrm{L}^{-1}\right)$.

Figura 15. Gráfico de degradação de COT no teste com 300 min de fotólise (100 mL de amostra e $\lambda=254 \mathrm{~nm}$ )

Figura 16. Gráfico de degradação de COT no teste com 480 min de fotólise (100 mL de amostra; $\lambda=254 \mathrm{~nm}$ ) .45

Figura 17. Gráfico para fotólise/peróxido durante $480 \mathrm{~min}$ (100 mL de amostra; $\lambda=254$ $\mathrm{nm}$ e $\left.\left[\mathrm{H}_{2} \mathrm{O}_{2}\right]=1000 \mathrm{mg} \mathrm{L}^{-1}\right)$.

Figura 18. Gráfico comparativo para a redução de COT para todos os processos.

Figura 19. Gráficos de cinética para o processo foto-Fenton. À direita, gráfico do In COT/COTinicial pelo tempo, à esquerda, gráfico de 1/COT pelo tempo.

Figura 20. Gráficos de cinética para o processo fotólise. Á direita, gráfico de In COT/COTinicial pelo tempo, à esquerda, gráfico de 1/COT pelo tempo. .51

Figura 21. Gráficos de cinética para o processo $\mathrm{UV} / \mathrm{H}_{2} \mathrm{O}_{2}$. Á direita, gráfico de In COT/COTinicial pelo tempo, à esquerda, gráfico de 1/COT pelo tempo. .52 
Tabela 1. Propriedades físico-químicas do diesel de petróleo e do biodiesel produzido por

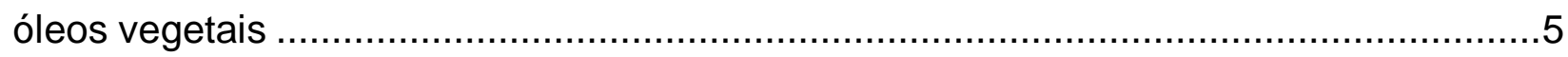

Tabela 2. Especificações técnicas para o biodiesel comercial ......................................11

Tabela 3. Parâmetros de caracterização da água de lavagem de biodiesel ...................12

Tabela 4. Tabela de potenciais de alguns oxidantes..............................................18

Tabela 5. Variáveis iniciais para os ensaios de Fenton...............................................31

Tabela 6. Caracterização parcial da água de lavagem. ..............................................36

Tabela 7. Concentrações Letais (\%) para $50 \%$ dos indivíduos (CL50) e valores de $r^{2} .38$ Tabela 8. Teste de significância entre as médias para os processos foto-Fenton e

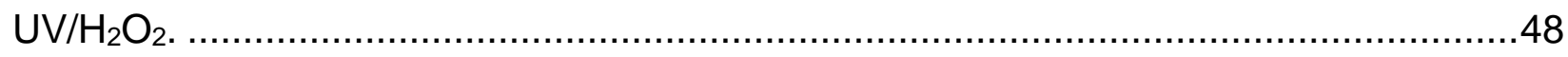

Tabela 9. Valores obtidos para os testes estatísticos. ...............................................48

Tabela 10. Redução dos parâmetros após o tratamento foto-Fenton com duração de 480

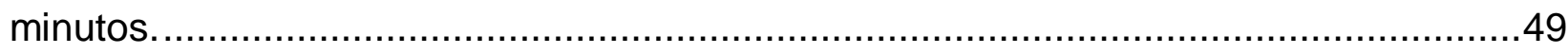


ANP: Agência Nacional do Petróleo, Gás Natural e Biocombustíveis

BC: Banda de Condução

BDD: Diamante Dopado com Boro

BV: Banda de Valência

Cl: Carbono Inorgânico

CONAMA: Conselho Nacional do Meio Ambiente

COT: Carbono Orgânico Total, 1; Carbono Orgânico Total

CT: Carbono Total

DBO: Demanda Biológica de Oxigênio

DQO: Demanda Química de Oxigênio

EE: Energia Elétrica

FET: Fish Embryo Acute Toxicity

HPA: Hidrocarbonetos Policíclicos Aromáticos

HPLC: High Performance Liquid Cromatography

IB: Instituto de Biologia

IQ: Instituto de Química

LMC: Laboratório de Materiais e Combustíveis

MME: Ministério de Minas e Energia

NTU: Unidades Nefeloméricas de Turbidez

OD: Oxigênio Dissolvido

OECD: Organisation for Economic Co-operation and Development 
PNPB: Programa Nacional de Produção de Biodiesel

POA: Processos Oxidativos Avançados

PPGQ: Programa de Pós-Graduação em Química

TOG: Teor de Óleos e Graxas

UnB: Universidade de Brasília

US: Ultrassom

USEPA: United States Environmental Protection Agency

UV: Ultravioleta

UV-Vis: Ultravioleta - Visível 


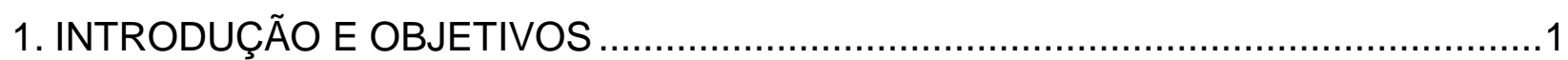

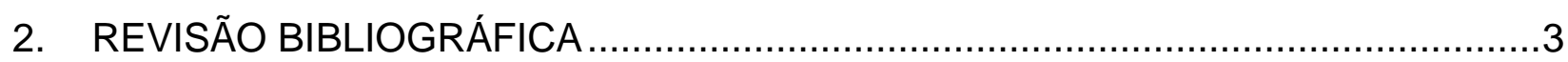

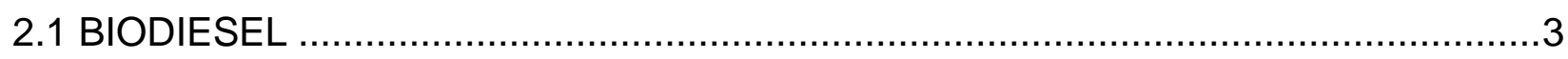

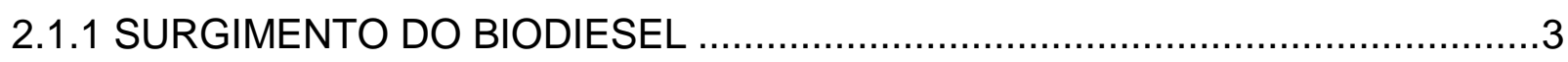

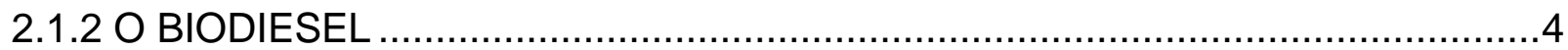

2.1.3 PROCESSOS DE PRODUÇÃO DO BIODIESEL …...................................

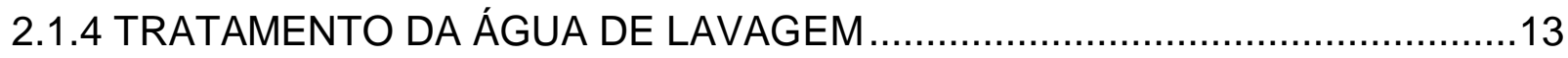

2.2 PROCESSOS OXIDATIVOS AVANÇADOS …................................................17

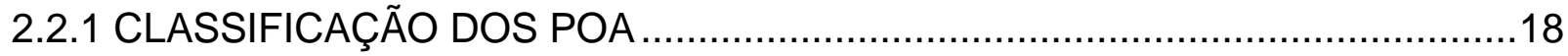

2.2.2 PROCESSOS OXIDATIVOS AVANÇADOS HETEROGÊNEOS .......................19

2.2.3 PROCESSOS OXIDATIVOS AVANÇADOS HOMOGÊNEOS .........................21

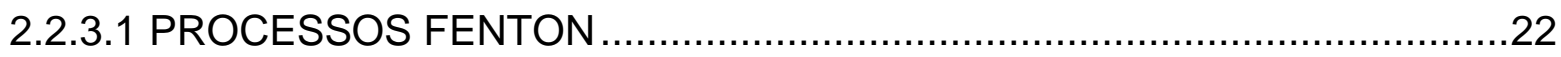

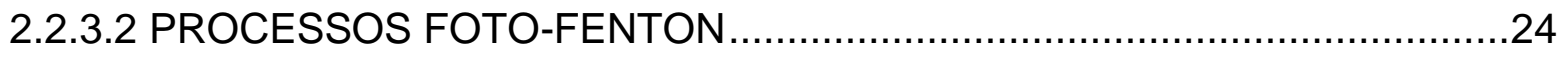

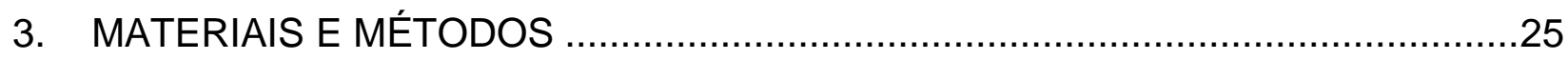

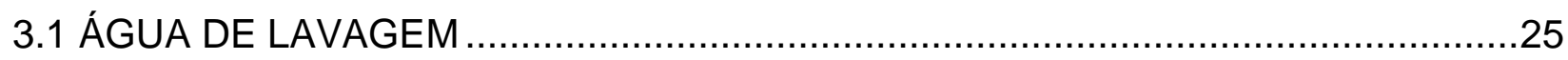

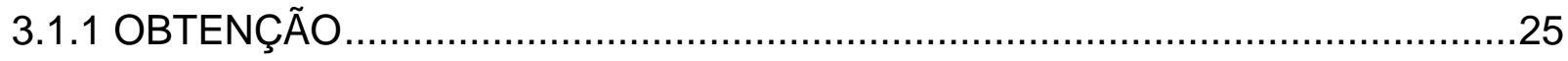

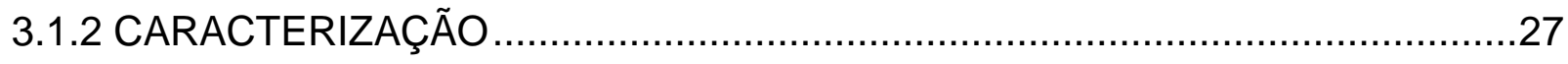

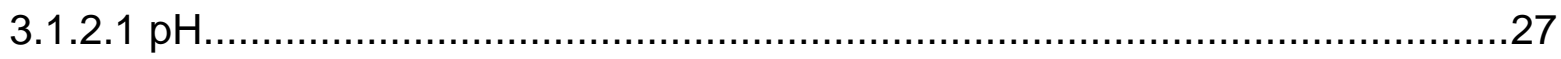

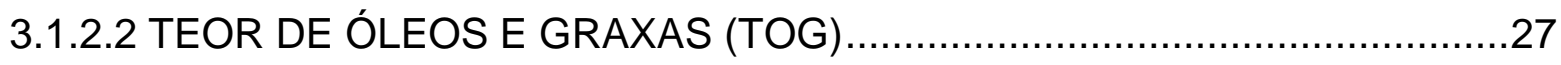

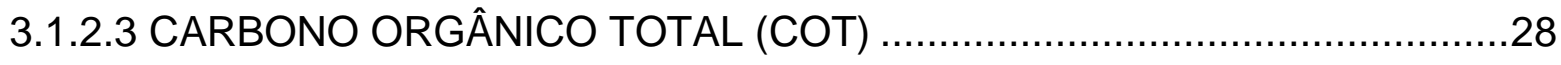

3.1.2.4 DEMANDA QUÍMICA DE OXIGÊNIO (DQO) ........................................29

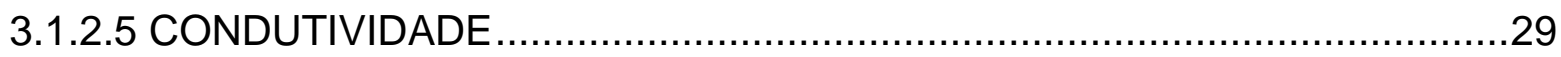




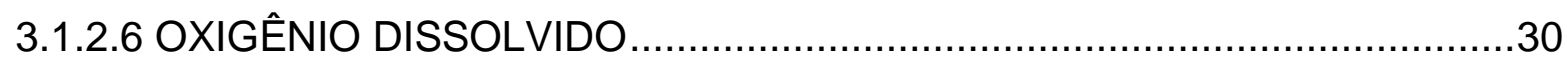

3.1.2.7 PERÓXIDO DE HIDROGÊNIO......................................................30

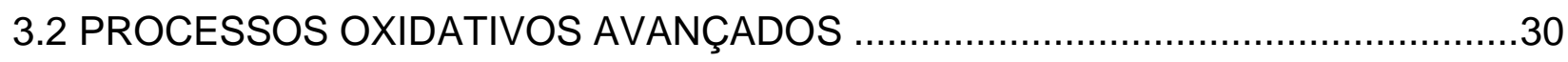

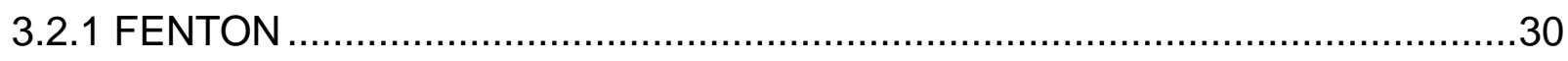

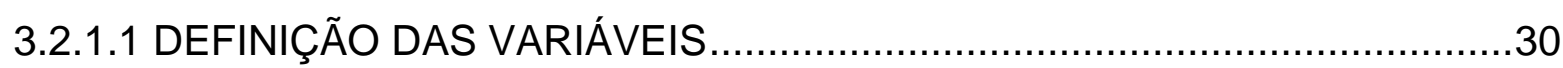

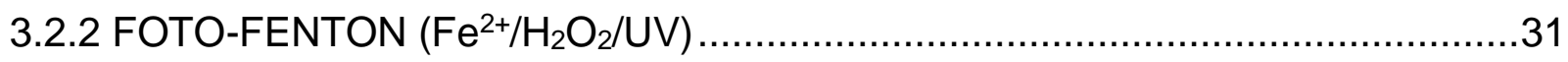

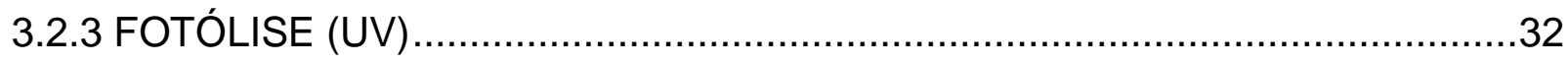

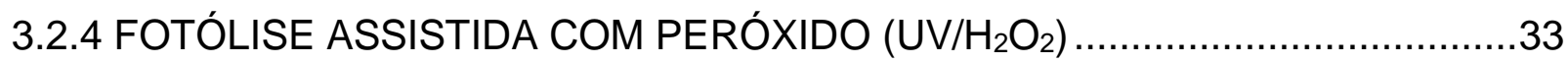

3.3 AVALIAÇÃO ECOTOXICOLÓGICA (Fish Embryo Acute Toxicity- FET)..................33

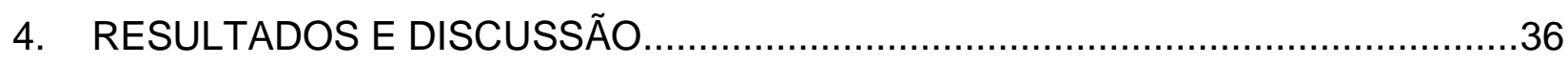

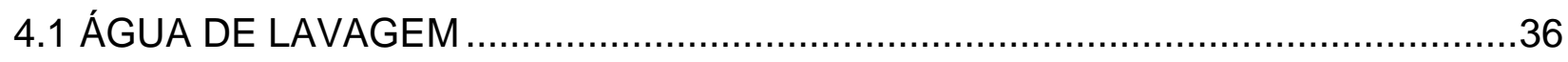

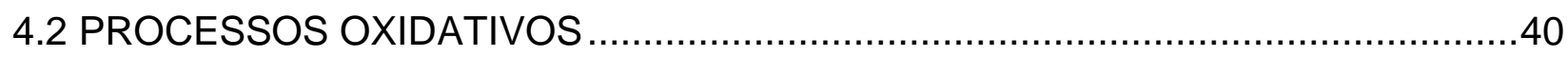

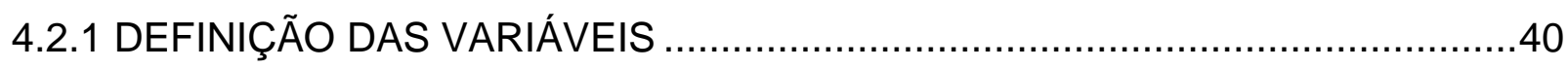

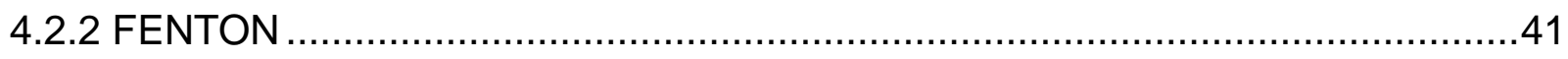

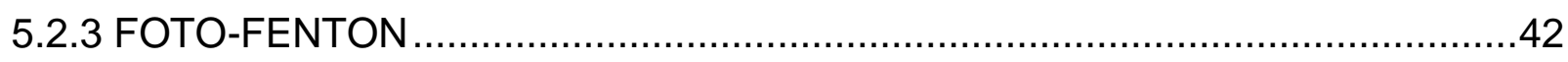

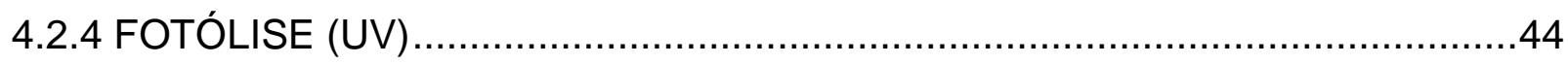

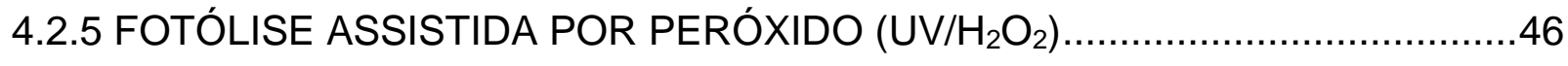

4.2.6 COMPARAÇÃO ENTRE OS PROCESSOS ….........................................4

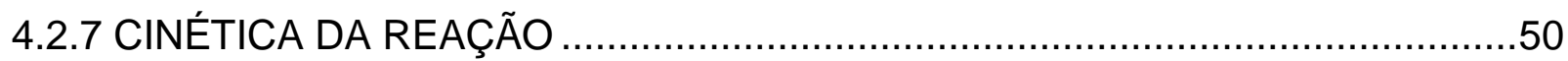

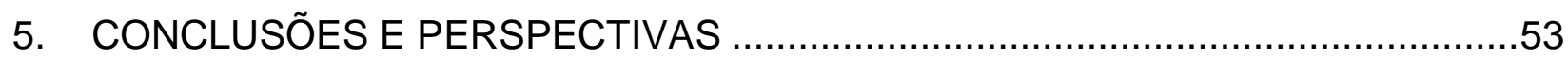

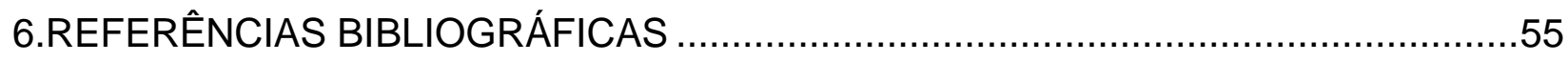

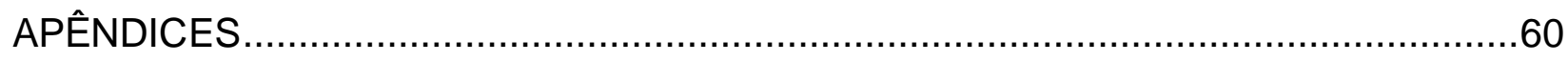




\section{INTRODUÇÃO E OBJETIVOS}

Devido ao acelerado crescimento econômico mundial registrado nas últimas décadas, o consumo de energia também tem crescido. Em consequência do aumento pela demanda energética surge a necessidade de novas fontes de energia que sejam economicamente viáveis e que tenham impacto reduzido ao ambiente. Inicialmente, o biodiesel tornou-se uma dessas novas alternativas de energia, com potencial para substituir o diesel por contribuir na redução das emissões de carbono provenientes da queima de combustíveis fósseis. Porém, o processo de utilização do biodiesel é relativamente novo em comparação à utilização do diesel de petróleo e está em constante aperfeiçoamento, seja devido a problemas na sua utilização, ou na sua produção (Cardoso e colaboradores, 2008).

O biodiesel é considerado um combustível sustentável pelo fato de que todo o dióxido de carbono emitido em sua queima é reabsorvido no crescimento de nova safra da soja. No entanto, com relação ao ciclo do nitrogênio, variados impactos são produzidos, desde o aumento na emissão de gases nitrogenados para a atmosfera até o aporte de altas cargas de nitrogênio para os cursos d'agua. Além do grande impacto no ciclo do nitrogênio, o processo de produção do biodiesel proveniente da soja ainda precisa ser otimizado, visando minimizar a geração de resíduos e tratar os resíduos gerados, principalmente a água utilizada na etapa de purificação (água de lavagem) que chega a ser produzida numa proporção de 1:3, biodiesel:água de lavagem.

Dessa maneira, o objetivo geral desse trabalho é a avaliação dos processos Fenton e foto-Fenton no tratamento do resíduo água de lavagem de biodiesel de soja, afim de verificar a viabilidade desses processos em escala laboratorial. Os objetivos específicos foram:

- Caracterizar o efluente água de lavagem com relação aos parâmetros pH, Carbono Orgânico Total (COT), Demanda Química de Oxigênio (DQO), Teor de Óleos e Graxas (TOG), Condutividade, Oxigênio Dissolvido (OD);

- Otimizar as concentrações de $\mathrm{Fe}^{2+}$ e $\mathrm{H}_{2} \mathrm{O}_{2}$ nos processos avaliados para $\mathrm{O}$ tratamento do efluente estudado; 
- Acompanhar o comportamento do COT durante e depois do tratamento bem como avaliar os parâmetros DQO, OD e condutividade após o tratamento;

- Avaliar a ecotoxicidade pelo método FET (Fish Embryo Acute Toxicity) do efluente antes e depois do tratamento realizado com as condições otimizadas. 


\section{REVISÃO BIBLIOGRÁFICA}

\subsection{BIODIESEL}

\subsubsection{SURGIMENTO DO BIODIESEL}

O primeiro registro do uso de biocombustível se deu no final do século XIX, quando Rudolf Diesel utilizou óleos vegetais em um de seus motores (ignição por compressão). Porém, com a queda nos valores do petróleo devido à descoberta de novas jazidas, nas primeiras décadas do século $X X$, o óleo vegetal foi abandoado e o petróleo foi refinado para servir como combustível nos motores desenvolvidos por Rudolf Diesel. Sendo assim a utilização dos óleos vegetais foi esquecida por um longo período, tendo sido utilizado como combustível apenas em situações de emergência (Ma \& Hanna, 1999; Agarwal, 2007).

Com a diminuição das reservas de petróleo na segunda metade do século $X X$, e com consequente aumento dos custos de exploração desse recurso, os óleos vegetais tornaram a ser alvo de pesquisas para utilização como combustível. Some-se a isto, crescentes preocupações ambientais relativas ao uso de combustíveis fosseis, principalmente devido a elevada taxa de emissão de gases estufa na atmosfera. Assim, a utilização de biocombustíveis passou a ser encarada como uma alternativa para reduzir a emissão de dióxido e monóxido de carbono na atmosfera (Ma \& Hanna, 1999; Agarwal, 2007).

Portanto, na década de 1970, óleos e gorduras provenientes da agricultura e pecuária tornaram-se foco de pesquisas para sua utilização como combustíveis e demonstraram ser eficientes para substituir uma grande fração dos destilados de petróleo (Agarwal, 2007; Graboski \& McCormick, 1998).

Porém, as moléculas dos óleos vegetais podem provocar diversos problemas no funcionamento de motores, entre eles a carbonização, dificuldade de partida a frio, queima irregular, redução da eficiência térmica e odor desagradável nos gases do escapamento (Santos \& Matai, 2008). Para minimizar os problemas relacionados ao uso 
direto de óleos vegetais nos motores de combustão, algumas opções propostas foram a síntese de bio-óleo (óleos vegetais craqueados, processo em que moléculas complexas são quebradas em moléculas mais simples pela ação de calor e/ou catalisador) e a síntese de ésteres de ácidos graxos obtidos por meio de transformação química do óleo vegetal, rota sintética de grande parte do biodiesel de soja produzido no Brasil. Na última década, esses biocombustíveis tem sido utilizados em misturas de até $30 \%$ no óleo diesel comercial pelo mundo (Santos \& Matai, 2008).

\subsubsection{O BIODIESEL}

O biodiesel consiste em uma mistura de ésteres metílicos ou etílicos de ácidos graxos de cadeias longas. A legislação brasileira (Resolução ANP no 14 de 11.5.2012) define biodiesel como "uma mistura de alquil ésteres de ácidos graxos de cadeias longas, derivado de óleos vegetais ou animais", ou ainda como um "biocombustível derivado de biomassa renovável para uso em motores à combustão interna com ignição por compressão ou, conforme regulamento, para geração de outro tipo de energia que possa substituir parcial ou totalmente combustíveis de origem fóssil" (Lei № 11097 de 13.01.2005). O biodiesel é produzido através de fontes renováveis de energia, como óleos vegetais e gorduras animais, e apresenta-se como uma alternativa ao diesel de petróleo, por apresentar semelhança nas propriedades físico-químicas (tabela 1). Desta forma, é possível fazer a substituição total ou parcial do diesel de petróleo, sem alterações substanciais de equipamentos nos motores (Agarwal, 2007; Santos \& Matai, 2008; Lotero e colaboradores, 2005). 
Tabela 1. Propriedades físico-químicas do diesel de petróleo e do biodiesel produzido por óleos vegetais

\begin{tabular}{|c|c|c|c|c|c|c|}
\hline $\begin{array}{l}\text { Oleaginosa } \\
\text { de Origem }\end{array}$ & $\begin{array}{c}\text { Viscosidade } \\
\qquad\left(\mathrm{mm}^{2} \mathrm{~s}^{-1}\right)\end{array}$ & $\begin{array}{c}\text { Número } \\
\text { de } \\
\text { cetano }\end{array}$ & $\begin{array}{c}\text { Poder } \\
\text { calorífico } \\
\text { MJ L-1 }\end{array}$ & $\begin{array}{c}\text { Ponto } \\
\text { nuvem } \\
\text { (으) }\end{array}$ & $\begin{array}{c}\text { Ponto } \\
\text { de } \\
\text { fulgor } \\
\text { (ㄷ) }\end{array}$ & $\begin{array}{c}\text { Densidade } \\
\left(g \mathrm{~L}^{-1}\right)\end{array}$ \\
\hline Amendoim & $4,9\left(37,8^{\circ} \mathrm{C}\right)$ & 54 & 33,6 & 5 & 176 & 0,883 \\
\hline Soja & $4,5\left(37,8^{\circ} \mathrm{C}\right)$ & 45 & 33,5 & 1 & 178 & 0,885 \\
\hline Babaçu & $3,6\left(37,0^{\circ} \mathrm{C}\right)$ & 63 & 31,8 & 4 & 127 & 0,879 \\
\hline Palma & $5,7\left(37,8^{\circ} \mathrm{C}\right)$ & 62 & 33,5 & 13 & 164 & 0,880 \\
\hline Girassol & $4,6\left(37,8^{\circ} \mathrm{C}\right)$ & 49 & 33,5 & 1 & 183 & 0,860 \\
\hline $\begin{array}{l}\text { Diesel de } \\
\text { petróleo }\end{array}$ & $12-3,5\left(40^{\circ} \mathrm{C}\right)$ & 51 & 35,5 & - & - & $0,835^{\star}$ \\
\hline
\end{tabular}

${ }^{*}$ Valor médio para a densidade a $15 \stackrel{\circ}{ } \mathrm{C}$. Adaptada de Fukuda e colaboradores (2001).

O teor de biodiesel adicionado ao diesel de petróleo é referido como BXX, onde $X X$ indica a quantidade de biodiesel na mistura (Agarwal, 2007). Por exemplo, B7 indica a adição de $7 \%$ de biodiesel em $93 \%$ de diesel de petróleo, proporção utilizada no Brasil atualmente (Lei 13.033 de 24 de Setembro de 2014). O biodiesel puro (B100) libera cerca de $90 \%$ da energia que o diesel comum, portanto, espera-se que a performance do motor seja semelhante. Já como aditivo, o biodiesel aumenta a lubricidade, mesmo em misturas com menos de $3 \%$, o que prolonga a vida do motor e reduz a frequência de troca de peças (Lotero e colaboradores, 2005).

Dentre as principais vantagens da utilização do biodiesel estão a biodegradabilidade, a baixa toxicidade e a reduzida emissão de diversos poluentes atmosféricos quando comparada à emissão do diesel derivado de petróleo (Ma \& Hanna, 1999). A utilização do biodiesel B100 implica em uma redução de aproximadamente $67 \%$ da emissão de hidrocarbonetos não queimados, $47 \%$ do material particulado, $48 \%$ do monóxido de carbono e de $90 \%$ de hidrocarbonetos policíclicos aromáticos (HPA), além da não emissão de enxofre (Ferreira e colaboradores, 2008). Essas características tornam sua 
utilização menos impactante ao ambiente, em comparação à utilização de combustíveis fósseis (Coronado e colaboradores, 2009), embora os valores de emissão de gases $\mathrm{NO}_{\mathrm{x}}$ (óxidos de nitrogênio) aumentem em torno de 10 \% (Ferreira e colaboradores, 2008).

Outra importante vantagem do biodiesel frente ao diesel de petróleo é o reaproveitamento do $\mathrm{CO}_{2}$ em um breve intervalo de tempo (alguns anos) após o seu lançamento na atmosfera, pois este gás é continuamente fixado pelas plantas e pode ser reaproveitado para a geração de novas safras de oleaginosas. Desta forma o uso de biodiesel não altera significativamente o ciclo biogeoquímico do carbono. Em contrapartida, a utilização de combustíveis fósseis não promove o reaproveitamento do $\mathrm{CO}_{2}$ lançado na atmosfera, uma vez que seu ciclo de formação apresenta um longo tempo de duração (milhões de anos) (Agarwal, 2007). Por este motivo, diversos autores consideram que o uso de biodiesel não contribui para o aquecimento global quando comparado à utilização do diesel de petróleo (Agarwal, 2007; Lotero e colaboradores, 2005).

Porém, não há consenso na literatura quanto à natureza sustentável do biodiesel. Por um lado, enquanto a redução na emissão de vários poluentes atmosféricos é suficiente para alguns autores considerarem o biodiesel um combustível limpo (Agarwal, 2007; Lotero e colaboradores, 2005), por outro, a emissão de determinados gases pode gerar novos problemas. Por exemplo, Cardoso e colaboradores (2008) afirmam que o biodiesel não pode ser considerado um combustível limpo, pois desde seu processo de produção até sua queima variados impactos são gerados na atmosfera, solo e águas superficiais e subterrâneas. No processo de produção e queima de biodiesel, os ciclos biogeoquímicos dos macroconstituintes enxofre, nitrogênio, fósforo e potássio são fortemente afetados. Um dos grandes impactos ao ciclo do nitrogênio e fósforo é o uso intensivo de fertilizantes nas plantações das oleaginosas (Cardoso e colaboradores, 2008).

Mesmo não havendo consonância na literatura sobre a natureza ambientalmente benéfica da utilização do biodiesel, quando considerado todo o ciclo de produção, o Brasil incentiva a produção e uso deste combustível por meio do Programa Nacional de 
Produção do Biodiesel (PNPB) de forma a gerar emprego e renda e incentivar a agricultura de pequeno porte (Ministério de Minas e Energia, 2015). Dados divulgados pela Agência Nacional do Petróleo Gás Natural e Biocombustível (ANP) e pelo Ministério de Minas e Energia (MME) apresentam o crescimento da produção de biodiesel nos últimos anos (Figura 1) (MME, 2015).

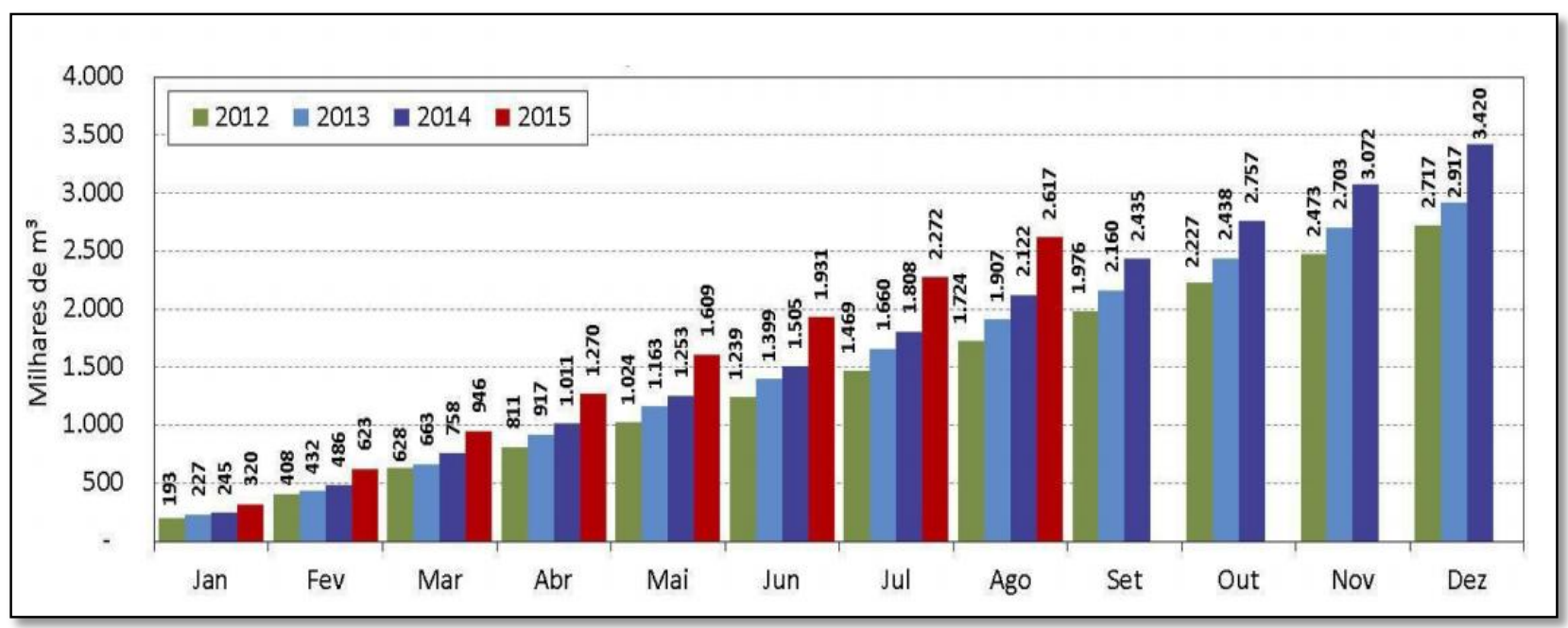

Figura 1. Produção de biodiesel acumulada mensalmente entre 2012 e agosto de 2015 (Fonte: MME, 2015).

Avaliando os valores apresentados na Figura 1 é possível notar que o crescimento anual na produção de biodiesel está evidente e pode ser corroborado pela política de incentivo à utilização do biodiesel como aditivo ao diesel de petróleo em proporções cada vez maiores. Em junho de 2014 era B5, foi aumentado para B6 em julho do mesmo ano e em novembro do mesmo ano subiu para B7 tendo sido mantido neste patamar até a presente data (MME, 2015). 


\subsubsection{PROCESSOS DE PRODUÇÃO DO BIODIESEL}

Os principais processos de produção do biodiesel são a pirólise, a microemulsão, a esterificação e a transesterificação (Fukuda e colaboradores, 2001). Entre eles, o processo mais utilizado é o de transesterificação (Ma \& Hanna, 1999; Meneghetti e colaboradores, 2013) que consiste na transformação de um éster em outro na presença de um álcool e um catalisador (Solomons \& Fryhle, 2006). A transesterificação (figura 2) pode acontecer de diversas maneiras, como por exemplo, a transesterificação por catálise ácida, básica, heterogênea ou ainda enzimática. Industrialmente a rota mais empregada é a transesterificação básica ou alcalina por apresentar melhor rendimento, menor tempo de reação e menor comprometimento de equipamentos devido à corrosão (Ma \& Hanna, 1999; Meneghetti e colaboradores, 2013).

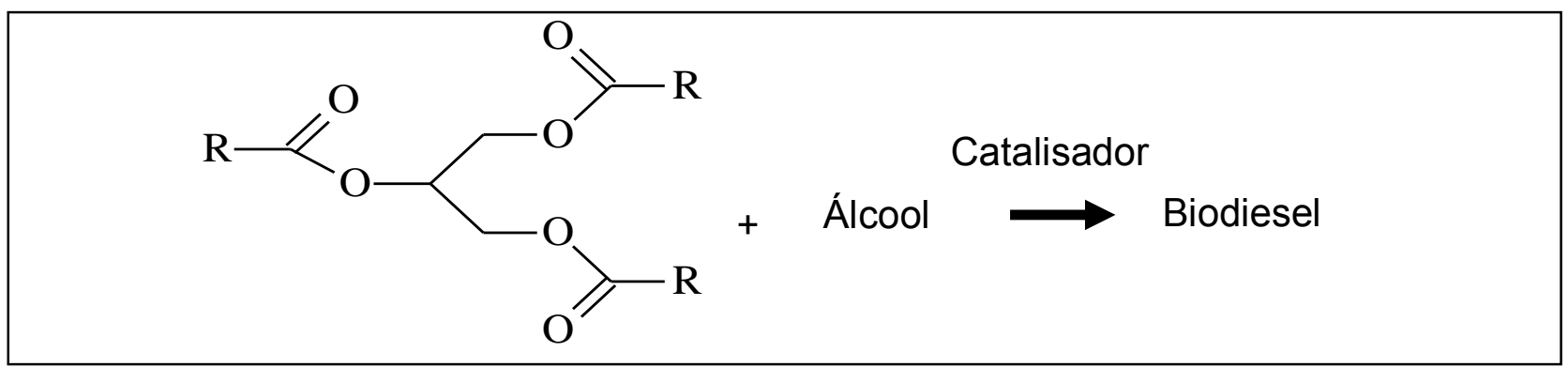

Figura 2. Esquema de conversão de um triacilglicerol em biodisel via alcóolise.

O processo de transesterificação alcalina envolve a reação de triacilglicerídeos com álcoois de cadeias curtas em presença de um catalisador básico, dando origem a uma mistura de ésteres de ácidos graxos e glicerol. A conversão de um triacilglicerol em biodiesel e glicerol ocorre em três etapas consecutivas e reversíveis, conforme a figura 3 , a seguir. 


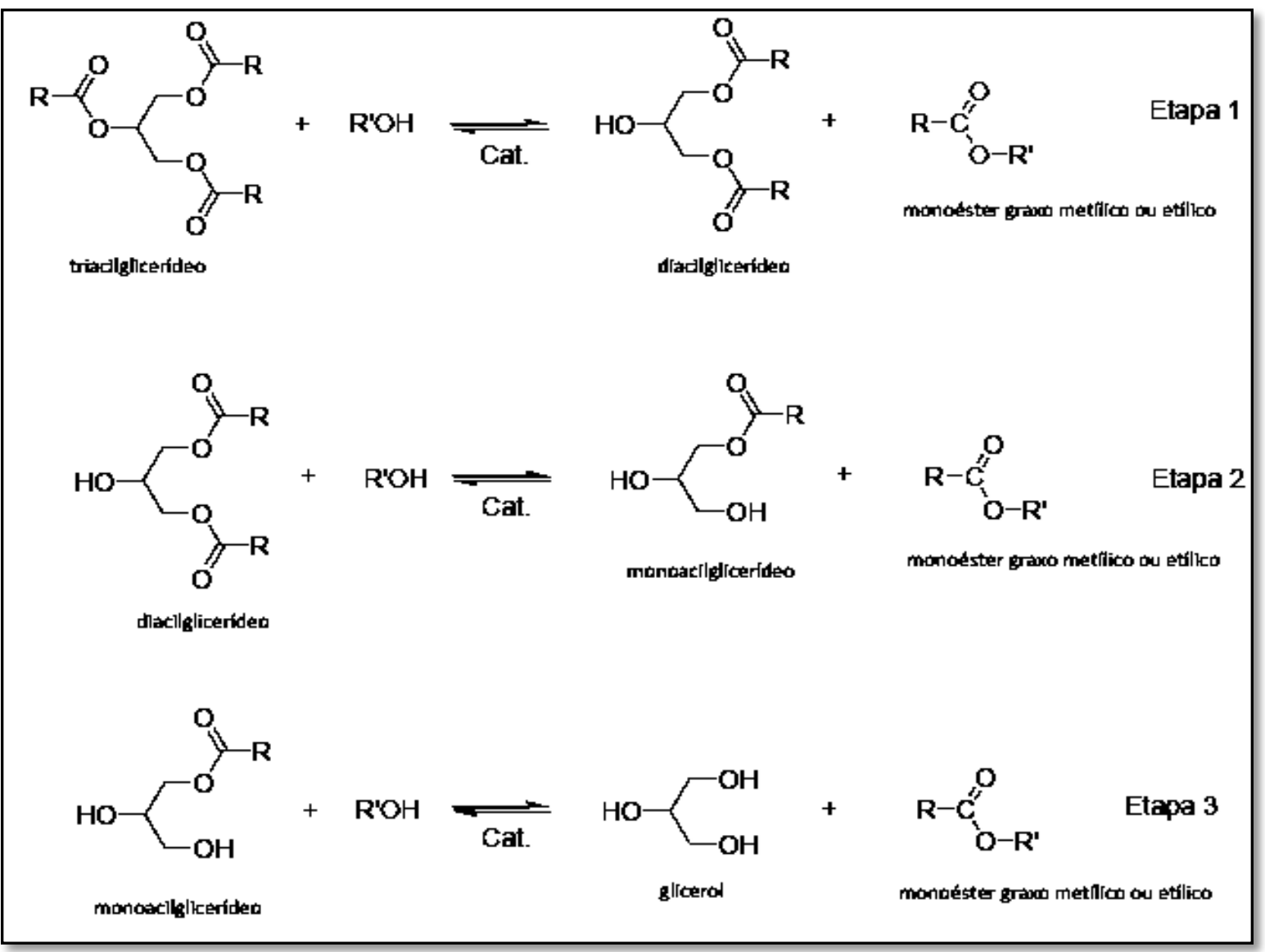

Figura 3. Etapas reacionais envolvidas na transesterificação de triacilglicerídeos (Meneghetti e Colaboradores, 2013).

$\mathrm{Na}$ primeira etapa existe a remoção de uma cadeia de ácido caboxílico e a formação de um éster e um diacilglicerídeo, na segunda, existe a remoção de uma segunda cadeia carboxílica e a formação de outro éster e um monoacilglicerídio, até a remoção da terceira e consequente formação do triálcool, também conhecido como glicerina e mais um éster (Oliveira e colaboradores, 2008).

Por tratar-se de uma reação reversível, a estequiometria 1:3 (3 mols de álcool para reagir com um mol de triglicerídeo), deve ser extrapolada, sendo necessário um excesso de álcool no meio reacional para que o equilíbrio seja deslocado para a formação dos monoésteres (Meneghetti e colaboradores, 2013). Normalmente essa reação é realizada em presença de metanol, como agente de alcoólise, pois a reação ocorre com maior 
eficácia, melhor velocidade e rendimento (Meneghetti e colaboradores, 2013; Agarwal, 2007), e o baixo custo do metanol o torna mais atrativo em comparação ao etanol (Lotero e colaboradores, 2005). O catalisador mais utilizado é geralmente $\mathrm{KOH}$ ou $\mathrm{NaOH}$ (Meneghetti e colaboradores, 2005).

Posteriormente à reação de transesterificação, que gera uma mistura de alquilésteres e glicerol, é realizada a purificação do produto (Quintella e colaboradores, 2009). Primeiramente é realizada uma separação por decantação, onde o glicerol impuro é a fase mais densa e o biodiesel impuro, a fase menos densa. Após um repouso prolongado (24 horas aproximadamente), é possível visualizar a formação das fases e separá-las (Coronado e colaboradores, 2009; Geris e colaboradores, 2007). Além da glicerina existe também a formação de sabões, ou sais de ácidos graxos, cuja presença é indesejada, pois além de competir pelo consumo do catalisador, diminuindo o rendimento da reação, sua presença no biodiesel final pode causar danos aos motores (Quintella e colaboradores, 2009).

Os valores limites de contaminantes no biodiesel produzido no Brasil são regulamentados pela Resolução da ANP $n^{\circ} 7$ de 19.03.2008. A tabela 2 apresenta as principais características indicativas de qualidade de biodiesel, que são a ausência de contaminantes ou a presença em concentrações muito baixas, além de algumas propriedades físico-químicas. Dentre os principais contaminantes, destacam-se a glicerina, sabões, água, produtos não reagidos completamente, como mono e diacilgliceróis, álcoois e catalisador que podem gerar problemas nos motores diesel e poderem gerar efluentes causadores de importante impactos ambientais (Quintella e colaboradores, 2009). 
Tabela 2. Especificações técnicas para o biodiesel comercial

\begin{tabular}{|c|c|}
\hline Característica & Limite \\
\hline Massa específica a $20^{\circ} \mathrm{C}$ & $850-900\left(\mathrm{~kg} \mathrm{~m}^{-3}\right)$ \\
\hline Viscosidade Cinemática a $40{ }^{\circ} \mathrm{C}$ & $3-6 \mathrm{~mm}^{2} \mathrm{~s}^{-1}$ \\
\hline Teor de água & $500 \mathrm{mg} \mathrm{kg}^{-1}$ \\
\hline Contaminação total & $24 \mathrm{mg} \mathrm{kg}^{-1}$ \\
\hline Ponto de fulgor (mínimo) & $100 \circ \mathrm{C}$ \\
\hline Teor de éster (mínimo) & $96,5 \%$ em massa \\
\hline Resíduo de Carbono & $0,05 \%$ em massa \\
\hline Cinzas sulfatadas & $0,02 \%$ em massa \\
\hline Enxofre total & $50 \mathrm{mg} \mathrm{kg}^{-1}$ \\
\hline Sódio + Potássio & $5 \mathrm{mg} \mathrm{kg}^{-1}$ \\
\hline Cálcio + Magnésio & $5 \mathrm{mg} \mathrm{kg}^{-1}$ \\
\hline Fósforo & $10 \mathrm{mg} \mathrm{kg}^{-1}$ \\
\hline Ponto de entupimento de filtro a frio & $19 \circ \mathrm{C}$ \\
\hline Índice de acidez & $0,5 \mathrm{mg} \mathrm{KOH} \mathrm{g}^{-1}$ \\
\hline Glicerol livre & $0,02 \%$ em massa \\
\hline Glicerol total & $0,25 \%$ em massa \\
\hline Mono, di, triacilglicerol & Anotar* \\
\hline Metanol ou etanol & $0,2 \%$ em massa \\
\hline Estabilidade à oxidação a $110 \stackrel{\circ}{ } \mathrm{C}$ & 6 horas \\
\hline
\end{tabular}

* Valor não definido pela legislação. Adaptada da Resolução ANP no 7 de 19.3.2008.

O principal processo de purificação do biodiesel utilizado hoje é a lavagem do produto com água (Geris e colaboradores, 2007). Utilizam-se, em média, três litros de água a cada litro de biodiesel produzido para se obter uma purificação satisfatória (Goldani e colaboradores, 2008). Após a lavagem, o biodiesel é tratado com sulfato de sódio anidro para secagem (Geris e colaboradores, 2007). Este processo de lavagem gera um grande volume de resíduo (água de lavagem) que merece atenção quanto ao seu destino devido à alta carga orgânica, assim como a presença dos vários subprodutos 
da síntese do biodiesel. Alguns trabalhos da literatura mostram as principais características da água de lavagem (Ramos e colaboradores, 2008; Fávaro e colaboradores, 2009; Grangeiro, 2009; Hincapié-Mejia e colaboradores, 2011). Estas informações foram agrupadas na tabela 3, que disponibiliza também alguns valores limites para o lançamento de efluentes de acordo com os contaminantes permitidos na legislação pertinente, as resoluções 357 de 18.03.2005 e 430 de 31.03.2011 do Conselho Nacional do Meio Ambiente (CONAMA). É possível observar algumas desconformidades entre os paramêtros $\mathrm{pH}$ e óleos e graxas obtidos pela água de lavagem em relação ao legislado para lançamento de efluentes e valores de contaminantes permitidos para águas salobras classe III (utilizadas apenas para paisagismo e navegação). Os valores da água de lavagem estão bem acima dos permitidos pela legislação.

Tabela 3. Parâmetros de caracterização da água de lavagem de biodiesel

\begin{tabular}{|c|c|c|}
\hline Parâmetros & $\begin{array}{l}\text { Água residual do } \\
\text { biodiesel }\end{array}$ & $\begin{array}{c}\text { Valores permitidos } \\
\text { para lançamento de } \\
\text { efluente (CONAMA, } \\
430 / 2011) \\
\end{array}$ \\
\hline $\mathrm{DBO}\left(\mathrm{mg} \mathrm{L}^{-1}\right)$ & 3.000 a 180000 & $\begin{array}{c}\text { Redução mínima de } 60 \\
\% \text { após } 5 \text { dias }\end{array}$ \\
\hline $\begin{array}{c}\mathrm{DQO}\left(\mathrm{mg} \mathrm{L}^{-1}\right) \\
\mathrm{pH}\end{array}$ & $\begin{array}{c}50000 \text { a } 160000 \\
8 \text { a } 11\end{array}$ & 5 a 9 \\
\hline $\mathrm{OD}\left(\mathrm{mg} \mathrm{L}^{-1}\right)$ & 5 & Não inferior a $3 \mathrm{mg} \mathrm{L}^{-1^{* \star}}$ \\
\hline Sólidostotais ( $\mathrm{mg} \mathrm{L}^{-1}$ ) & 33000 & - \\
\hline Óleos e graxas ( $\mathrm{mg} \mathrm{L}^{-1}$ ) & 2700 a 5000 & $\begin{array}{l}\text { Minerais até } 20 \mathrm{mg} \mathrm{L}^{-1} \\
\text { Vegetais e gorduras } \\
\text { animais até } 50 \mathrm{mg} \mathrm{L}^{-1}\end{array}$ \\
\hline $\operatorname{Cor}\left(\mathrm{mgL}^{-1}\right)$ & 500 a 3000 & Virtualmente ausente $^{* *}$ \\
\hline Turbidez (NTU) & 800 a 1000 & Virtualmente ausente ${ }^{* *}$ \\
\hline COT $\left(\mathrm{mgL}^{-1}\right)$ & 4200 & $10 \mathrm{mg} \mathrm{L}^{-1^{* *}}$ \\
\hline
\end{tabular}

*Adaptado de LOBO, T.M., Exame de qualificação, PPGQ/UnB. 2014.

** Valores regulados para águas salobras classe III com destinação à navegação e à harmonia paisagística.

NTU: Unidades Nefeloméricas de Turbidez.

Adaptada de Lobo, T.M.*; Resolução CONAMA № 430 de 31.03.2011. 


\subsubsection{TRATAMENTO DA ÁGUA DE LAVAGEM}

Como já citado, a produção de biodiesel gera um volume importante de água de lavagem. $O$ despejo direto desse efluente em corpos hídricos pode causar prejuízos ambientais, como o consumo de oxigênio para o processo de decomposição da matéria orgânica, que pode causar a morte de peixes, e também a eutrofização devido ao excesso de nutrientes que podem estar presentes no resíduo. Atualmente não há legislação específica para regulamentar o descarte deste efluente, e se considerarmos o crescimento da indústria de biodiesel no Brasil é provável que em um futuro próximo se tenha sérios problemas ambientais.

Verifica-se que é pequena a quantidade de artigos publicados sobre métodos de tratamento da água de lavagem do biodiesel. No entanto, destaca-se um trabalho de revisão bibliográfica publicado em 2014 sobre vários métodos de tratamento de água de lavagem de biodiesel (Veljković e colaboradores, 2014). Esses autores apontam que na literatura são encontrados trabalhos que tratam esse resíduo por adsorção, acidificação, coagulação/floculação, flotação, eletrocoagulação, eletrólise hidrotermal, acidificação/eletrocoagulação, eletroquímico/coagulação, acidificação/eletro-oxidação, ozonização, fotocatálise heterogênea, foto-Fenton e tratamentos biológicos e biológicos combinados com processos físico-químicos. Os principais artigos descritos neste trabalho estão descritos a seguir em conjunto com alguns trabalhos acadêmicos não publicados em revistas científicas disponíveis na internet.

Os principais métodos utilizados nos trabalhos encontrados na literatura utilizam (1) processos biológicos (Suehara e colaboradores, 2005; Rocha, 2010; Phukingngam e colaboradores, 2011), (2) físico-químicos (Goldani e colaboradores, 2008; Fávaro e colaboradores, 2009; Srirangsan e colaboradores, 2009; Chavalparit \& Ongwandee, 2009; Brito e colaboradores, 2012; Kumjadpai e colaboradores, 2011; Ngamlerdpokin e colaboradores, 2011; Rattanapan e colaboradores, 2011; De Gisi e colaboradores, 2013; Jaruwat e colaboradores, 2009), (3) processos oxidativos avançados (Melo, 2010; Hincapié-Mejia e colaboradores, 2011; Patiño e colaboradores 2012; Júnior, 2012; Filho, 2013; Nascimento, 2013) e (4) processos oxidativos avançados combinados a processos 
biológicos de tratamento (Ramírez e colaboradores, 2012). A relativa escassez da literatura evidencia que ainda há pouco cuidado com o destino da água de lavagem do biodiesel e que há necessidade de mais pesquisas que envolvam desenvolvimento e aplicação de novos métodos para o tratamento desse resíduo (Palomino-Romero e colaboradores, 2012).

Entre os trabalhos citados, é possível observar que a utilização de processos físico-químicos $(50 \%)$ se destaca em relação à utilizaçao de tratamentos biológicos (20 $\%)$ e processos oxidativos avançados (35\%). Os processos oxidativos avançados são ainda pouco explorados para essa finalidade, sendo que os poucos trabalhos encontrados na literatura são apresentados a seguir:

Melo (2010) estudou a fotocatálise heterogênea utilizando o $\mathrm{TiO}_{2}$ em suspensão com a utilização de radiação solar em um reator tipo tanque durante o período de 4 horas. A água de lavagem foi obtida em escala laboratorial, os valores de $\mathrm{pH}$ foram mantidos entre 5 e 9, a quantidade de catalisador variou entre 0,1 e $0,5 \%$ e a agitação foi variada entre os níveis médio e alto. O parâmetro utilizado para acompanhamento da eficiência de tratamento foi a Demanda Química de Oxigênio (DQO). O experimento em pH 5 e carga de $0,1 \%$ de catalisador apresentou melhor desempenho em uma agitação mediana, porém, a redução substancial da DQO (aproximadamente 70 \%) pôde ser observada apenas nos primeiros 30 minutos, mantendo-se constante até o final das 4 horas.

Hincapié-Mejía e colaboradores (2010) aplicaram os processos oxidativos avançados foto-Fenton e fotocatálise heterogênea no tratamento da água de lavagem do biodiesel de palma produzido em escala laboratorial. Na fotocatálise, aproximadamente $0,1 \mathrm{~g}$ de $\mathrm{TiO}_{2}$ foi imobilizado em anéis de vidro borossilicato que ficaram em uma câmara também de borossilicato irradiada por uma fonte de radiação ultravioleta Nippon 3U (365 nm e 26 Watts) com um coletor parabólico de alumínio para concentrar a radiação. 0 sistema contava também com uma bomba peristáltica para recirculação e os parâmetros avaliados foram $\mathrm{pH}$ (3 e 9), concentração de peróxido de hidrogênio (1 e $2 \mathrm{~mL} \mathrm{~L}^{-1}$ ) e fluxo de amostra $(0,68$ e $1 \mathrm{~L})$. Foram realizados também fotólise (UV) e fotólise com adição de 
peróxido $\left(\mathrm{UV} / \mathrm{H}_{2} \mathrm{O}_{2}\right)$. O experimento teve duração de duas horas e a concentração dos contaminantes foi monitorada a cada 20 minutos. O processo foto-Fenton utilizou um reator comercial do tipo UV Min-1.5, da marca Mighty Pure, como fonte de radiação que consiste em um cilindro de aço inoxidavel onde em seu interior tem uma lâmpada (254 nm) protegida por um tubo de quartzo. O sistema contou também com uma bomba peristáltica para recirculação. Foram avaliadas a concentração de íons ferrosos, tendo como fonte sulfato ferroso heptahidratado, $(0,1,0,3$ e $0,5 \mathrm{mM})$ e a concentração de peróxido de hidrogênio (35, 85 e $135 \mathrm{mM}$ ), com valores de pH mantidos entre 2 e 2,3 e com fluxo de $1 \mathrm{~L}$ por minuto. Os contaminantes também foram monitorados durante duas horas em intervalos de 20 minutos. Devido à elevada carga orgânica medida, os experimentos foram realizados com amostras diluídas 100 vezes. A fotocatálise heterogênea proporcionou remoções de DQO e de COT de 60 e 54 \%, respectivamente, com os parâmetros otimizados de $1 \mathrm{~mL} \mathrm{~L}^{-1}$ de peróxido de hidrogênio e fluxo de $0,68 \mathrm{~L}$ $\mathrm{min}^{-1}$ em pH 9. Porém, os valores de remoção de COT pela fotólise e $\mathrm{UV} / \mathrm{H}_{2} \mathrm{O}_{2}$ foram similares, e quando o processo foi aplicado a um resíduo menos diluído, a remoção de DQO e COT girou em torno de 3,0 e 2,0 \%, respectivamente.

O processo Fenton não apresentou mudança significativa na remoção de DQO. Já o foto-Fenton apresentou-se muito eficiente na destruição da matéria orgânica presente na água tratada, indicada pelas altas remoções de COT, DQO e metanol $(85,7 ; 80,3$ e $99,5 \%$, respectivamente), com a utilização de 0,3 mM de ferro e $35 \mathrm{mM}$ de peróxido de hidrogênio em uma amostra diluída apenas 5 vezes. Para o efluente bruto, com os parâmetros otimizados já citados, o processo foto-Fenton foi capaz de reduzir $27,2 \%$ do COT em apenas duas horas.

Patiño e colaboradores (2012) aplicaram os processos oxidativos avançados, baseados na ozonização e oxidação eletroquímica, como possível alternativa para tratar a água de lavagem de biodiesel. Foi utilizado um ozonizador (Ozonind) alimentado diretamente com oxigênio a um fluxo de $2 \mathrm{~L} \mathrm{~min}^{-1}$. A água residual foi colocada em um reservatório de vidro com $2 \mathrm{~L}$ de capacidade e o ozônio foi fornecido por meio de um difusor para garantir a distribuição do agente oxidante de forma homogênea. Foram avaliados três níveis de pH $(4,5 ; 7,0$ e 12) e também o fluxo de ozônio, conforme a 
capacidade do ozonizador $\left(0,17 ; 0,26\right.$ e $\left.0,34 \mathrm{~g} \mathrm{~h}^{-1}\right)$. Os ensaios eletroquímicos de oxidação foram realizados utilizando uma célula eletroquímica com capacidade de 250 $\mathrm{mL}$ com quatro saídas para retirada de amostas, medida de temperatura e aplicação de voltagem, com agitação magnética constante. Como ânodo foi utlizado um eletrodo de diamante dopado com boro suportado sobre silício (BDD-adamant Technologies) e como catôdo um eletrodo em espiral de zircônio. O sistema foi alimentado com uma fonte direta de corrente, fixando valores entre 0,01 e $0,04 \AA$ e concentração de eletrólito variada $(0,7$; 1,0; 1,8; 2,5 e 2,8 $\mathrm{g} \mathrm{L}^{-1}$ ). Ao início de cada amostragem, foi adicionado o valor de eletrólito correspondente e cloreto de sódio. Nos dois experimentos foram analisados DQO e COT.

O procedimento experimental de ozonização foi aplicado a uma amostra diluída 100 vezes, devido à elevada carga orgânica obtida da amostra original. O planejamento experimental apresentou o ozônio como a variável que mais interfere no processo e os melhores valores de remoção de DQO $(81,2 \%)$ e COT $(79,4 \%)$ foram obtidos com as varíavels $0,34 \mathrm{~g} \mathrm{~h}^{-1}$ para fluxo de ozônio, e pH igual a 12. Aplicando o procedimento otimizado na amostra original (sem diluição), remoções de COT, DQO e metanol foram de 22,0; 21,3 e 31,4\%, respectivamente. A oxidação eletroquímica sobre uma amostra diluída 100 vezes também foi avaliada. As remoções mais altas de DQO e COT (58,5 e $61,1 \%$ ) foram obtidas em uma corrente de $0,04 \AA$ e uma concentração de eletrólito de $2,5 \mathrm{~g} \mathrm{~L}^{-1}$ de $\mathrm{NaCl}$. Essas condições foram aplicadas à amostra diluída 5 vezes e também na amostra original. Para a amostra original tratada por oxidação eletroquímica, remoções de 10,4; 9,0 e 27,5 \% de COT, DQO e metanol, respectivamente, foram obtidas. Embora os processos não apresentem remoção superior a $50 \%$ na amostra original em nenhum dos parâmetros avaliados, a biodegradabilidade, mensurada pela relação $\mathrm{DBO}_{5} / \mathrm{DQO}$ aumentou $(0,45$ para 0,49 na ozonização e 0,45 para 0,47 para a oxidação eletroquímica).

Junior (2012) propôs a utilização de fotocatálise heterogênea com a utilização de $\mathrm{TiO}_{2}$ para o tratamento da água de lavagem do biodiesel. O sistema reacional utilizado foi de irradiação direta com uma lâmpada de vapor de mercúrio de média pressão (250 W) sobre um reator tipo tanque com sistema de circulação termostatizado e aeração. Os parâmetros que forneceram uma melhor resposta para remoção de DQO $(77,8$ \%) em 
240 min foram $\mathrm{pH} 3,3$; temperatura $20^{\circ} \mathrm{C}$ e $0,1 \mathrm{~g} \mathrm{~L}^{-1}$ de $\mathrm{TiO}_{2}$. $\mathrm{O}$ autor afirma que a fotólise do efluente também apresentou remoções de contaminantes semelhantes à fotocatálise, porém não apresenta valores de remoção de DQO ou COT, apenas de absorbância obtidos por espectroscopia UV-Vis.

Filho (2013) também aplicou o $\mathrm{TiO}_{2}$ no tratamento da água de lavagem do biodiesel. $\mathrm{O} \mathrm{TiO}$ foi imobilizado numa placa de vidro irradiada por quatro lâmpadas (254 $\mathrm{nm}$ ) em um sistema reator com recirculação constante durante $4 \mathrm{~h}$. $\mathrm{O} \mathrm{pH}$ e a condutividade não foram avaliados enquanto parâmetros reacionais, mas foram acompanhados no decorrer do experimento. $O$ tratamento proporcionou uma remoção de $62 \%$ da DQO do efluente.

Nascimento (2013) propõe a utilização da radiação solar para tratamento fotocatalítico da água de lavagem de biodiesel. O experimento consistiu na utilização de um reator do tipo parabólico concentrador de energia e teve uma duração de $240 \mathrm{~min}$, tendo o ângulo ajustado a cada hora para melhor aproveitamento da radiação solar. $\mathrm{O}$ tratamento foi do tipo batelada e o fotocatalisador $\left(\mathrm{TiO}_{2}\right)$ foi utilizado em suspensão na amostra a ser tratadaque foi recirculada por uma motobomba durante 240 min do período das 10:00 $\mathrm{h}$ às 14:00 $\mathrm{h}$, para maior incidência solar. $\mathrm{O} \mathrm{pH}$, a condutividade e a temperatura, bem como a incidência de radiação foram avaliados durante todo 0 experimento. A remoção da DQO também foi avaliada e apresentou uma redução de $71 \%$ com $0,1 \mathrm{~g} \mathrm{~L}^{-1}$ de catalisador, $\mathrm{pH}$ inicial 8,92 e temperatura inicial $31^{\circ} \mathrm{C}$.

\subsection{PROCESSOS OXIDATIVOS AVANÇADOS}

Os processos oxidativos avançados (POA) tem sido alvo de interesse de estudo na busca por soluções eficientes e economicamente viáveis para o tratamento de resíduos tóxicos e persistentes (Bosco, 2012). 


\subsubsection{CLASSIFICAÇÃO DOS POA}

Os POA são definidos como processos baseados na formação do radical hidroxila $\left(\mathrm{OH}^{*}\right)$, um forte oxidante não seletivo com capacidade de mineralizar compostos orgânicos devido ao seu elevado potencial de redução $(E=2,73 \mathrm{~V})$, superior ao dos oxidantes convencionais e inferior apenas ao do fluoreto (tabela 4). Esses processos caracterizam-se, entre outros fatores, por apresentarem elevada velocidade de reação $\left(10^{6} \mathrm{a} 10^{9} \mathrm{M}^{-1} \mathrm{~s}^{-1}\right)$ com diversas reações intermediárias. Os produtos das reações são $\mathrm{CO}_{2}, \mathrm{H}_{2} \mathrm{O}$, sais inorgânicos e algumas vezes intermediários mais resistentes à degradação (Bosco, 2012; Teixeira \& Jardim, 2004; Andreozzi e colaboradores, 1999).

Tabela 4. Tabela de potenciais de alguns oxidantes

\begin{tabular}{cc}
\hline Espécies & Potencial de redução (V) \\
\hline Fluoreto & 3,03 \\
Radical hidroxila & 2,80 \\
Átomo de oxigênio & 2,42 \\
Ozônio & 2,07 \\
Peróxido de hidrogênio & 1,78 \\
Radical perhidroxila & 1,70 \\
Permanganato & 1,68 \\
Ácido hipobromoso & 1,59 \\
Dióxido de cloreto & 1,57 \\
Ácido hipocloroso & 1,49 \\
Ácido hipoiodoso & 1,45 \\
Cloreto & 1,36 \\
Brometo & 1,09 \\
lodeto & 0,54 \\
\hline
\end{tabular}

Adaptado de Poyatos e colaboradores, 2010. 
Os POA são divididos em homogêneos e heterogêneos, cuja classificação esquemática está apresentada na figura 4. Os homogêneos apresentam-se na forma de um sistema monofásico, enquanto o heterogêneo apresenta mais de uma fase onde geralmente é empregado o uso de catalisadores na forma sólida. Ambos podem compor sistemas com ou sem a utilização de energia, geralmente radiação ultravioleta (UV), ultrassom (US) e energia elétrica (EE) (Poyatos e colaboradores, 2010; Araújo, 2002).

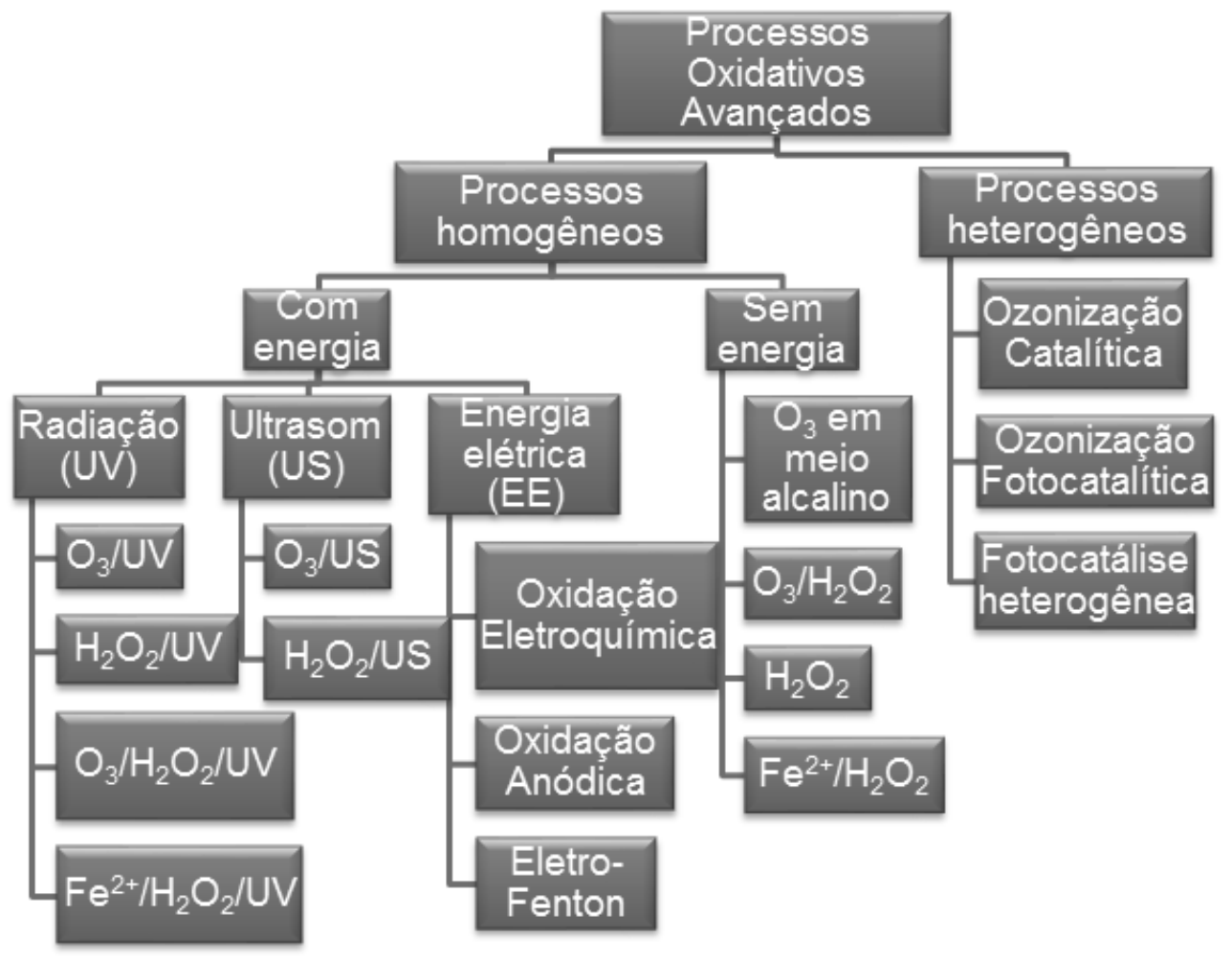

Figura 4. Classificação dos processos oxidativos (adaptado de Poyatos e colaboradores, 2010).

\subsubsection{PROCESSOS OXIDATIVOS AVANÇADOS HETEROGÊNEOS}

Entre os principais processos oxidativos avançados heterogêneos, destacam-se a ozonização catalítica e fotocatalítica e a fotocatálise heterogênea. Porém, a fotocatálise heterogênea apresenta-se como melhor alternativa para o tratamento de águas residuais, pois remove de maneira mais eficiente a carga orgânica do que a ozonização, que por sua vez, se destaca na remoção de cor e desinfecção (Teixeira \& Jardim, 2004; Martins, 2011). 
A fotocatálise heterogênea consiste na formação de radicais hidroxila pela irradiação de um material semicondutor (figura 5). Quando um material semicondutor como o $\mathrm{TiO}_{2}$ é sujeito a uma fonte de energia superior ( $h v$ ) à energia de band gap, ocorre a formação de pares elétron/lacuna $\left(\mathrm{e}_{\mathrm{bc}} / \mathrm{h}_{\mathrm{bv}}{ }^{+}\right)$pela transferência do elétron da banda de valência (BV) para a banda de condução $(B C)$ (equação 1). Quando não recombinados podem gerar radicais hidroxila pela presença da água adsorvida na superfície do material (equação 2) ou podem ser formadas outras espécies radicalares pela captura dos elétrons gerados por oxigênio conforme a reação representada pela equação 3 a seguir (Teixeira \& Jardim, 2004).

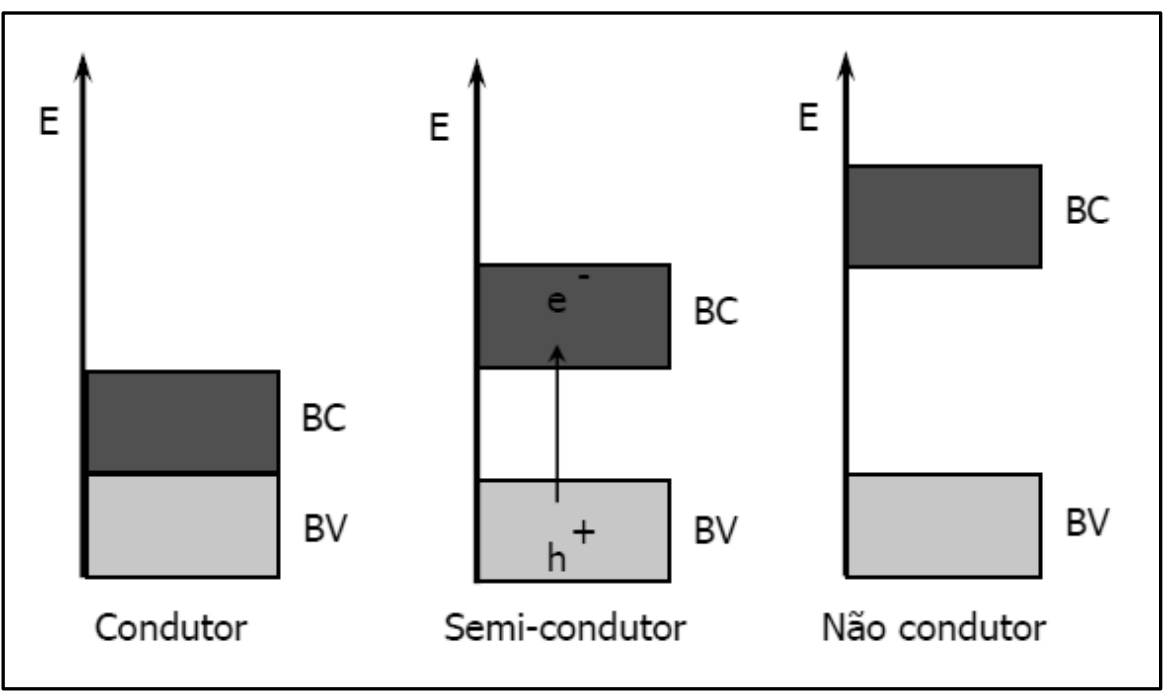

Figura 5. Níveis energéticos dos materiais (Adaptado de Teixeira \& Jardim, 2004).

$$
\begin{gathered}
\mathrm{TiO}_{2}+h v \rightarrow \mathrm{h}_{\mathrm{bv}}^{+}+\mathrm{e}_{\mathrm{bc}}^{-} \\
\mathrm{k}=70 \mathrm{M}^{-1} \mathrm{~s}^{-1} \\
\mathrm{H}_{2} \mathrm{O}(\mathrm{ads})+\mathrm{h}_{\mathrm{bv}}^{+} \rightarrow \mathrm{HO}^{\circ} \\
\mathrm{k}=3,2 \times 10^{8} \mathrm{M}^{-1} \mathrm{~s}^{-1}
\end{gathered}
$$




$$
\begin{gathered}
\mathrm{HO}^{-}+\mathrm{h}_{\mathrm{bv}}^{+} \rightarrow \mathrm{HO}^{\circ} \\
\mathrm{k}=0,001-0,01 \mathrm{M}^{-1} \mathrm{~s}^{-1}
\end{gathered}
$$

\subsubsection{PROCESSOS OXIDATIVOS AVANÇADOS HOMOGÊNEOS}

Os principais processos oxidativos avançados em fase homogênea para o tratamento de águas residuais consistem na combinação de peróxido de hidrogênio com UV $\left(\mathrm{UV} / \mathrm{H}_{2} \mathrm{O}_{2}\right)$ e nas reações de Fenton (Martins, 2011). A combinação entre peróxido de hidrogênio e a radiação UV é um processo mais eficiente do que a utilização dos processos separadamente, pois a formação de radicais hidroxila é aumentada. $O$ mecanismo aceito para a formação de radicais $\mathrm{HO} \cdot$ para o processo de fotólise auxiliada com peróxido de hidrogênio está apresentado na equação 4 , onde uma molécula de peróxido forma dois radicais. É importante considerar também que esses radicais podem se recombinar formando novamente o peróxido.

$$
\begin{aligned}
& \mathrm{H}_{2} \mathrm{O}_{2}+h v \rightleftharpoons 2 \mathrm{HO}^{\circ} \\
& \mathrm{k}=1,1 \times 10^{2} \mathrm{M}^{-1} \mathrm{~s}^{-1}
\end{aligned}
$$

As reações de Fenton são os processos oxidativos avançados que utilizam ferro e peróxido de hidrogênio e podem ser classificados como processos Fenton (sem irradiação UV) e foto-Fenton (com irradiação UV). Tais processos são assim chamados, pois foram descobertos por Henry John Horstman Fenton, no final do século XIX, ao observar que os ácidos tartárico, málico e outros compostos orgânicos eram oxidados em soluções de peróxido de hidrogênio e sais de ferro (Fenton, 1894). 


\subsubsection{PROCESSOS FENTON}

Também conhecido como reagente de Fenton, a mistura entre $\mathrm{H}_{2} \mathrm{O}_{2}$ e $\mathrm{Fe}^{2+}$ em meio aquoso gera radicais hidroxila conforme a reação representada pela equação 5 . Porém, a formação desses radicais em meio aquoso envolve uma série de reações, apresentadas a seguir com as suas respectivas constantes de equilíbrio (k) (Neyens \& Bayens, 2003).

$$
\begin{gathered}
\mathrm{Fe}^{2+}+\mathrm{H}_{2} \mathrm{O}_{2} \rightleftharpoons \mathrm{Fe}^{3+}+\mathrm{OH}^{-}+\mathrm{OH}^{-} \\
\mathrm{k}=1,3 \times 10^{6} \mathrm{M}^{-1} \mathrm{~s}^{-1} \mathrm{em} \mathrm{pH} 3 \\
\mathrm{OH}^{\cdot}+\mathrm{Fe}^{2+} \rightleftharpoons \mathrm{OH}^{-}+\mathrm{Fe}^{3+} \\
\mathrm{k}=1,2 \times 10^{6} \mathrm{M}^{-1} \mathrm{~s}^{-1} \mathrm{em} \mathrm{pH} 3 \\
\mathrm{Fe}^{3+}+\mathrm{H}_{2} \mathrm{O}_{2} \rightleftharpoons \mathrm{Fe}^{-} \mathrm{OOH}^{2+}+\mathrm{H}^{+} \\
\mathrm{k}=3,3 \times 10^{7} \mathrm{M}^{-1} \mathrm{~s}^{-1} \\
\mathrm{Fe}_{-} \mathrm{OOH}{ }^{2+} \rightleftharpoons \mathrm{HO}_{2}^{-}+\mathrm{Fe}^{3+} \\
\mathrm{k}=5,3 \times 10^{9} \mathrm{M}^{-1} \mathrm{~s}^{-1} \\
\mathrm{Fe}^{2+}+\mathrm{HO}_{2}^{\cdot} \rightleftharpoons \mathrm{Fe}^{3+}+\mathrm{HO}_{2}^{-} \\
\mathrm{k}=7 \times 10^{9} \mathrm{M}^{-1} \mathrm{~s}^{-1} \\
\mathrm{Fe}^{3+}+\mathrm{HO}_{2}^{\circ} \rightleftharpoons \mathrm{Fe}^{2+}+\mathrm{O}_{2}+\mathrm{H}^{+}
\end{gathered}
$$




$$
\mathrm{OH}^{\cdot}+\mathrm{H}_{2} \mathrm{O}_{2} \rightleftharpoons \mathrm{H}_{2} \mathrm{O}+\mathrm{HO}_{2}^{\circ}
$$

É possível observar, na equação 11, que o peróxido de hidrogênio pode funcionar também como um sequestrador de radicais hidroxila bem como os próprios radicais podem reagir entre si e formarem novamente o peróxido de hidrogênio (equação 4). Logo, a razão entre $\mathrm{Fe}^{2+} / \mathrm{Fe}^{3+} / \mathrm{H}_{2} \mathrm{O}_{2}$ deve ser otimizada conjuntamente com os parâmetros reacionais $\mathrm{pH}$ (apresentado a seguir na equação 12), temperatura e concentração, para a obtenção de um processo oxidativo eficaz, ou seja, que objetive a total mineralização dos contaminantes desejados (Neyens \& Bayens, 2003).

$$
\mathrm{H}^{+}+\mathrm{HO}^{\circ}+\mathrm{e}^{-} \rightleftharpoons \mathrm{H}_{2} \mathrm{O}
$$

Tal mineralização ocorre quando os radicais hidroxila formados são capazes de oxidar os compostos orgânicos, gerando $\mathrm{CO}_{2}$ e $\mathrm{H}_{2} \mathrm{O}$. Essa oxidação pode acontecer de três maneiras, por abstração de hidrogênio (equações 13 e 14), adição eletrofílica (equação 15) e transferência eletrônica (equação 16) (Martins, 2011).

$$
\begin{gathered}
\mathrm{RH}+\mathrm{HO}^{\bullet} \rightleftharpoons \mathrm{R}^{\circ}+\mathrm{H}_{2} \mathrm{O} \\
\mathrm{R}^{\cdot}+\mathrm{O}_{2} \rightleftharpoons \mathrm{RO}_{2}
\end{gathered}
$$

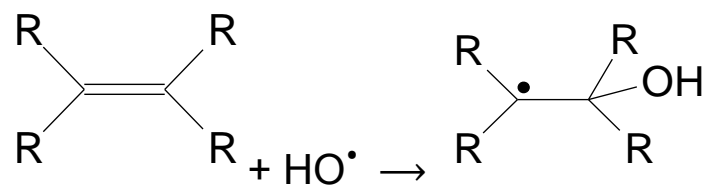




$$
\mathrm{RX}+\mathrm{HO}^{\circ} \rightleftharpoons \mathrm{RX}+\mathrm{HO}^{-}
$$

O processo é muito utilizado para a remoção de compostos recalcitrantes, além de ser de simples funcionamento. Porém, a grande desvantagem na utilização do processo Fenton, é a formação de um lodo residual constituído principalmente por $\mathrm{Fe}^{3+}$ (Poyatos e colaboradores, 2010).

\subsubsection{PROCESSOS FOTO-FENTON}

O processo foto-Fenton introduziu a utilização de radiação, seja ela ultravioleta ou visível, para auxiliar na formação de radicais hidroxila (conforme as equações 4, 5 e 17). O uso da radiação no processo auxilia na formação dos radicais hidroxila, também reduz a formação do lodo e aumenta a velocidade da reação (Poyatos e colaboradores, 2010).

$$
\mathrm{Fe}^{3+}+\mathrm{H}_{2} \mathrm{O}+h v \rightleftharpoons \mathrm{Fe}^{2+}+\mathrm{H}^{+}+\mathrm{HO}^{\bullet}
$$

Ao receber um fóton ( $\mathrm{hv}$ ), o $\mathrm{Fe}^{3+}$ se reduz, regenerando $\circ \mathrm{Fe}^{2+}$ inicialmente oxidado, além de liberar um radical hidroxila (equação 17), assim mais radicais hidroxila são formados (interação da luz com o peróxido de hidrogênio e redução do $\mathrm{Fe}^{3+}$ ) ocorrendo aumento da velocidade da reação. 


\section{MATERIAIS E MÉTODOS}

\section{1 ÁGUA DE LAVAGEM}

\subsubsection{OBTENÇÃO}

Com o intuito de manter domínio sobre as variáveis na produção do biodiesel e consequentemente sobre o resíduo gerado na sua lavagem, optou-se por produzir em escala laboratorial o biocombustível a partir de óleo de soja comercial. A rota sintética utilizada para a produção é a transesterificação alcalina utilizando metanol como agente de alcóolise e hidróxido de potássio como catalisador. Para a produção de 1,5 litros de água de lavagem são utilizados:

- $500 \mathrm{~mL}$ de óleo de soja (comercial);

- $200 \mathrm{~mL}$ de metanol (MTEDIA, para HPLC);

- $5 \mathrm{~g}$ de hidróxido de potássio - KOH (IMPEX, pureza mínima $85 \%$ );

- $750 \mathrm{~mL}$ de uma solução de ácido fosfórico $\left(\mathrm{H}_{3} \mathrm{PO}_{4}\right) 10$ \% v/v.;

- $750 \mathrm{~mL}$ de água destilada por osmose reversa;

- Fita indicadora de pH.

Primeiramente o óleo foi pré-tratado a $80^{\circ} \mathrm{C}$ por 3 horas em agitação magnética constante. Após o esfriamento do óleo, foi adicionada uma solução de metóxido de potássio, preparada com $5 \mathrm{~g}$ de $\mathrm{KOH}$ em $200 \mathrm{~mL}$ de metanol e agitação até a homogeneização. Após a adição do metóxido o sistema permaneceu sob agitação constante durante uma hora e a mistura de duas fases foi transferida para um funil de separação. A mistura permaneceu em descanso durante 24 horas para a decantação da glicerina produzida, a qual foi separada e armazenada em frasco devidamente identificado.

O biodiesel (outra fase) foi neutralizado e purificado com adição de 3 frações de $250 \mathrm{~mL}$ de solução de ácido fosfórico $10 \% \mathrm{v} / \mathrm{v}$, seguido da adição de 3 frações de 250 $\mathrm{mL}$ de água deionizada. Esta etapa retira o excesso de metanol, sabões, além do mono, 
di e triacilglicerídeos que não reagiram completamente. A figura 6 mostra as principais etapas da produção do biodiesel.

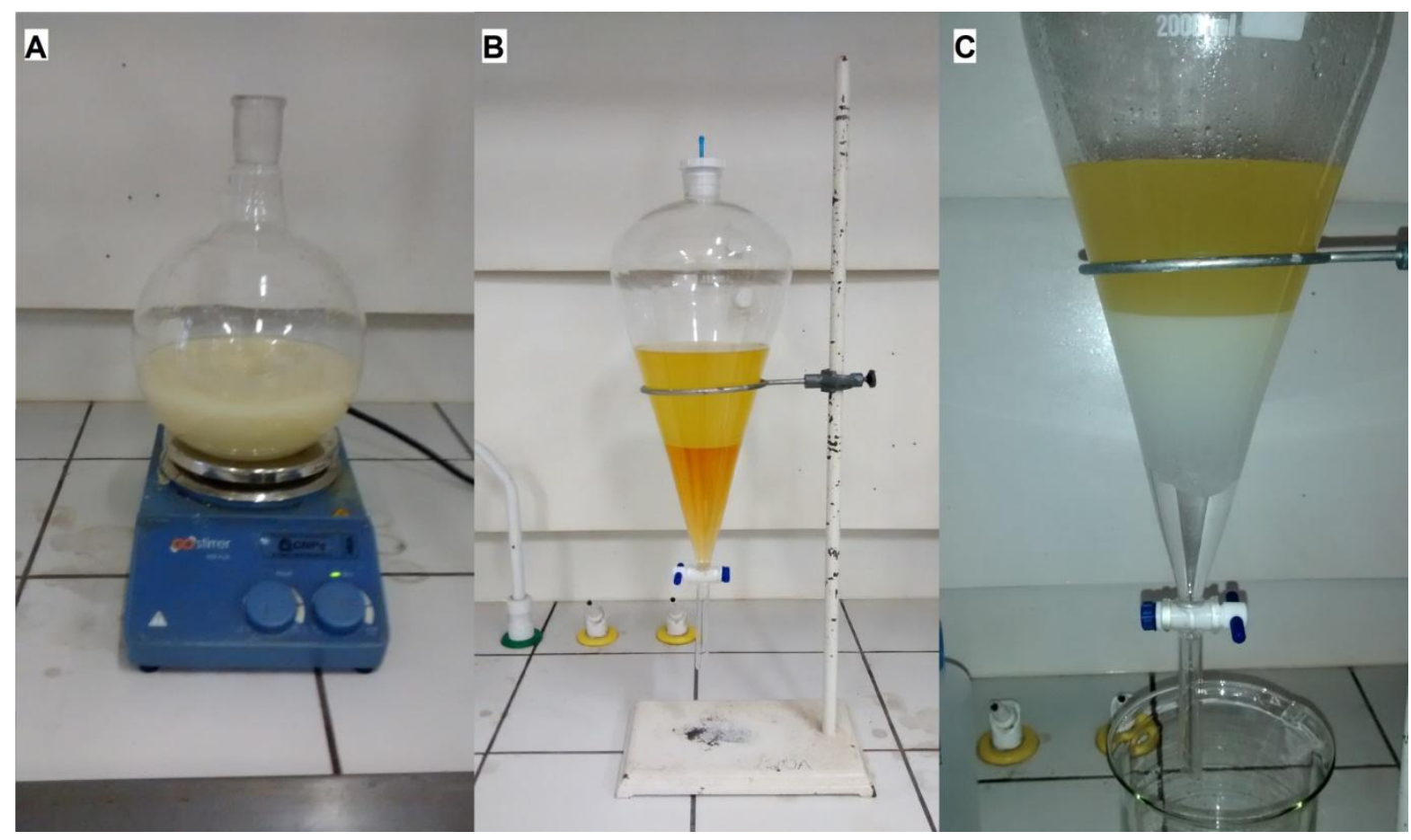

Figura 6. Etapas de produção e coleta da água de lavagem do biodiesel de soja. A - alcóolise; B decantação da glicerina e C - lavagem (Fotografias de arquivo do autor).

A eficiência da lavagem é atestada pela verificação do pH na última fração da água coletada com a fita indicadora (Hincapié-Mejía, 2011). Em condições ideais de lavagem, o pH da última água deverá ser igual ao da água utilizada na lavagem. A metodologia de síntese do biodiesel consiste num procedimento interno utilizado e cedido pelo Laboratório de Materiais e Combustíveis do Instituto de Química da Universidade de Brasília (LMC/IQ-UnB). 


\subsubsection{CARACTERIZAÇÃO}

\subsubsection{1 pH}

$\mathrm{O} \mathrm{pH}$ da água de lavagem foi determinado utilizando-se um pHmetro (HANNA $\mathrm{pH}$ 21), previamente calibrado. Foram feitas medidas de pH logo após o processo de lavagem, após o tratamento do efluente e também nas alterações de $\mathrm{pH}$ para realização dos testes ecotoxicológicos. A verificação do pH foi realizada em triplicata em cada caso.

\subsubsection{TEOR DE ÓLEOS E GRAXAS (TOG)}

O teor de óleos e graxas foi determinado aplicando-se o método 1664 da agência de proteção ambiental norte americana (USEPA - United States Environmental Protection Agency), também chamado de $n$-Hexane Extractable Material (USEPA, 1999) ou Teor de Óleos e Graxas.

O método consiste em uma extração líquido-líquido, utilizando n-hexano de pureza acima de $85 \%$ na proporção de $90 \mathrm{~mL}$ de $\mathrm{n}$-hexano para cada $250 \mathrm{~mL}$ de amostra. A amostra deve estar em $\mathrm{pH}$ abaixo de 2 e pode ser acidificada com $\mathrm{HCl}$ e armazenada por até 28 dias.

Em um funil de separação de $500 \mathrm{~mL}$, foram adicionados $250 \mathrm{~mL}$ da amostra (água de lavagem) previamente homogeneizada por agitação. Em seguida, foram adicionados $30 \mathrm{~mL}$ de $\mathrm{n}$-hexano e após agitação, a mistura era submetida a um descanso de alguns minutos até que as fases (água-hexano) fossem bem definidas. Finalmente, a amostra que encontrava-se na parte inferior do funil, foi transferida para outro frasco a fim de drenar a fase do hexano que era reservada. Repetiu-se o procedimento mais duas vezes, totalizando 3 extrações. As 3 frações de amostra foram transferidas para um único frasco e levadas a uma coluna de sulfato de sódio anidro para secagem. Em seguida a amostra foi rotoevaporada (Rotoevaporador IKA RV 10 basic) sob pressão reduzida e em uma temperatura de $70{ }^{\circ} \mathrm{C}$, com a utilização de uma bomba a vácuo (Lab ECO 740). O TOG foi calculado pela diferença entre o peso final do balão após a roto-evaporação e o peso 
inicial do balão vazio, aferido em balança analítica com quatro casas decimais (Shimadzu AX 200).

\subsubsection{CARBONO ORGÂNICO TOTAL (COT)}

O teor de carbono orgânico total foi determinado com o auxílio do equipamento TOC-L Shimadzu. O equipamento funciona com calibração externa, sendo necessária a construção de duas curvas analíticas, uma para carbono total (CT), cuja solução mãe é preparada com biftalato de potássio previamente seco, e outra para carbono inorgânico (Cl), cuja solução mãe é preparada com carbonato e bicarbonato de potássio previamente secos.

Para o preparo dos padrões, foram utilizados balões volumétricos de $100 \mathrm{~mL}$, previamente lavados em $\mathrm{HNO}_{3} 15 \%$, e a água obtida de um purificador por osmose reversa. Os padrões foram constituídos por uma solução de $1000 \mathrm{mg} \mathrm{C} \mathrm{L}^{-1}$ (miligramas de carbono por litro de solução) produzido a partir de 2,125 $\mathrm{g} \mathrm{L}^{-1}$ de biftalato de potássio para carbono total, e por uma solução $1000 \mathrm{mg} \mathrm{C} \mathrm{L}^{-1}$ produzido a partir de $4,412 \mathrm{~g} \mathrm{~L}^{-1}$ de carbonato e $3,497 \mathrm{~g} \mathrm{~L}^{-1}$ de bicarbonato de potássio para carbono inorgânico. As concentrações de carbono escolhidas para as curvas foram 1000, 900, 800, 700, 600, 500, 400, 300, 200 e $100 \mathrm{mg} \mathrm{C} \mathrm{L}^{-1}$ para CT e 100, 90, 80, 70, 60, 50, 40, 30, 20 e $10 \mathrm{mg}$ $\mathrm{C} \mathrm{L} \mathrm{L}^{-1}$ para $\mathrm{Cl}$. As diluições foram obtidas automaticamente pelo equipamento com a utilização de água destilada.

O carbono orgânico total (COT) é calculado automaticamente pelo equipamento, sendo a diferença entre o carbono total e o carbono inorgânico, conforme a equação 18.

$$
\mathrm{CT}-\mathrm{Cl}=\mathrm{COT}
$$




\subsubsection{DEMANDA QUÍMICA DE OXIGÊNIO (DQO)}

A DQO foi determinada pelo método colorimétrico adaptado do procedimento do Standard Methods (Standard test methods, 2012). O método consiste na determinação da quantidade de oxigênio necessária para oxidar espécies presentes na água. A oxidação é intermediada pela redução do dicromato dentro de condições específicas.

O método apresenta a possibilidade de duas faixas de linearidade sendo denominadas faixa alta, a faixa que abrange concentrações superiores a $50 \mathrm{mg} \mathrm{O}_{2} \mathrm{~L}^{-1} \mathrm{e}$ faixa baixa, a faixa de concentrações abaixo de $50 \mathrm{mg} \mathrm{O}_{2} \mathrm{~L}^{-1}$. Optou-se por utilizar a faixa alta para a construção da curva analítica, com as seguintes concentrações: 50, 100, 200, 400, 600 e $800 \mathrm{mg} \mathrm{O}_{2} \mathrm{~L}^{-1}$, utilizando um padrão de biftalato de potássio, cujo valor teórico de DQO para cada grama de sal é $1,175 \mathrm{~g} \mathrm{O}_{2} \mathrm{~L}^{-1}$. A leitura do sinal é feita com o auxílio de um fotocolorímetro (AT1OP microprocessado) a $600 \mathrm{~nm}$ para calibração do equipamento.

Cada ponto, realizado em triplicata, consiste na digestão ácida durante duas horas sob uma temperatura de $150 \stackrel{\circ}{ } \mathrm{C}$ em bloco digestor (Alfakitat 520 ) de uma mistura de 2,5 $\mathrm{mL}$ de padrão/amostra, $1,5 \mathrm{~mL}$ de uma solução de dicromato de potássio $0,0347 \mathrm{~mol} \mathrm{~L}^{-1}$ e 3,5 mL de uma solução de ácido sulfúrico concentrado contendo um catalisador de sulfato de prata (5,5 $\mathrm{g}$ de $\mathrm{Ag}_{2} \mathrm{SO}_{4} / \mathrm{kg}$ de $\mathrm{H}_{2} \mathrm{SO}_{4}$ ), em tubo próprio. A adição de sulfato de mercúrio, utilizada para minimizar a interferência dos cloretos, não foi realizada nesse caso, pois a presença deles em solução não foi considerada.

\subsubsection{CONDUTIVIDADE}

A condutividade foi determinada com o auxílio de um condutivímetro MCA 150 da marca Adamo. 


\subsubsection{OXIGÊNIO DISSOLVIDO}

O oxigênio dissolvido foi determinado com a utilização de uma sonda multiparamétrica da marca OAKTON PCD 650, previamente calibrada.

\subsubsection{PERÓXIDO DE HIDROGÊNIO}

Foi utilizado o método analítico colorimétrico descrito por Silva e colaboradores (2004) para avaliar o consumo de peróxido de hidrogênio no ensaio de foto-Fenton. Foram tomadas de uma solução padrão ( $30 \mu \mathrm{L}$ de $\mathrm{H}_{2} \mathrm{O}_{2} 30 \%$ (v/v) diluído em $100 \mathrm{~mL}$ de água destilada) 1 a $10 \mathrm{~mL}$ e introduziram-se em balões volumétricos de $25 \mathrm{~mL}$. Completou-se o volume com água destilada e em seguida transferiu-se para béqueres de $50 \mathrm{~mL}$. Adicionaram-se em cada béquer, $4 \mathrm{~mL}$ de uma solução de metavanadato de amônio $\left(0,705 \mathrm{mg}\right.$ de metavanadato de amônio $\left(\mathrm{NH}_{4} \mathrm{VO}_{3}\right)$ e diluiu-se para $100 \mathrm{~mL} \mathrm{com}$ $\mathrm{H}_{2} \mathrm{SO}_{4} \quad 0,36 \mathrm{moL} \mathrm{L}^{-1}$ ) e mediu-se a absorbância em $452,5 \mathrm{~nm}$. A concentração de peróxido nas amostras degradadas foi determinada utilizando-se o mesmo procedimento, porém sem adição do padrão de $\mathrm{H}_{2} \mathrm{O}_{2}$.

\subsection{PROCESSOS OXIDATIVOS AVANÇADOS}

\subsubsection{FENTON}

\subsubsection{DEFINIÇÃO DAS VARIÁVEIS}

Foi realizado um ensaio inicial de Fenton com variação da concentração de $\mathrm{Fe}^{2+} \mathrm{e}$ de $\mathrm{H}_{2} \mathrm{O}_{2}$ em dois níveis, de acordo com valores selecionados da literatura. As concentrações de ferro avaliadas foram de 20 e $50 \mathrm{mg} \mathrm{L}^{-1}$ (Grčić e colaboradores, 2014; Sabaikai e colaboradores, 2014; Cunha e colaboradores, 2007) e as de peróxido foram de $100 \mathrm{mg} \mathrm{L}^{-1}$ e $1000 \mathrm{mg} \mathrm{L}^{-1}$ (Grčić e colaboradores, 2014; Silva e colaboradores, 2006). 
Os testes foram realizados utilizando-se sulfato ferroso heptahidratado ( $\mathrm{FeSO}_{4} .7 \mathrm{H}_{2} \mathrm{O}$, FMAIA P.A.) como fonte de $\mathrm{Fe}^{2+}$. O volume da amostra foi fixado em 100 $\mathrm{mL}$. O pH do meio não foi ajustado, sendo o pH do efluente bruto aproximadamente 1,4 . A adição de peróxido foi feita de $15 \mathrm{em} 15 \mathrm{~min}$. Alíquotas de $250 \mu \mathrm{L}$ de amostra foram coletadas de 30 em 30 min para a medição do COT após diluição com água destilada em balão volumétrico de $25 \mathrm{~mL}$. Os ensaios, com duração total de 180 minutos, foram realizados em duplicata e foram nomeados de 1 a 4 em conformidade e com a tabela 5 .

Tabela 5. Variáveis iniciais para os ensaios de Fenton.

\begin{tabular}{ccc}
\hline Ensaios & {$\left[\mathrm{Fe}^{2+}\right]$} & {$\left[\mathbf{H}_{2} \mathbf{O}_{2}\right]$} \\
\hline Ensaio 1 & 20 & 100 \\
Ensaio 2 & 20 & 1000 \\
Ensaio 3 & 50 & 100 \\
Ensaio 4 & 50 & 1000 \\
\hline
\end{tabular}

Após a definição das concentrações ideais das variáveis $\left[\mathrm{Fe}^{2+}\right]=20 \mathrm{mg} \mathrm{L}^{-1} \mathrm{e}\left[\mathrm{H}_{2} \mathrm{O}_{2}\right]$ $=1000 \mathrm{mg} \mathrm{L}^{-1}$, um novo conjunto de testes foi realizado até o tempo de 300 minutos com monitoramento de COT de 30 em 30 minutos.

\subsubsection{FOTO-FENTON $\left(\mathrm{Fe}^{2+} / \mathrm{H}_{2} \mathrm{O}_{2} / \mathrm{UV}\right)$}

Para o teste de foto-Fenton, utilizou-se as mesmas concentrações otimizadas para os ensaios de Fenton ( $\mathrm{Fe}^{2+}$ a $20 \mathrm{mg} \mathrm{L}^{-1}$ e $\mathrm{H}_{2} \mathrm{O}_{2}$ a $1000 \mathrm{mg} \mathrm{L}^{-1}$ ) e mesmo volume de amostra. Porém, a amostra foi submetida à radiação UV em um reator tipo tanque, caseiro, equipado com uma lâmpada de mercúrio de alta pressão $(\lambda=254 \mathrm{~nm})$ e de potência igual a $125 \mathrm{~W}$ (Figura 7). 


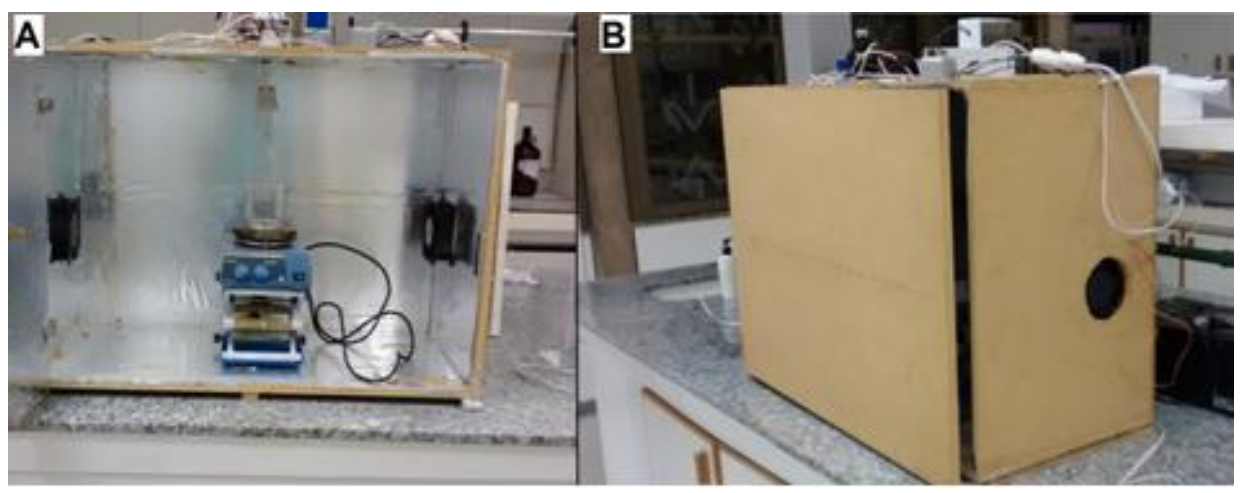

Figura 7. Sistema reator para realização de foto-ensaio para degradação da água de lavagem do biodiesel. A - Interior do reator e B - Exterior (Fotografias do arquivo do autor).

Os ensaios foram realizados em triplicata e foram coletadas, de $30 \mathrm{em} 30 \mathrm{~min}$ alíquotas de $250 \mu \mathrm{L}$ para medida de COT após diluição em balão volumétrico de $25 \mathrm{~mL}$. A duração total do ensaio foi de 300 min. Foram realizados ainda ensaios com um tempo prolongado até 480 minutos em triplicata, mantendo-se as variáveis supracitadas.

A temperatura da solução foi monitorada apenas durante a execução dos testes foto-Fenton.

\subsubsection{FOTÓLISE (UV)}

Os testes de fotólise foram realizados apenas com irradiação UV $(\lambda=254 \mathrm{~nm}, 125$ W) sem a presença de $\mathrm{Fe}^{2+}$ ou peróxido de hidrogênio. Foi utilizado o mesmo volume de amostra e o mesmo reator utilizado para o foto-Fenton.

Alíquotas de $250 \mu \mathrm{L}$ foram coletadas de 60 em 60 min para medidas de COT após diluição em balões volumétricos de $25 \mathrm{~mL}$. Os ensaios com duração de 300 e 480 minutos, foram realizados em triplicata. 


\subsubsection{FOTÓLISE ASSISTIDA COM PERÓXIDO $\left(\mathrm{UV} / \mathrm{H}_{2} \mathrm{O}_{2}\right)$}

Um terceiro teste consistiu no uso de UV ( $\lambda=254 \mathrm{~nm}, 125 \mathrm{~W})$ associado ao peróxido de hidrogênio. Foram usadas as mesmas condições empregadas para os testes foto-Fenton, ou seja, com concentração de peróxido de hidrogênio igual a $1000 \mathrm{mg} \mathrm{L}^{-1}$ adicionado a cada $15 \mathrm{~min}$. O monitoramento do COT foi realizado a cada 60 minutos pela coleta de $100 \mu \mathrm{L}$ das amostras (diluídas em seguida em balão volumétrico de $10 \mathrm{~mL}$ ). $\mathrm{O}$ procedimento foi realizado em triplicata com duração de $480 \mathrm{~min}$.

\subsection{AVALIAÇÃO ECOTOXICOLÓGICA (Fish Embryo Acute Toxicity- FET)}

Com a colaboração do Laboratório de Genética Toxicológica (G-Tox) do Instituto de Biologia da Universidade de Brasília (IB/UnB), foram realizados testes FET (do Inglês Fish Embryo Toxicity), toxicidade em embriões de peixe-zebra (Danio rerio ou ainda zebrafish), conforme protocolo da OECD o 236 (OECD, 2013) a fim de determinar o nível da toxicidade inicial do efluente e sua redução após o tratamento por processos oxidativos avançados.

Os peixes e ovos utilizados nos testes foram obtidos diretamente de cultura estabelecida no IB/UnB. Os peixes-zebra são mantidos em água filtrada por carvão ativado e membrana de osmose reversa a uma temperatura de 28,0 $\pm 1 \stackrel{\circ}{\circ}$. Periodicamente são adicionados sais minerais à água para manter a condutividade do meio a $550 \pm 50 \mu \mathrm{S} \mathrm{cm} \mathrm{cm}^{-1}$ e pH a $7,5 \pm 0,5$. Bombas de oxigenação são utilizadas para manter o conteúdo de oxigênio dissolvido em $95 \%$ de saturação. A sala de cultura tem o fotoperíodo controlado de $16 \mathrm{~h}$ de luz e $8 \mathrm{~h}$ de escuro. Os peixes-zebra adultos são alimentados duas vezes por dia com ração comercial e uma vez por dia com Artemia salina cultivada em laboratório ou comprada sob a forma congelada.

O procedimento do teste FET pode ser resumido pelo esquema mostrado na figura 6. A primeira etapa corresponde à obtenção de embriões. Nesta etapa há a separação de machos e fêmeas por uma divisória durante a noite e, ao iniciar o dia, com o estimulo 
da luz e a remoção das divisórias, acontece a desova e fertilização dos ovos (Fig. 8a). Após uma hora, os ovos são coletados, lavados e separados em placas de Petri com o meio de cultivo (Fig. 8b). Os ovos são selecionados em estereomicroscópio (Zeis KL 1500 LCD), e os não fecundados, danificados ou com anomalias no desenvolvimento são descartados (Fig. 8c). Os demais são distribuídos em placas de teste de 24 poços (Fig. 8d).

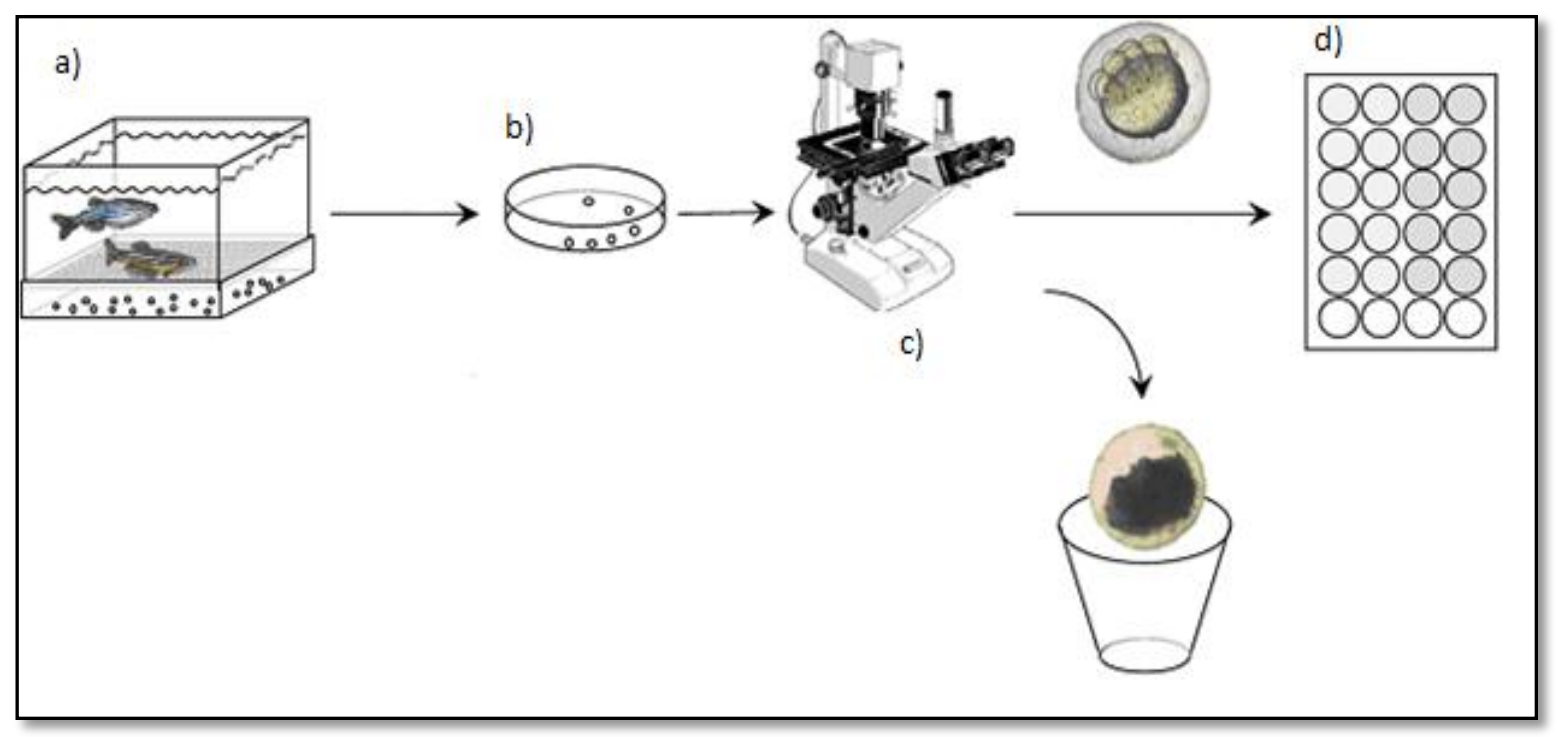

Figura 8. Esquema dos testes de toxicidade em embriões de peixe-zebra (adaptada de OECD, 2013).

Foram testadas amostras de água de lavagem de biodiesel bruta com três valores de $\mathrm{pH}$ diferentes: inicial $(1,4)$, ajustado para 4 e ajustado para 7 , por meio da adição de $\mathrm{KOH} 8 \mathrm{M}$. A toxicidade da amostra tratada pelo processo foto-Fenton durante 480 minutos com pH ajustado para 7 também foi avaliada. Para cada amostra foram utilizadas sete diluições $(75,50,25,10,1,0,1$ e 0,01\%) além da amostra original (100\%). As placas de teste foram preenchidas com $2 \mathrm{~mL}$ de amostra por poço com a utilização de uma pipeta automática. Quatro destes poços são destinados à verificação da qualidade interna da placa (grupo controle), portanto, não contém contaminante, apenas água do meio de cultivo. As placas foram acondicionadas em uma câmara climatizada com temperatura 
controlada ( $26 \pm 1^{\circ} \mathrm{O}$ ) e fotoperíodo $12 \mathrm{~h}$ de luz e $12 \mathrm{~h}$ escuro. O acompanhamento foi feito uma vez por dia durante um período de 96 horas, como é recomendado pelo protocolo OECD (2013). As leituras do teste foram realizadas em triplicata para cada concentração, além de uma triplicata controle.

Durante o período de observação, são levados em considerações quatro indicadores de letalidade: a) coagulação dos ovos fertilizados; b) falta de formação de somito; c) não desprendimento da calda do saco vitelino e d) ausência de batimentos cardíacos. Após o período de exposição, a toxicidade foi determinada levando em consideração qualquer uma das alterações citadas acima e foi possível, então, calcular a $\mathrm{CL}_{50}$, concentração letal, ou seja, capaz de matar 50 \% dos indivíduos expostos.

O programa Origin 7.0 foi utilizado para análise dos dados. As concentrações letais $\left(C L_{50}\right)$ para os embriões de zebrafish foram calculadas usando uma função logística de ajuste sigmoidal. 


\section{RESULTADOS E DISCUSSÃO}

\section{1 ÁGUA DE LAVAGEM}

A água de lavagem coletada apresenta odor muito semelhante ao do biodiesel, coloração turva e viscosidade semelhante à da água comum. Uma caracterização inicial dessa água foi feita em relação aos parâmetros pH, TOC, TOG, Condutividade e Oxigênio Dissolvido, cujos resultados são apresentados na tabela 6.

Tabela 6. Caracterização parcial da água de lavagem.

\begin{tabular}{cc}
\hline Parâmetro & Resultado \\
\hline COT & $40700 \pm 570 \mathrm{mg} \mathrm{L}^{-1}$ \\
DQO & $24210 \pm 265 \mathrm{mg} \mathrm{L}^{-1}$ \\
TOG & $2237 \pm 204 \mathrm{mg} \mathrm{L}^{-1}$ \\
$\mathrm{pH}$ & $1,66 \pm 0,03$ \\
Condutividade & $35,62 \pm 0,07 \mathrm{mS} \mathrm{cma}^{-1}$ \\
Oxigênio dissolvido & $7,07 \pm 0,06 \mathrm{mg} \mathrm{L}^{-1}$ \\
\hline
\end{tabular}

Existe, durante o processo de separação, a formação de espuma devido à presença de sabões formados durante a síntese do biodiesel. Essa espuma fica entre 0 biodiesel e a água e quando coletada junto com a água forma uma camada branca sobrenadante. Para garantir a limpeza do biodiesel, é necessário que o sabão também seja removido, porém, a presença do mesmo nas amostras de água de lavagem foi considerado um resíduo com outras características e, portanto, esta fase foi desprezada nos estudos de caracterização e degradação por processos oxidativos, já que a presença da espuma causava uma grande variação nos valores de TOG, COT e DQO. 


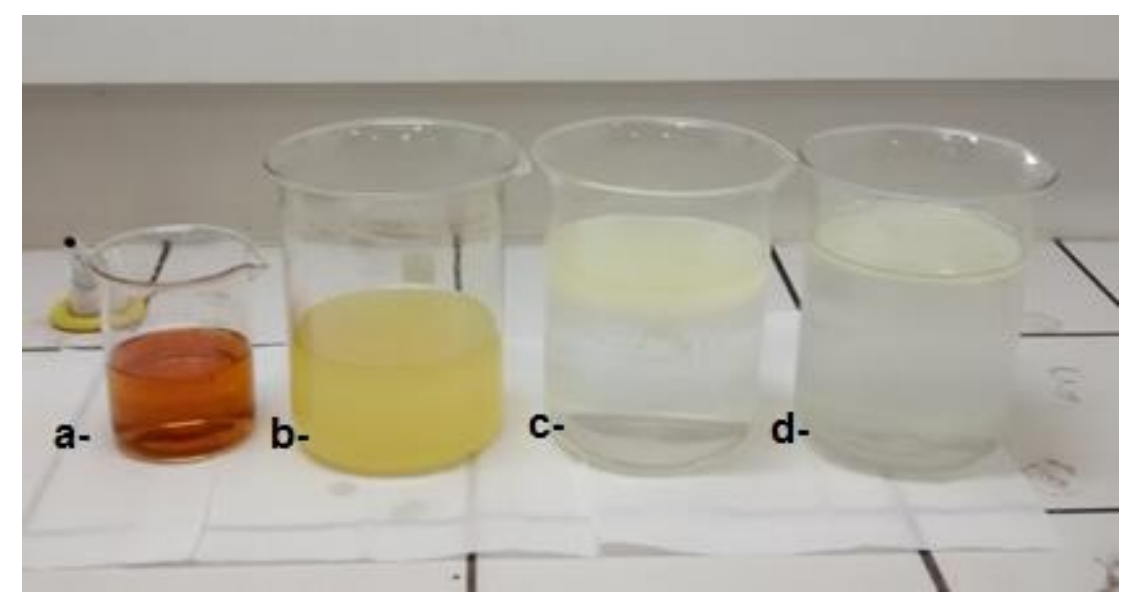

Figura 9. Da esquerda para direita. a- Glicerina bruta; b- Biodiesel; c- Primeira fração da água de lavagem; d-Segunda fração da água de lavagem (Fotografia do arquivo do autor).

A água de lavagem do biodiesel de soja foi caracterizada ainda pela sua ecotoxicidade. A ecotoxicidade desse resíduo foi verificada pelo método FET descrito anteriormente e apresentou-se tóxica em uma ampla faixa de concentração em diferentes valores de $\mathrm{pH}$.

A figura 10 apresenta as curvas de dose resposta para os testes com a água de lavagem sem tratamento com $\mathrm{pH} 1,4$ (original), com $\mathrm{pH}$ alterado para 4 e para 7 . As curvas apresentam comportamento sigmoidal, cujas correlações são apresentadas na tabela 7 , juntamente com os dados de $\mathrm{CL}_{50}$. 


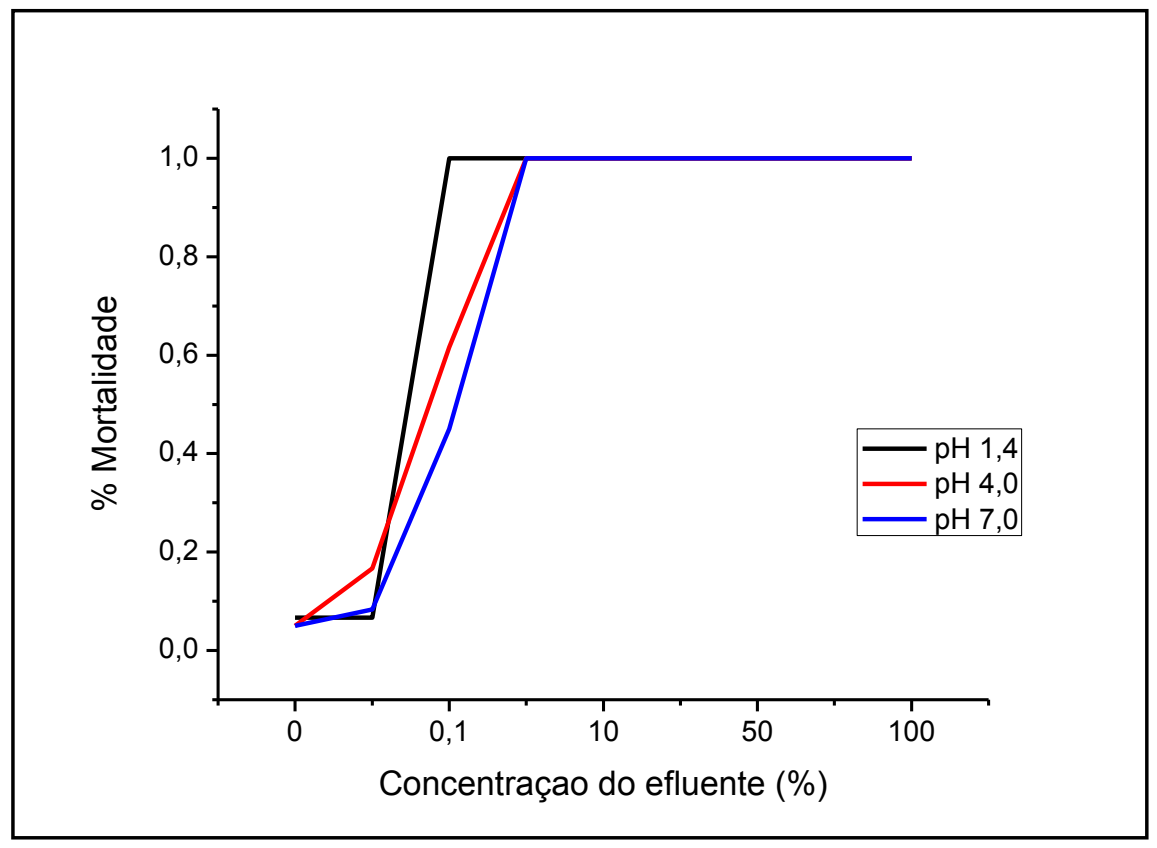

Figura 10. Curvas de dose resposta para o zebrafish após o quarto dia do teste com água de lavagem de biodiesel.

Tabela 7. Concentrações Letais (\%) para $50 \%$ dos indivíduos (CL50) e valores de $r^{2}$.

\begin{tabular}{cccc}
\hline $\mathbf{p H}$ & $\mathbf{1 , 4}$ & $\mathbf{4 , 0}$ & $\mathbf{7 , 0}$ \\
\hline $\mathrm{r}^{2}$ & 1,0 & 0,99747 & 0,99944 \\
$\mathrm{CL}_{50}$ & $0,033 \pm 0,003$ & $0,070 \pm 0,006$ & $0,118 \pm 0,005$ \\
\hline
\end{tabular}

Os elevados valores de contaminantes e a elevada toxicidade apresentada pelo resíduo (água de lavagem sem tratamento e com pHs alterados), mesmo apresentando um aumento nos valores da $\mathrm{CL}_{50}$ após a correção do pH corrobora as informações da literatura em relação à necessidade de tratamento desse efluente, visto que não existem políticas de despejo nem de tratamento específico regulamentadas no nosso país acerca deste resíduo. 
Uma avaliação ecotoxicológica da água de lavagem do biodiesel de soja foi realizada por Holanda e colaboradores (2012) utilizando o Danio rerio adulto como organismo-teste. O efluente foi caracterizado como "muito tóxico" pelos autores, sendo enquadrado como um efluente industrial, com uma $\mathrm{CL}_{50}$ após $48 \mathrm{~h}$ de exposição de $13,94 \%$ após correção do $\mathrm{pH}$ para $6,86 \pm 0,67$. Neste trabalho, o valor de $\mathrm{CL}_{50}$ obtido pelo teste FET para o efluente com pH corrigido para 7 foi de $0,12 \%$, cerca de 100 vezes menor do que o obtido com a utilização do Danio rerio adulto (Holanda e colaboradores, 2012). A diferença no valor de $C L_{50}$ para os testes pode estar relacionado à sensibilidade do método FET em relação ao método utilizado por Holanda e colaboradores, devido a utilização de organismos em desenvolvimento, menos robustos do que os peixes adultos.

O baixo valor de $\mathrm{CL}_{50}$ pode estar relacionado principalmente à presença de metanol na água de lavagem (Grangeiro, 2009; Braga, 2012). Porém, Hincapié-Mejía e colaboradores (2011), bem como Patiño e colaboradores (2012), após procedimento de recuperação de metanol em rotoevaporador a $80{ }^{\circ} \mathrm{C}$ numa etapa prévia à lavagem do biodiesel cujos valores de recuperação de 2,54 e 3,15\%, reportaram uma toxicidade de $100 \%$ para organismos-teste Daphnia Magna e Daphnia Pulex, respectivamente. Tal processo de recuperação, além de apresentar um aumento no custo não elimina a presença do contaminante por completo, sendo este ainda encontrado no resíduo após a recuperação e também após o tratamento pela metodologia proposta pelos autores.

Portanto, apesar de toxicidade elevada, o metanol provavelmente não é o único e nem o principal fator de toxicidade no resíduo. Araújo e colaboradores (2011) afirmam que a glicerina bruta, também presente na água de lavagem do biodiesel, apresenta-se tóxica para a espécie Danio rerio adulto, com valor de $\mathrm{CL}_{50}$ após 48 horas de exposição igual a $0,11 \% \mathrm{~m} / \mathrm{v}$, sendo também classificado como muito tóxico. 


\subsection{PROCESSOS OXIDATIVOS}

\subsubsection{DEFINIÇÃO DAS VARIÁVEIS}

Um teste preliminar foi realizado para fixar as variáveis de concentração (Ferro e Peróxido) não só para os próximos testes Fenton, mas também para o foto-Fenton. A definição dessas concentrações iniciais foi baseada na literatura, visto que, devido ao elevado número de publicações relativas aos processos citados, não foi considerado relevante o desenvolvimento de um planejamento fatorial com um número maior de concentrações.

As variáveis utilziadas estão apresentadas na tabela 5 e o gráfico apresentado na figura 11 apresenta os resultados de carbono orgânico total com o passar do tempo até um tempo final de $180 \mathrm{~min}$.

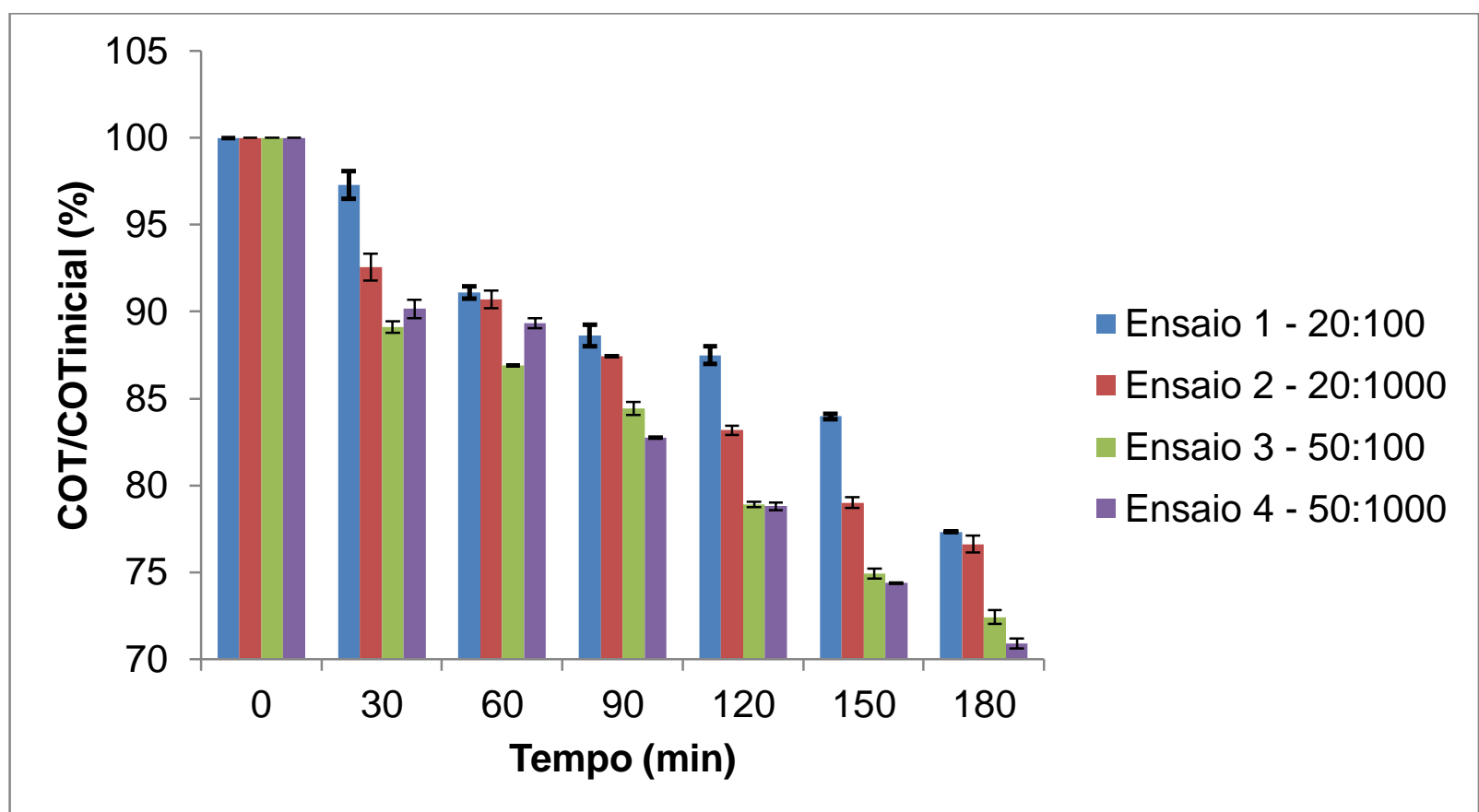

Figura 11. Ensaio preliminar com duração de 180 minutos (proporção $\mathrm{Fe}^{2+}: \mathrm{H}_{2} \mathrm{O}_{2} \mathrm{em} \mathrm{mgL}^{-1}$ ). $\mathrm{O}$ eixo vertical foi iniciado em $70 \%$ para efeitos de melhor visualização. 
Nota-se que, os ensaios 2 e 4, que utilizam uma concentração maior (1000 mg L-1) de peróxido de hidrogênio apresentaram uma redução maior ao final do experimento, do que quando utilizada a menor concentração (100 mg L-1), para ambas as concentrações de $\mathrm{Fe}^{2+}$.

Uma comparação estatística entre os ensaios 2 e 4 foi então realizada. Foi utilizado um teste $\mathrm{F}$ bilateral, seguido de um teste t e t pareado conforme sugerido por Miller \& Miller (2005). O teste $\mathrm{F}$ foi utilizado para verificar se existe diferença significativa entre o desvio padrão dos processos, o valor calculado para esse caso foi de 2,88 , enquanto 0 valor tabelado com n-1 graus de liberdade é igual a 161,4; portanto, os desvios não diferem significativamente, ou seja a hipótese nula foi verdadeira, permitindo a realização de um teste t. O segundo teste, para avaliar se a porcentagem de remoção de COT é significativamente diferente, apresentou valor $t$ calculado de 14,55 acima do tabelado para 2 graus de liberdade e $\mathrm{P}$ valor $95 \%(4,30)$, ou seja, a hipótese nula é rejeitada, as médias são estatisticamente diferentes, colocando como melhor concentração de $\mathrm{Fe}^{2+} \mathrm{a}$ de $50 \mathrm{mg} \mathrm{L}^{-1}$. Porém, considerando a elevada concentração e possíveis problemas relativos à toxicidade além do aumento no custo do processo pelo gasto maior de reagentes optou-se por utilizar a concentração de $\mathrm{Fe}^{2+}$ de $20 \mathrm{mg} \mathrm{L}^{-1}$.

Em seguida serão detalhados os resultados para cada tipo de processo utilizado com as condições previamente definidas.

\subsubsection{FENTON}

Após a definição das variáveis para os processos oxidativos, prosseguiu-se a realização do processo Fenton para o efluente, cujo resultado da remoção de carbono orgânico (\%) ao longo do tempo está apresentado na Figura 12. 


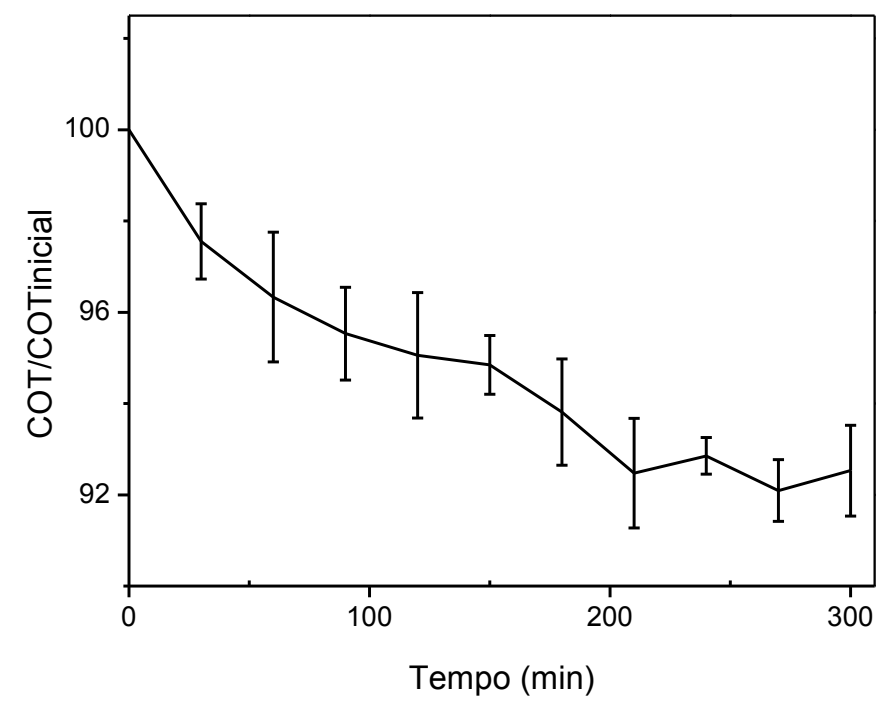

Figura 12. Gráfico de degradação de COT por processo Fenton $\left(100 \mathrm{~mL}\right.$ de amostra; $\left[\mathrm{Fe}^{2+}\right]=20 \mathrm{mg} \mathrm{L}^{-1} \mathrm{e}$ $\left[\mathrm{H}_{2} \mathrm{O}_{2}\right]=1000 \mathrm{mg} \mathrm{L}^{-1}$ ) da água de lavagem de biodiesel de soja.

Mesmo com tempo estendido a 300 minutos, o processo Fenton não foi capaz de reduzir de forma significativa a carga orgânica do efluente, com uma remoção máxima de $7,5 \pm 1,0 \%$.

Os resultados obtidos neste trabalho foram concordantes com os apresentados por Hincapié-Mejía e colaboradores (2011), quando se compara as reduções obtidas pelo processo Fenton. Nos dois trabalhos o uso de Fenton gerou baixas reduções nas concentrações de COT, provavelmente devido a interferência de sais inorgânicos oxidáveis, segundo Hincapié-Mejía. Os estudos prosseguiram, portanto, com a inclusão da radiação UV ao processo Fenton (foto-Fenton), apresentado a seguir.

\subsubsection{FOTO-FENTON}

O processo foto-Fenton (100 mL de amostra; $\lambda=254 \mathrm{~nm}$; $\left[\mathrm{Fe}^{2+}\right]=20 \mathrm{mg} \mathrm{L}^{-1} \mathrm{e}$ $\left.\left[\mathrm{H}_{2} \mathrm{O}_{2}\right]=1000 \mathrm{mg} \mathrm{L}^{-1}\right)$, apresentou, em $300 \mathrm{~min}$, uma eficiência bem maior na remoção 
da carga orgânica da amostra do que o Fenton (aproximadamente 7,5 \% para Fenton versus $77,5 \%$ para foto-Fenton). Ao observar a inclinação da curva gerada (Figura 13), é possível prever que, prolongando o tempo de duração do processo fotocatalítico, uma maior redução possa acontecer.

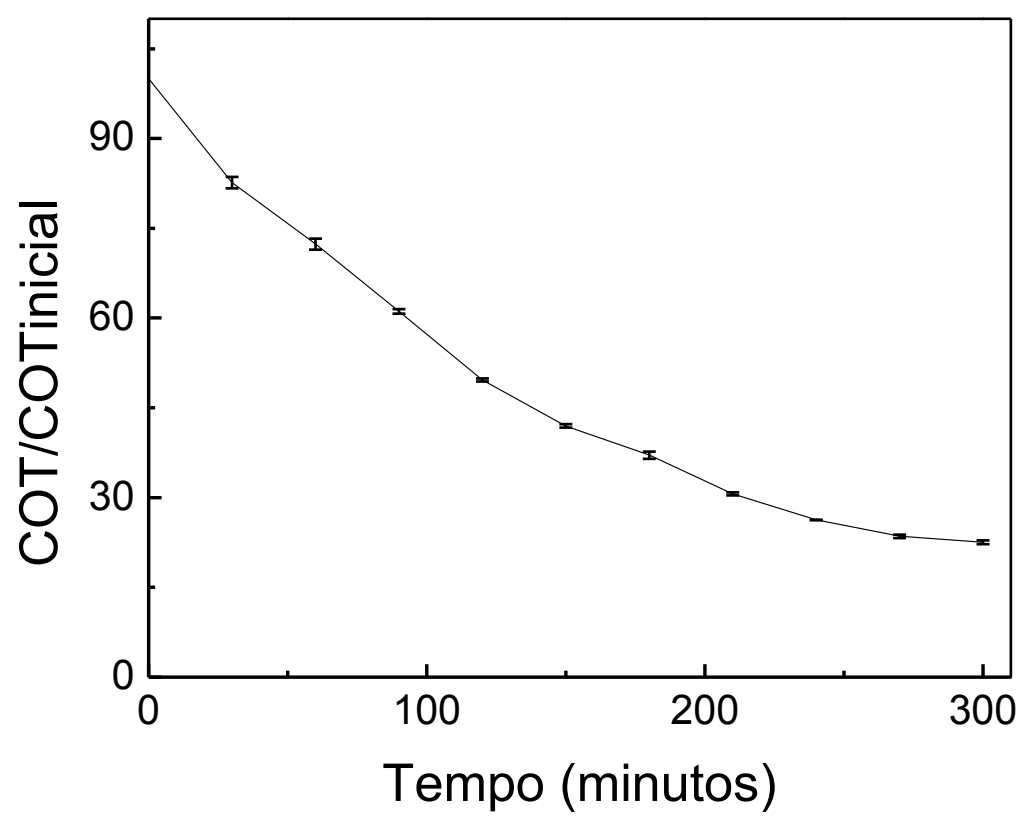

Figura 13. Gráfico de degradação de COT pelo processo foto-Fenton (100 mL de amostra; $\lambda=254 \mathrm{~nm}$; $\left[\mathrm{Fe}^{2+}\right]=20 \mathrm{mg} \mathrm{L}^{-1}$ e $\left.\left[\mathrm{H}_{2} \mathrm{O}_{2}\right]=1000 \mathrm{mg} \mathrm{L}^{-1}\right)$.

Novos ensaios foram realizados em 480 min de duração, com valores de degradação de COT atingindo $93,8 \pm 0,2 \%$ de redução. $O$ teste resultou no gráfico apresentado na (Figura 14). 


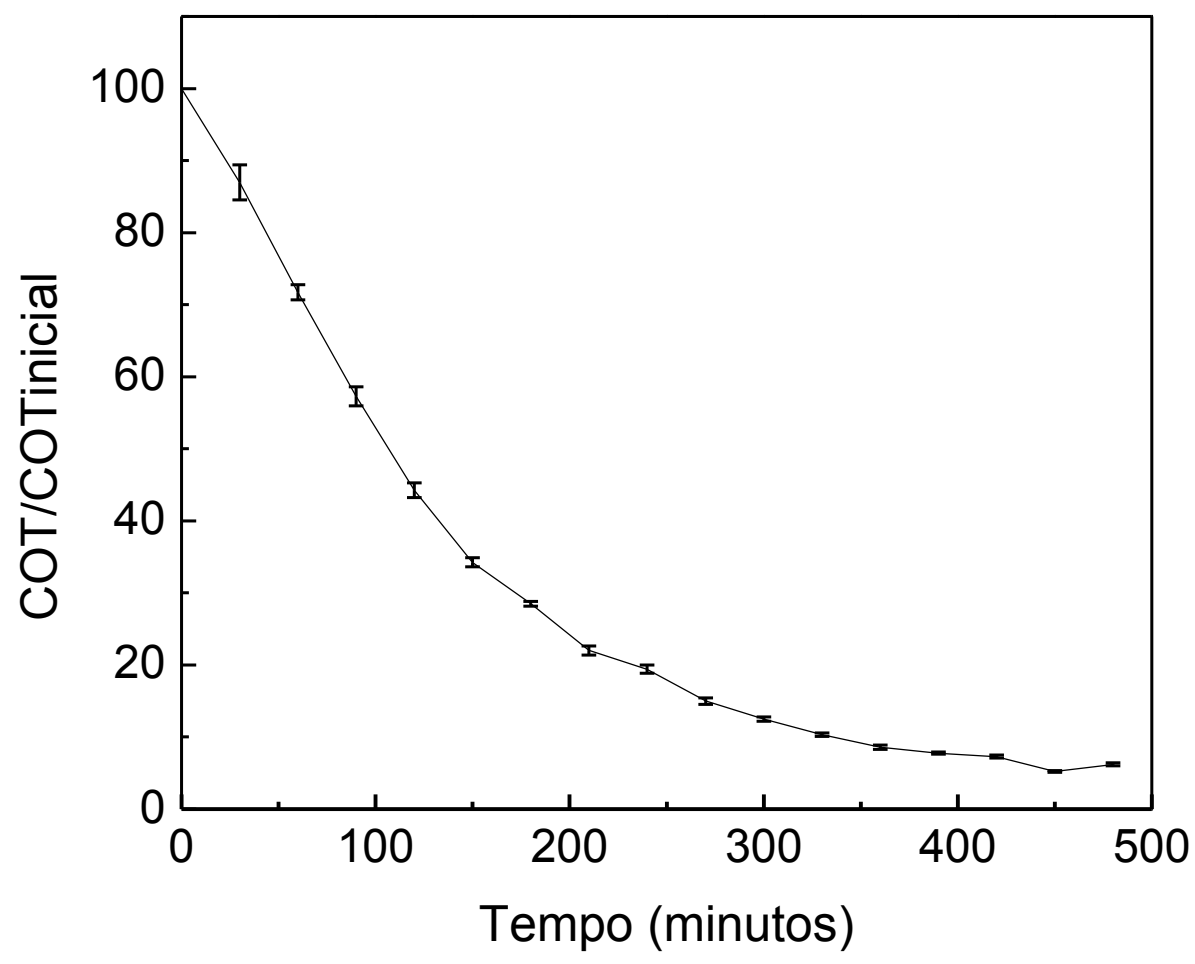

Figura 14. Gráfico de degradação de COT por processo foto-Fenton (100 mL de amostra; $\lambda=254 \mathrm{~nm}$; $\left[\mathrm{Fe}^{2+}\right]=20 \mathrm{mg} \mathrm{L}^{-1}$ e $\left.\left[\mathrm{H}_{2} \mathrm{O}_{2}\right]=1000 \mathrm{mg} \mathrm{L}^{-1}\right)$.

\subsubsection{FOTÓLISE (UV)}

O objetivo desta etapa foi avaliar o quanto a degradação do COT obtido pelo processo foto-Fenton era fruto do processo completo e o quanto era proveniente apenas da radiação UV (fotólise). Para isso, foram realizados os ensaios da fotólise da amostra no período de 300 minutos (Figura 15) e também com o tempo prolongado a 480 minutos (Figura 16), em ambos foram coletadas alíquotas de 60 em 60 minutos para acompanhamento do COT. 


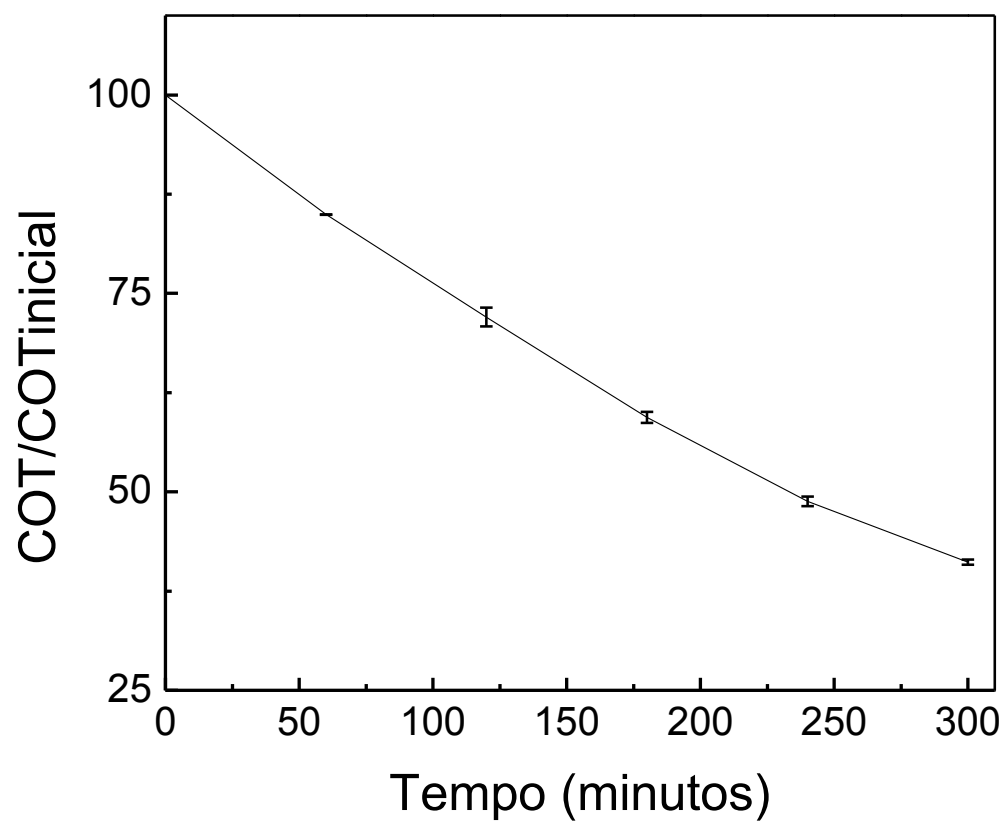

Figura 15. Gráfico de degradação de COT no teste com 300 min de fotólise $(100 \mathrm{~mL}$ de amostra e $\lambda=$ $254 \mathrm{~nm})$

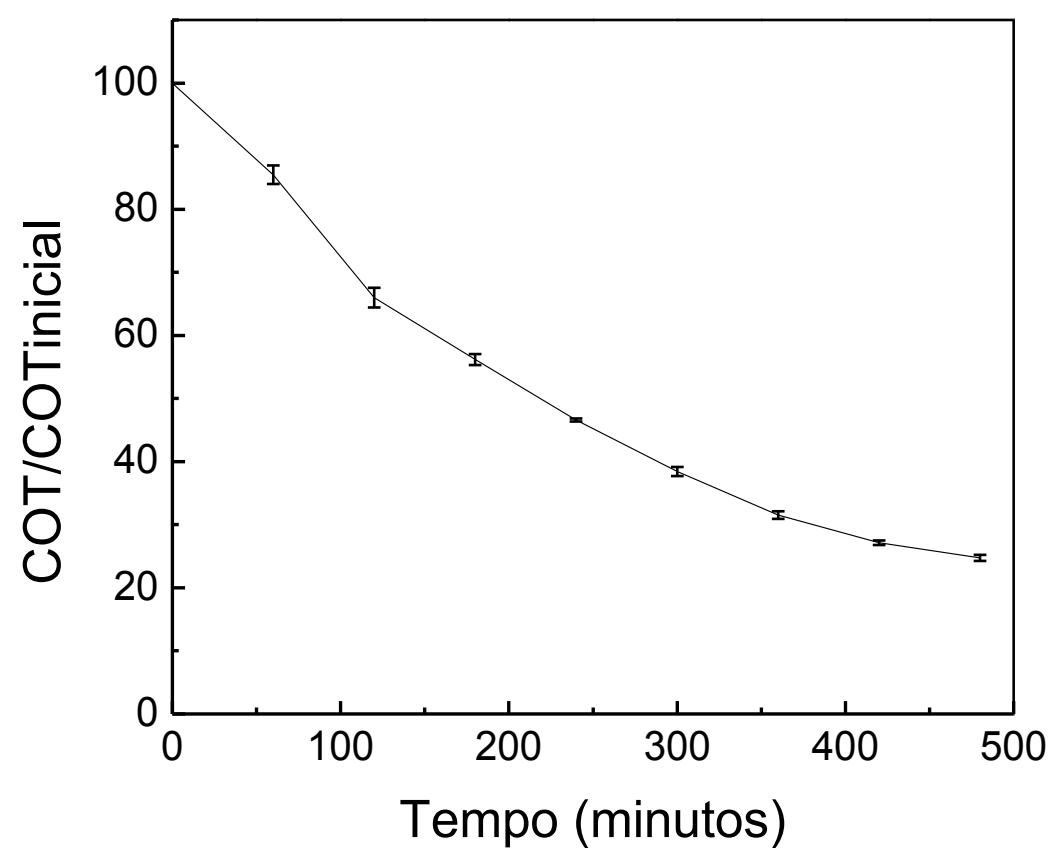

Figura 16. Gráfico de degradação de COT no teste com 480 min de fotólise (100 mL de amostra; $\lambda=254$ $\mathrm{nm})$ 
Os processos apresentaram redução de COT maior do que o Fenton, $58,9 \pm 0,3 \%$ e 75,2 $\pm 0,5 \%$ para os tempos de 300 e $480 \mathrm{~min}$, respectivamente. Embora relativamente altos, ainda foram inferiores aos valores de redução obtidos pelo fotoFenton, mas comprovam que a uso da radiação para a redução da carga orgânica desempenha um papel importante, provavelmente devido ao aumento do número de radicais hidroxilas formados.

\subsubsection{FOTÓLISE ASSISTIDA POR PERÓXIDO $\left(\mathrm{UV} / \mathrm{H}_{2} \mathrm{O}_{2}\right)$}

O processo de fotólise com adição de peróxido a cada 15 minutos foi realizado acompanhando a redução de COT com o passar do tempo (100 mL de amostra; $\lambda=254$ $\mathrm{nm}$ e $\left[\mathrm{H}_{2} \mathrm{O}_{2}\right]=1000 \mathrm{mg} \mathrm{L}^{-1}$ ). Tal processo, em 480 minutos (Figura 17), apresentou maior redução da carga orgânica em comparação à utilização apenas de radiação e também em relação ao processo Fenton, com resultado de redução de $85,52 \pm 0,30 \%$, porém ainda inferior ao processo foto-Fenton.

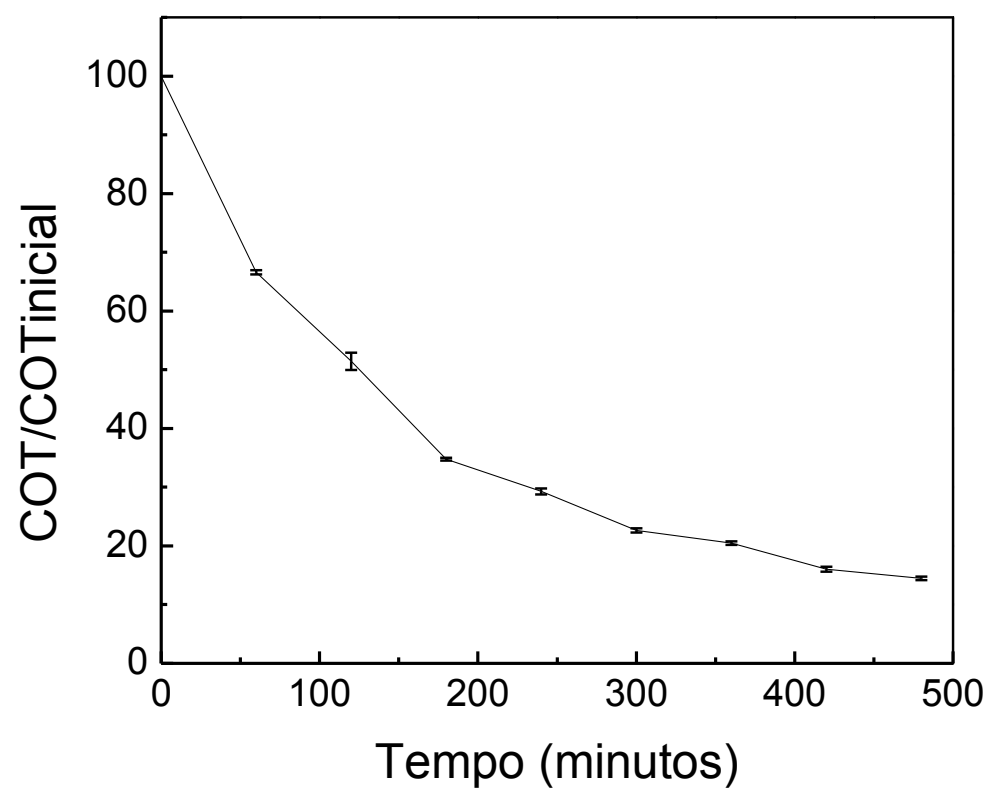

Figura 17. Gráfico para fotólise/peróxido durante $480 \mathrm{~min}$ (100 $\mathrm{mL}$ de amostra; $\lambda=254$ $\mathrm{nm}$ e $\left.\left[\mathrm{H}_{2} \mathrm{O}_{2}\right]=1000 \mathrm{mg} \mathrm{L}^{-1}\right)$. 


\subsubsection{COMPARAÇÃO ENTRE OS PROCESSOS}

O gráfico a seguir (figura 18) apresenta um comparativo entre todos os processos para a redução do COT em relação aos seus tempos finais.

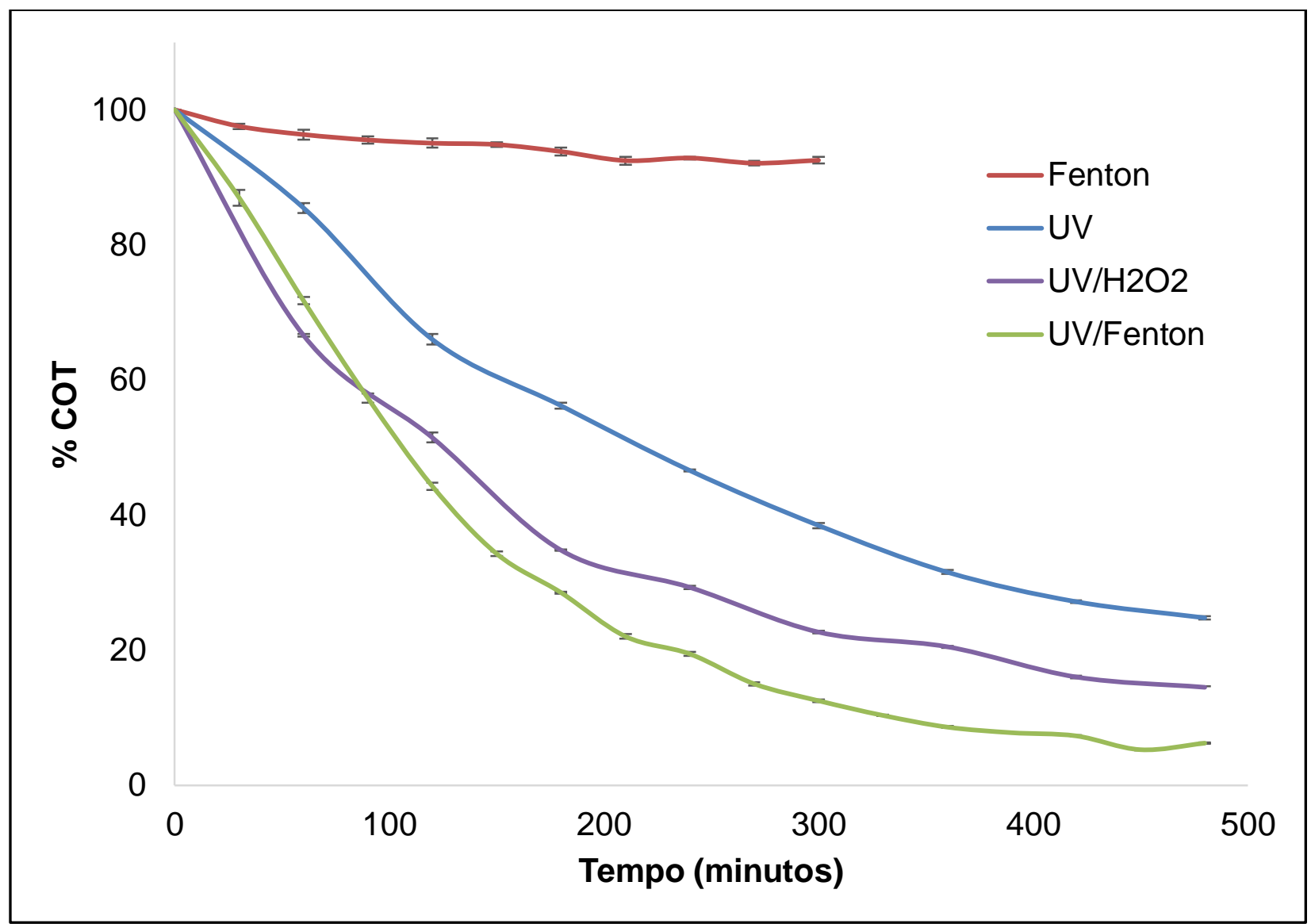

Figura 18. Gráfico comparativo para a redução de COT para todos os processos.

Embora os processos $\mathrm{UV} / \mathrm{H}_{2} \mathrm{O}_{2}$ e $\mathrm{Fe}^{2+} / \mathrm{UV} / \mathrm{H}_{2} \mathrm{O}_{2}$ apresentassem aparentemente valores de redução de TOC diferentes, foi realizado um teste $F$, seguido de um teste te t pareado, para verificar se existe diferença significativa nos valores obtidos (Miller \& Miller, 2005). 
Tabela 8. Teste de significância entre as médias para os processos foto-Fenton e $\mathrm{UV} / \mathrm{H}_{2} \mathrm{O}_{2}$.

\begin{tabular}{ccc}
\hline Processo & $\mathrm{UV} / \mathrm{H}_{2} \mathbf{O}_{2}$ & $\mathrm{Fe}^{2+} / \mathbf{U V} / \mathrm{H}_{2} \mathbf{O}_{2}$ \\
\hline Replicata 1* $^{*}$ & 85,179 & 93,573 \\
Replicata 2* $^{*}$ & 85,652 & 93,984 \\
Replicata 3* $^{*}$ & 85,730 & 93,824 \\
Média & 85,520 & 93,794 \\
Desvio Padrão & 0,298 & 0,207 \\
\hline
\end{tabular}

${ }^{*}$ Os valores são apresentados em \% de redução de COT.

O valor de $\mathrm{F}$ calculado, baseado nos valores disponíveis na tabela 8 , corresponde a 2,08. O valor tabelado para o teste, com 2 graus de liberdade para o denominador e numerador é igual a 39,00. Portanto, o desvio padrão dos dois métodos não diferem significativamente com n-1 graus de liberdade (onde n é o número de replicatas). O teste $F$ é realizado para verificar se os desvios diferem significativamente, requisito importante para avaliação das médias, que posteriormente são avaliadas pelo teste $t$.

Dois testes, um teste t e um teste t pareado foram realizados com o intuito de avaliar se os valores obtidos para $\mathrm{UV} / \mathrm{H}_{2} \mathrm{O}_{2}$ são estatisticamente diferentes aos valores obtidos para o $\mathrm{Fe}^{2+} / \mathrm{UV} / \mathrm{H}_{2} \mathrm{O}_{2}$. Os valores obtidos para os três testes estão disponíveis na tabela 9.

Tabela 9. Valores obtidos para os testes estatísticos.

\begin{tabular}{cccc}
\hline & Teste F & Teste t & Teste t pareado \\
\hline $\begin{array}{c}\text { Valor } \\
\text { Calculado } \\
\text { Valor }\end{array}$ & 2,07 & 2,13 & 4,3 \\
$\begin{array}{c}\text { Tabelado } \\
\text { Graus de } \\
\text { liberdade }\end{array}$ & 2 & 4 & $36,00^{*}$ \\
& & $39,47^{*}$ & 2
\end{tabular}

*Valor tabelado para os respectivos graus de liberdade e p valor igual a 0,05 
O valor obtido para t é igual a 39,47 e o valor tabelado para o teste t com 4 graus de liberdade e P valor igual a 0,05 é de 2,13, bem abaixo do valor calculado. Então a hipótese nula, de que as médias sejam estatisticamente iguais, é rejeitada pelo teste t. Em um teste t pareado o valor obtido para t é 36,01. O número de graus de liberdade é igual a n-1, ou seja, 2. Para 2 graus de liberdade o valor de t tabelado é igual a 4,30 para um $P$ valor igual a 0,05 . Portanto, as médias são significativamente diferentes e a hipótese nula também é rejeitada.

Comprovado estatisticamente o melhor desempenho do método foto-Fenton na degradação da água de lavagem do biodiesel, as concentrações dos principais contaminantes estudados, além do parâmetro COT, foram avaliados antes e após o tratamento por foto-Fenton durante $480 \mathrm{~min}$.

A variação dos parâmetros COT, DQO, Condutividade, oxigênio dissolvido, $\mathrm{pH}$ e toxicidade antes e após o tratamento foto-Fenton do resíduo em 480 minutos estão descritas na tabela 10.

Tabela 10. Redução dos parâmetros após o tratamento foto-Fenton com duração de 480 minutos.

\begin{tabular}{cccc}
\hline Parâmetro & Amostra Original & Amostra Tratada & $\begin{array}{c}\text { Percentual } \\
\text { removido/aumentado } \\
(\%)\end{array}$ \\
\hline TOC $\left(\mathrm{mg} \mathrm{L}^{-1}\right)$ & $27728,1 \pm 175,6$ & $5092,4 \pm 88,0$ & 81,6 \\
DQO $\left(\mathrm{mg} \mathrm{L}^{-1}\right)$ & $24210,3 \pm 265,5$ & $15428,3 \pm 222,2$ & 36,3 \\
Condutividade $(\mathrm{mS})$ & $35,62 \pm 0,07$ & $22,85 \pm 0,36$ & 35,9 \\
Oxigênio dissolvido & $7,08 \pm 0,06$ & $10,52 \pm 0,37$ & 48,7 \\
$\quad\left(\mathrm{mg} \mathrm{L}^{-1}\right)$ & & & \\
$\mathrm{pH}$ & $1,67 \pm 0,03$ & $1,68 \pm 0,02$ & 0,8 \\
Ecotoxicidade & $0,118 \pm 0,005$ & $0,032 \pm 0,001$ & 72,9 \\
Peróxido residual & $\mathrm{nd}$ & $\mathrm{nd}$ & $\mathrm{nd}$ \\
\hline
\end{tabular}

*Valor da $\mathrm{CL}_{50}$ obtida para as amostras em $\mathrm{pH}=7,0$

nd $=$ não detectado 
A redução de COT final registrada apresentou-se inferior do que a demonstrada nos processos iniciais de tratamento, tal diferença pode ser justificada pela diferença das características iniciais do resíduo a cada síntese devido a heterogeneidade da amostra. A DQO não apresenta uma remoção tão significativa quanto o COT podendo ser justificada pela presença de novas espécies oxidáveis no meio. A condutividade, relativamente alta, apresenta uma redução, comportamento que pode ser justificado pela possível neutralização das espécies iônicas relacionadas ao $\mathrm{pH}$. O oxigênio dissolvido apresenta um aumento em torno de $30 \%$, provavelmente devido à auto degradação do peróxido de hidrogênio em água e oxigênio gasoso. Não existe uma variação significativa do $\mathrm{pH}$ antes e após o tratamento e a presença de peróxido após o tratamento não é observada pelo método descrito.

O valor de $\mathrm{CL}_{50}$ contrariamente ao previsto, apresenta uma redução, ou seja, embora todas essas reduções nos parâmetros citados anteriormente, a ecotoxicidade verificada pelo método FET aumenta. Isso pode se dar devido a presença de espécies radicalares ainda presentes no meio devido a não mineralização dos contaminantes orgânicos ou ainda à formação de intermediários mais tóxicos do que os contaminantes iniciais, visto que não é verificada a presença de peróxido residual (tabela 9).

\subsubsection{CINÉTICA DA REAÇÃO}

Para avaliar a cinética pela redução do carbono orgânico, foram construídas curvas do logaritmo neperiano (In) do COT/COTinicial em relação ao tempo, bem como curvas do inverso da concentração de carbono em relação ao tempo. A primeira fornece uma curva característica de uma reação de primeira ordem, caso apresente-se linear, onde a constante cinética do processo é o coeficiente angular dessa curva. Da mesma maneira, a segunda curva, quando linear apresenta o comportamento de uma reação de segunda ordem onde a constante cinética é o coeficiente angular da curva. (Atkins \& Paula, 2008) 
O processo foto-Fenton em 480 minutos apresentou comportamento de pseudoprimeira ordem, cuja linearidade do In COT/COT inicial vs Tempo apresentou-se maior do que o inverso da variação do COT vs tempo. Esses resultados estão apresentados na figura 19 que informa também os valores das equações, cujo coeficiente angular representa a constante cinética. $\left(k=6,4 \times 10^{-3} \mathrm{~h}^{-1}\right)$.

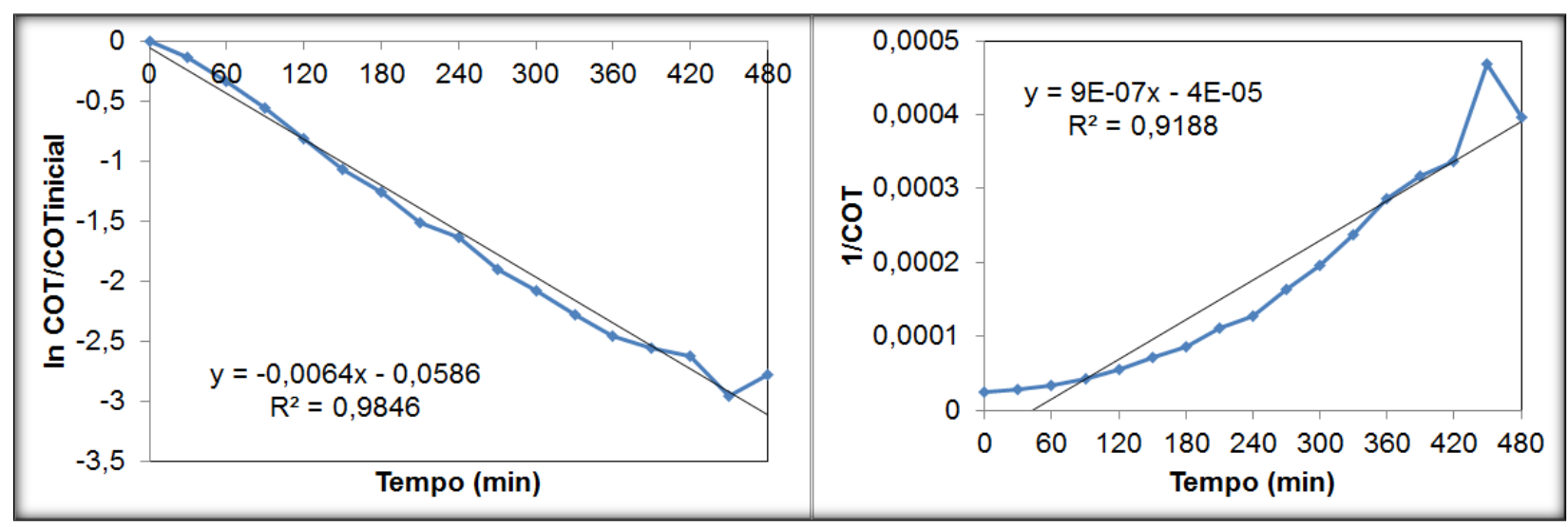

Figura 19. Gráficos de cinética para o processo foto-Fenton. À direita, gráfico do In COT/COTinicial pelo tempo, à esquerda, gráfico de 1/COT pelo tempo.

A fotólise apresentou comportamento semelhante ao foto-Fenton, observado pelos gráficos apresentados na figura 20 , de onde também é possível observar o valor da constante cinética para o processo $\left(k=3 \times 10^{-3} \mathrm{~h}^{-1}\right)$.

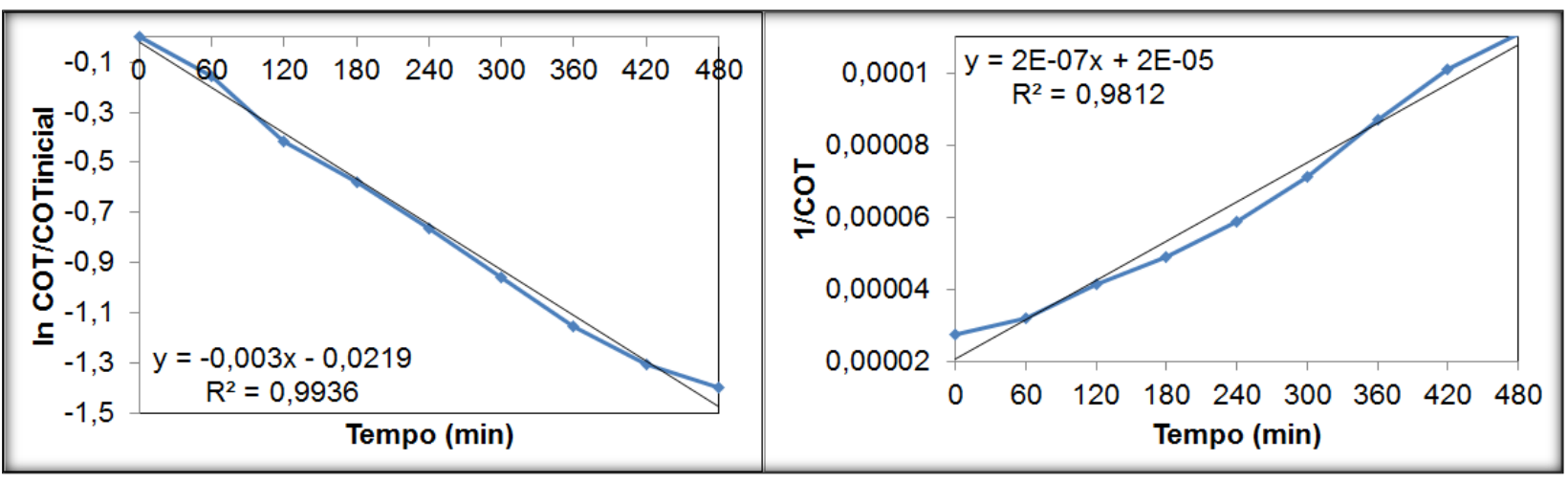

Figura 20. Gráficos de cinética para o processo fotólise. Á direita, gráfico de In COT/COTinicial pelo tempo, à esquerda, gráfico de 1/COT pelo tempo. 
A fotólise com peróxido $\left(\mathrm{UV} / \mathrm{H}_{2} \mathrm{O}_{2}\right)$, apresentou comportamento diferente dos processos citados anteriormente, cujo comportamento de primeira ordem predominou. $\mathrm{O}$ $\mathrm{UV} / \mathrm{H}_{2} \mathrm{O}_{2}$ apresenta melhor linearidade no segundo gráfico (1/COT pelo tempo), cujo comportamento assemelha-se a uma reação de segunda ordem (figura 21). Portanto, não é possível comparar o valor de uma constante de segunda ordem $\left(\mathrm{k}=3 \times 10^{-7}\right) \mathrm{com}$ de primeira ordem $\left(k=4 \times 10^{-3} \mathrm{~h}^{-1}\right)$.

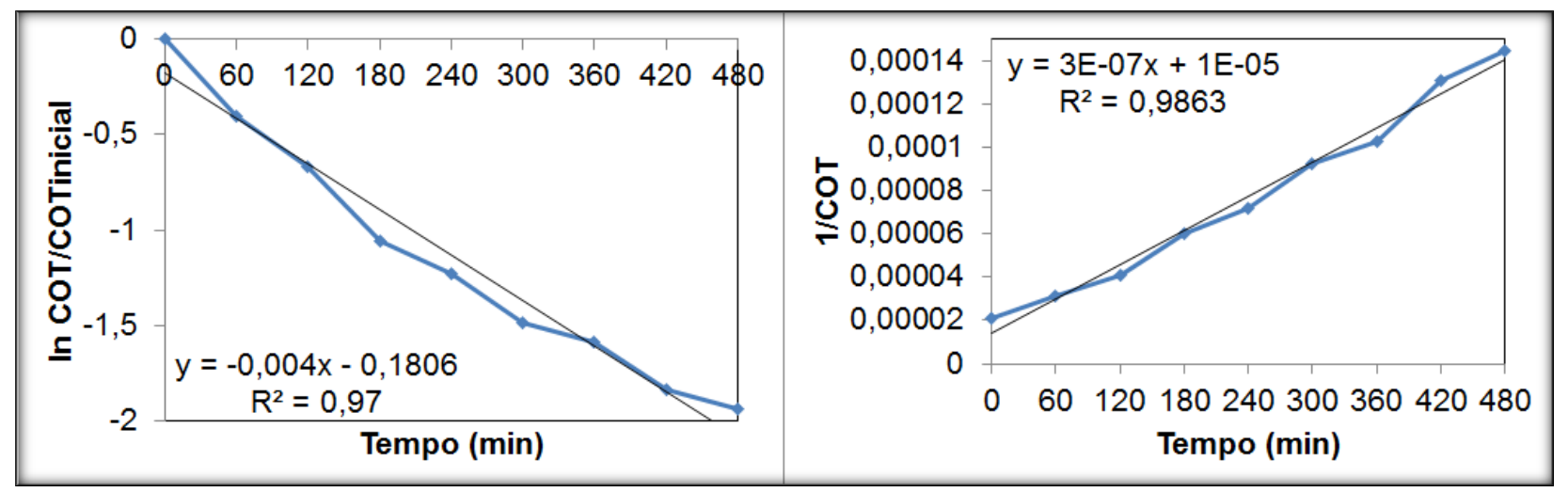

Figura 21. Gráficos de cinética para o processo UV/ $\mathrm{H}_{2} \mathrm{O}_{2}$. Á direita, gráfico de In COT/COTinicial pelo tempo, à esquerda, gráfico de 1/COT pelo tempo.

Embora não apresentem comportamento igual, é possível comparar as constantes de primeira ordem obtidas para os três processos avaliados, onde o foto-Fenton apresenta maior constante do que o $\mathrm{UV} / \mathrm{H}_{2} \mathrm{O}_{2}$ que, por sua vez, apresenta maior constante que a fotólise. 


\section{CONCLUSÕES E PERSPECTIVAS}

Levando em consideração os objetivos propostos, foi possível caracterizar a água de lavagem do biodiesel de soja produzido por rota metílica e catalisada por base. Com as caracterizações, foi possível descrever um resíduo rico em carga orgânica com elevado valor de DQO e baixos valores de $\mathrm{pH}$.

Foi possível realizar o tratamento da água de lavagem pela metodologia proposta com as condições otimizadas, verificando a inviabilidade do processo Fenton e a superioridade do processo foto-Fenton em relação à fotólise e fotólise com UV na remoção dos contaminantes e parâmetros estudados, principalmente do carbono orgânico total (COT).

Remoções de COT de até aproximadamente $93 \%$ foram atingidas pelo processo foto-Fenton, porém, a toxicidade do efluente tratado apresentou-se superior para 0 efluente tratado.

Um ajuste cinético de primeira ordem foi obtido para os processos, com exceção do Fenton. Foram obtidas as constantes cinéticas para os outros processos, atestando que, devido ao maior valor da constante e consequentemente a velocidade de reação para os processos foto-Fenton, $\mathrm{UV} / \mathrm{H}_{2} \mathrm{O}_{2}$ e UV, respectivamente. O processo foto-Fenton apresenta-se como uma boa alternativa no tratamento prévio da água de lavagem do biodiesel antes do seu despejo no ambiente.

Tendo em vista os elevados valores de contaminantes presentes na água mesmo após o tratamento, o tratamento foto-Fenton proposto apresenta-se como uma boa alternativa no tratamento prévio da água de lavagem, pois apesar da alta remoção de contaminante o efluente não estaria apto a ser descartado na natureza, conforme as legislações vigentes (CONAMA 430 de 31.03.2011).

Espera-se que, novas metodologias possam ser desenvolvidas para a utilização dos processos Fenton no tratamento desse resíduo, como a criação de reatores solares, por exemplo. Outra importante sugestão para ser desenvolvida após a realização desse trabalho seria a utilização de processos do tipo Fenton, com catalisadores heterogêneos 
à base de ferro, que diminuiria o impacto ambiental que pode ser causado pela dispensa de enxofre no ambiente (no caso da utilização de $\mathrm{Fe} \cdot \mathrm{SO}_{4}$ ), uma vez que, embora homogêneo, o $\mathrm{Fe}^{2+}$ pode ser removido da solução pela alteração do $\mathrm{pH}$. 


\section{REFERÊNCIAS BIBLIOGRÁFICAS}

AGARWAL, A.K. Biofuels (alcohols and biodiesel) applications as fuel for internal combustion engines. Progress in Energy and Combustion Science, 33, 2007. 233-271. ANDREOZZI, R. et al. Advanced oxidation processes (AOP) for water purification and recovery. Catalysis Today, 53, 15 Outubro 1999. 51-59.

ARAÚJO, P.H.; GOMES, O.L.; TAVARES, M.G.O. A análise ecotoxicológica do glicerol bruto, derivado de biocombustível e etanol combustível. Anais da 63a reunião Anual da SBPC. Goiás: Goiânia, 2011.

ARAÚJO, R. N. D. Degradação do corante azul reativo 19 usando UV; $\mathrm{H}_{2} \mathrm{O}_{2} ; \mathrm{UV} / \mathrm{H}_{2} \mathrm{O}_{2}$; Fenton e foto-Fenton. Aplicação em efluentes texteis, Campinas, 2002.

ATKINS, P.; PAULA, J. Físico-Química. 8ª Ed. Rio de Janeiro: LTC, 2008. v. 2. 434 p.

BOSCO, S. M. D. Degradação de Ivermectina por Processos Oxidativos Avançados, Campinas, 2012. Tese de Doutorado.

BRITO, J. F. D. et al. Tratamento da água de purificação do biodiesel utilizando eletrofloculação. Química Nova, 35, n. 4, 2012. 728-732.

CARDOSO, A. A.; MACHADO, C. D. M. D.; PEREIRA, E. A. Biocombustível, o Mito do Combustível Limpo. Química Nova na Escola, n. 28, Maio 2008.

CHAVALPARIT, O.; ONGWANDEE, M. Optimizing electrocoagulation process for the treatment of biodiesel wastewater using response surface methodology. Journal of Environmental Sciences, 21, 2009. 1491-1496.

CORONADO, C.R.; CARVALHO JR., J.A.; SILVEIRA, J.A. Biodiesel $\mathrm{CO}_{2}$ emissions: A comparison with the main fuels in the brazilian market. Fuel Processing Technology, $n$. 90, 2009. 204-211.

CUNHA, G.M.A.; NETO, A.A.E.; MEDEIROS, G.G.D.; SILVA, D.N.; MOTA, A.L.N.; CHIAVONE-FILHO, O. Uso do processo foto-Fenton no tratamento de águas produzidas em campos de petróleo. 4ํ PDPETRO, Campinas, SP. Outubro de 2007.

D.O.U. Lei 11.097/2005, 13 Janeiro 2005.

D.O.U. Lei no 13.033, de 24 de Setembro de 2014, 24 Setembro 2014. Seção 1, página 3.

D.O.U. Resolução ANP no 7 de 19 de Março de 2008, 20 Março 2008.

D.O.U. Resolução ANP no 14 de 11 de Maio de 2012, 18 Março 2012.

D.O.U. Resolução CONAMA oㅜ 357 de 17 de Março de 2005, 18 Março 2005.

D.O.U. Resolução CONAMA no 430 de de 13 de Maio de 2011, 16 Março 2011.

DE GISI, S.; GALASSO, M.; DE FEO, G. Full-scale treatment of wastewater from abiodiesel fuel production plant with alkali-catalyzed transesterification. Environ Technol 2013;34:861-70. 
FÁVARO, L. G.; ZENATTI, D. C.; GOMES, B. M. Caracterização da água de lavagem do biodiesel e determinação do $\mathrm{pH}$ e da dosagem ótima de sulfato de alumínio para remoção de turbidez. Anais do XVIII EAIC, 30 Setembro 2009.

FENTON, H.J.H.M.A. Oxidation of Tartaric Acid in presence of Iron. Journal of the Chemical Society , Transactions, 65, 1894. 899-910.

FERREIRA, S. L. et al. Análise por cromatografia gasosa de BTEX nas emissões de motor de combustão interna alimentado com diesel e mistura diesel-biodiesel (B10). Química Nova, 31, n. 3, 2008. 539-545.

FILHO, H.T. Aplicação do processo fotocatalítico heterogêneo no tratamento de águas de lavagem de biodiesel. Campina Grande - PB, 2013. 43f. Trabalho de conclusão de curso.

FUKUDA, H.; KONDO, A.; NODA, H. Biodiesel Fuel Production by Transesterification of oils. Journal of Bioscience and Bionengineering, 92, n. 5, 2001. 405-416.

GERIS, R. et al. Biodiesel de soja: reação de transesterificação para aulas práticas de química orgânica. Química Nova, 30, n. 5, 2007. 1369-1373.

GOLDANI, E. et al. Tratamento físico-químico dos efluentes líquidos provenientes da purificação do biodiesel. Anais do II Simpósio Estadual de Agroenergia - II Reunião Técnica, Porto Alegre, 2008.

GRABOSKI, M. S.; MCCORMICK, R. L. Combustion of fat and vegetable oil derived fuels in diesel engines. Progress in Energy and Combustion Science, 24, 1998. 125164.

GRANGEIRO, R. V. T. Caracterização da água de lavagem proveniente da purificação do biodiesel, João Pessoa - PB, 2009. 40f. Dissertação de mestrado.

GRCIC, I.; PAPIC, S.; MESEC, D.; KOPRIVANAC, N.; VUJEVIC, D. The kinects and efficiency of UV assisted advanced oxidation of various types of organic dyes in water. Journal of Photochemistry and Photobiology A: Chemistry, 273, 2014. 49-58.

HINCAPIÉ-MEJÍA, G. M. et al. Fotocatálisis Heterogénea y Foto-Fenton Aplicadas al Tratamiento de Aguas de Lavado de la Producción de Biodiesel. Información Tecnológica, 2011. 33-42.

HOLANDA, J.N.; MACIEL, A.P.; SANTOS, R. L. Avaliação ecotoxicológica da água de lavagem do biodiesel de soja metílico utilizando Danio rerio como organismo-teste. Boletim do laboratório de hidrobiologia, 25(I), 2012. 13-20.

JARUWAT, P.; KONGJAO, S.; HUNSOM, M. Management of biodiesel wastewaterby the combined processes of chemical recovery and electrochemical treatment. Energy Conversion and Management, 51, 2010. 531-537.

JUNIOR, A.C.B. Tratamento fotocatalítico $\left(\mathrm{TiO}_{2} / \mathrm{UV}\right)$ de águas ácidas de lavagem de biodiesel. Dissertação de mestrado. Universidade de São Carlos, 2012, 58f.

KUMJADPAI, S.; NGAMLERDPOKIN, K.; CHATANON, P.; LERTSATHITPHONGS, P.; HUNSOM, M. Management of fatty acid methyl ester (FAME) wastewater by a combined twostage chemical recovery and coagulation process. Can J Chem Eng2011;89:369-76. 
LOTERO, E. et al. Synthesis of Biodiesel via Acid Catalysis. Industrial \& Engineering Chemistry Research, 44, 2005. 5353-5363.

MA, F.; HANNA, M. A. Biodiesel production: a review. Biosource Technology, 70, 1999. $1-15$.

MARTINS, L. M. Estudo da aplicação de processos oxidativos avançados no tratamento de efluentes têxteis visando o seu reúso, Teresina-PI, 2011. Dissertação de mestrado.

MELO, M.B.S. Aplicação da fotocatálise heterogênea no tratamento de efluentes de lavagem de biodiesel. I Congresso Químico do Brasil, 2010, João Pessoa.

MENEGHETTI, S. M. P.; MENEGHETTI, M. R.; BRITO, Y. C. A Reação de Transesterificação, Algumas Aplicações e Obtenção de Biodiesel. Revista Virtual de Química, 5, n. 1, 2013. 63-73.

MILLER, J.N.; MILLER, J.C. Statistics and chemometrics for analytical chemistry. $5^{\mathrm{a}} \mathrm{ed}$. England: Pearson, 2005. $285 \mathrm{f}$.

MINISTÉRIO DE MINAS E ENERGIA. Boletim mensal dos combustíveis renováveis. Disponível em:

<http://www.mme.gov.br/documents/1138769/1732805/Boletim+DCR+n\%C2\%BA+92++setembro+de+2015.pdf/bf693a36-94c7-4f87-9f27-6f2dc2258491 >; acesso em novembro de 2015.

MINISTÉRIO DE MINAS E ENERGIA. Programa Nacional de Produção e Uso de Biodiesel. Disponível em: <http://www.mme.gov.br/programas/biodiesel>; acesso em maio de 2015.

NASCIMENTO, D.J.N. Utilização da fotocatálise heterogênea com $\mathrm{TiO}_{2}$ e radiação solar no tratamento de águas de lavagem de biodiesel. Campina Grande - PB, 2013. 47f.

Trabalho de conclusão de curso.

NEYENS, E.; BAEYENS, J. A review of classic Fenton's peroxidation as an advanced oxidation technique. Journal of Hazardous Materials, B98, 2003. 33-50.

NGAMLERDPOKIN, K.; KUMJADPAI, S.; CHATANON, P.; TUNGMANEE, U.; CHUENCHUANCHOM, S.; JARUWAT, P.; LERTSATHITPHONGS, P.; HUNSON, M. Journal of Environmental Management, 92, 2011. 2454-2460.

OECD - Organization for Economic Co-operation and Development. Guidelines for the Testing of Chemicals. 2013, 236.

OLIVEIRA, F. C. C.; SUAREZ, P. A. Z.; SANTOS, W. L. P. D. Biodiesel: Possibilidades e Desafios. Química Nova na Escola, 28, 2008.

PALOMINO-ROMERO, J. A. et al. Tratamento dos Efluentes Gerados na Produção do Biodiesel. Química Nova, 35, n 2, 2012. 367-378.

PATIÑO, K.V.; ARROYAVE, S.M.; MARÍN, J.M. Oxidación electroquímica y ozonización aplicadas al tratamiento de aguas de lavado de la producción de biodiesel. Inform Tecnológ 2012, n. 23. 41-52.

PHUKINGNGAM, D.; CHAVALPARIT, O.; SOMCHAI, D.; ONGWANDEE, M. Anaerobic baffledreactor treatment of biodiesel-processing wastewater with high strength of 
methanol and glycerol: reactor performance and biogas production. Chem Pap 2011, $\mathrm{n}$. 65. 644-651.

POYATOS, J. M. et al. Advanced Oxidation Processes for Wastewater Treatment: State of the Art. Water Air Soil Pollut, 205, 2010. 187-204.

QUINTELLA, C. M. et al. Cadeia do biodiesel da bancada à industria: uma visão geral com prospecção de tarefas e oportunidades para P\&D\&L. Química Nova, 32, n. 3, 2009. 793-808.

RAMÍREZ, X.M.V.; MEJÍA, G.M.H.; VIVIANA, K.; LÓPEZ, P.; VÁSQUEZ, G.R.; SEPÚLVEDA, J.M.M.Wastewater treatment from biodiesel production via a coupled photo-Fenton-aerobic sequential batch reactor (SBR) system. Water Sci Technol 2012, n 66. 824-30.

RAMOS, M.; DANKA, G.; RODRIGUES, M. B. Análise de DQO, DBO e sólidos para determinar seu potencial para futura deposição em corpo receptor. Synergismus Scyentifica UTFPR, Pato Branco, 03, n. 04, 2008.

RATTANAPAN, C.; SAWAIN, A.; SUKSAROJ, T.; SUKSAROJ, C. Enhanced efficiency of dissolved air flotation for biodiesel wastewater treatment by acidification and coagulation processes. Desalination, 280, 2011. 370-377.

ROCHA, D. C. Pré-tratamento biológico da água residuária de lavagem do biodiesel de óleo de soja por microorganismos produtores de lipase. Cascavel - PR, 2010. $70 f$. Dissertação de mestrado.

SABAIKAI, W.; SEKINE, M.; TOKUMURA, M.; KAWASE, Y. UV-light photo-Fenton degradation of polyphenols in oolong tea manufacturing wastewater. Journal of Environmental Science Health A, 49, n. 2, 2014. 193-202.

SANTOS, M. A. D.; MATAI, P. H. L. D. S. Aspéctos técnicos e ambientais relativos ao uso de biodiesel em motores de combustão. InterfacEHS, 3, Janeiro-Abril 2008.

SILVA, C.E.; LANGE, L.C. AMARAL, M.C.S.; ARTHUZO, P.P. Aplicação dos processos Fenton e foto-Fenton no tratamento de percolados de aterros sanitários. XVI Congresso Brasileiro de Engenharia Química. Santa Maria - RS, 2006.

SILVA, M.R.A.; OLIVEIRA, M.C.; NOGUEIRA, R.F.P. Estudo da aplicação do processo foto-Fenton solar na degradação de efluentes de indústria de tintas. Eclética Química, Volume 29, n 2, 2004. 19-26.

SOLOMONS, T. W. G.; FRYHLE, C. B. Química Orgânica. 8. ed. São Paulo: LTC, 2006.

SRIRANGSAN, A.; ONGWANDEE, M.; CHAVALPARIT, O. Treatment of Biodiesel Wastewater by Eletrocoagulation Process. EnvironmentAsia, 2, 2009. 15-19.

STANDART TEST METHODS FOR CHEMICAL OXYGEN DEMAND OF WATER. Dichromate Oxygen Demand. Designation: D1252-06, 2012.

SUEHARA, K.-I. et al. Biological Treatment of Wastewater Discharged from Biodiesel Fuel Production Plant with Alkali-Catalyzed Transesterification. Journal of Bioscience and Bioengineering, 100, n. 4, 2005. 437-442. 
TEIXEIRA, C. P. D. A. B.; JARDIM, W. D. F. Processos oxidativos avançados:Conceitos teóricos. Caderno Temático, Campinas/SP, 03, Agosto 2004.

UNITED STATES ENVIRONMENTAL PROTECTION AGENCY (USEPA). Office of water, 1999, Washington DC.

VELJKOVIC, V.B.; STAMENKOVIC, O.S.; TASIC, M.B. The wastewater treatment in the biodiesel production with alkali-catalyzed transesterification. Renewable and Sustainable Energy Reviews, 32, 2014. 40-60. 


\section{APÊNDICES}

\section{Definição das variáveis}

\begin{tabular}{|c|c|c|c|c|c|c|}
\hline \multicolumn{7}{|c|}{ Ensaio 1} \\
\hline \multirow[b]{2}{*}{$\begin{array}{l}\text { Tempo } \\
\text { (min) }\end{array}$} & \multicolumn{2}{|c|}{ Replicata 1} & \multicolumn{2}{|c|}{ Replicata 2} & \multirow{2}{*}{$\begin{array}{l}\text { Média do } \\
\text { COT (\%) }\end{array}$} & \multirow{2}{*}{$\begin{array}{l}\text { Desvio } \\
\text { padrão }\end{array}$} \\
\hline & $\begin{array}{c}\mathrm{COT} \\
\left(\mathrm{mgL}^{-1}\right)\end{array}$ & COT (\%) & $\begin{array}{c}\mathrm{COT} \\
\left(\mathrm{mgL}^{-1}\right) \\
\end{array}$ & СОT (\%) & & \\
\hline 0 & 36947,09 & 100,00000 & 38629,33 & 100,00000 & 100,00000 & 0,000000 \\
\hline 30 & 36365,41 & 98,42563 & 37144,18 & 96,15539 & 97,29051 & 1,605306 \\
\hline 60 & 33846,84 & 91,60895 & 35003,09 & 90,61274 & 91,11084 & 0,704433 \\
\hline 90 & 33073,33 & 89,51538 & 33889,23 & 87,72928 & 88,62233 & 1,262966 \\
\hline 120 & 32590,66 & 88,20899 & 33517,95 & 86,76812 & 87,48856 & 1,018847 \\
\hline 150 & 31111,7 & 84,20607 & 32348,39 & 83,74049 & 83,97328 & 0,329219 \\
\hline 180 & 28580,75 & 77,3559 & 29854,58 & 77,28474 & 77,32032 & 0,050316 \\
\hline
\end{tabular}

\begin{tabular}{|c|c|c|c|c|c|c|}
\hline \multicolumn{7}{|c|}{ Ensaio 2 } \\
\hline \multirow{2}{*}{$\begin{array}{c}\text { Tempo } \\
(\mathrm{min})\end{array}$} & \multicolumn{2}{|c|}{ Replicata 1 } & \multicolumn{2}{|c|}{ Replicata 2 } & Média do \\
\cline { 2 - 6 } & $\begin{array}{c}\text { COT } \\
\left.\mathrm{mgL}^{-1}\right)\end{array}$ & COT (\%) & $\begin{array}{c}\text { COT } \\
\left(\mathrm{mgL}^{-1}\right)\end{array}$ & COT (\%) & $\begin{array}{c}\text { Desvio } \\
\text { padrão }\end{array}$ \\
\hline 0 & 36947,09 & 100,00000 & 37757,74 & 100,00000 & 100,00000 & 0,000000 \\
\hline 30 & 34607,98 & 93,66903 & 34539,91 & 91,47772 & 92,57337 & 1,549494 \\
\hline 60 & 33778,77 & 91,42472 & 33982,98 & 90,0027 & 90,71371 & 1,005516 \\
\hline 90 & 32262,69 & 87,32131 & 33054,76 & 87,54435 & 87,43283 & 0,157713 \\
\hline 120 & 30876,55 & 83,56963 & 31254,02 & 82,77515 & 83,17239 & 0,56178 \\
\hline 150 & 29354,27 & 79,44947 & 29663,68 & 78,56318 & 79,00632 & 0,626707 \\
\hline 180 & 28562,19 & 77,30565 & 28673,58 & 75,94093 & 76,62329 & 0,965002 \\
\hline
\end{tabular}




\begin{tabular}{|c|c|c|c|c|c|c|}
\hline \multicolumn{7}{|c|}{ Ensaio 3 } \\
\hline \multirow{2}{*}{$\begin{array}{c}\text { Tempo } \\
(\mathrm{min})\end{array}$} & \multicolumn{2}{|c|}{$\begin{array}{c}\text { Replicata 1 } \\
\left(\mathrm{mgL}^{-1}\right)\end{array}$} & \multicolumn{2}{|c|}{ Replicata 2 } & Média do & Desvio \\
\cline { 2 - 6 } & $\begin{array}{c}\text { COT } \\
\left(\mathrm{mgL}^{-1}\right)\end{array}$ & COT (\%) & COT (\%) & padrão \\
\hline 0 & 38104,27 & 100,00000 & 38512,69 & 100,00000 & 100,00000 & 0,000000 \\
\hline 30 & 33778,77 & 88,64827 & 34496,6 & 89,57204 & 89,11015 & 0,653203 \\
\hline 60 & 33141,4 & 86,97555 & 33426,05 & 86,79232 & 86,88393 & 0,129566 \\
\hline 90 & 32380,26 & 84,97804 & 32306 & 83,88406 & 84,43105 & 0,773561 \\
\hline 120 & 30152,54 & 79,13165 & 30301,05 & 78,67811 & 78,90488 & 0,320703 \\
\hline 150 & 28698,33 & 75,31526 & 28704,52 & 74,53263 & 74,92394 & 0,553402 \\
\hline 180 & 27813,43 & 72,99294 & 27671,1 & 71,84932 & 72,42113 & 0,808666 \\
\hline
\end{tabular}

\begin{tabular}{|c|c|c|c|c|c|c|}
\hline \multicolumn{7}{|c|}{ Ensaio 4 } \\
\hline \multirow{2}{*}{$\begin{array}{c}\text { Tempo } \\
(\mathrm{min})\end{array}$} & \begin{tabular}{c} 
Replicata 1 \\
\cline { 2 - 6 } \\
$\begin{array}{c}\text { COT } \\
\left.\mathrm{mgL}^{-1}\right)\end{array}$
\end{tabular} & COT (\%) & $\begin{array}{c}\text { Replicata 2 } \\
\text { COT } \\
\left(\mathrm{mgL}^{-1}\right)\end{array}$ & COT (\%) & $\begin{array}{c}\text { Média do } \\
\text { COT (\%) }\end{array}$ & $\begin{array}{c}\text { Desvio } \\
\text { padrão }\end{array}$ \\
\hline 0 & 38104,27 & 100,00000 & 38512,69 & 100,00000 & 100,00000 & 0,000000 \\
\hline 30 & 34638,92 & 90,90562 & 34440,9 & 89,42743 & 90,16652 & 1,045242 \\
\hline 60 & 34205,75 & 89,76882 & 34242,88 & 88,91326 & 89,34104 & 0,604976 \\
\hline 90 & 31563,43 & 82,83436 & 31829,52 & 82,64684 & 82,7406 & 0,132598 \\
\hline 120 & 30133,97 & 79,08293 & 30232,98 & 78,50136 & 78,79215 & 0,41123 \\
\hline 150 & 28320,85 & 74,32462 & 28661,2 & 74,42016 & 74,37239 & 0,067553 \\
\hline 180 & 27163,68 & 71,28775 & 27145,11 & 70,48356 & 70,88565 & 0,568648 \\
\hline
\end{tabular}




\section{ProcessosOxidativosAvançados}

\begin{tabular}{|c|c|c|c|c|c|c|c|c|c|}
\hline \multicolumn{10}{|c|}{ Fenton 300 minutos } \\
\hline \multirow{2}{*}{$\begin{array}{c}\text { Tempo } \\
\text { (min) }\end{array}$} & \multicolumn{2}{|c|}{ Replicata 1} & \multicolumn{2}{|c|}{ Replicata 2} & \multicolumn{2}{|c|}{ Replicata 3} & \multirow{2}{*}{$\begin{array}{l}\text { Média do } \\
\text { COT (\%) }\end{array}$} & \multirow{2}{*}{$\begin{array}{l}\text { Média do } \\
\text { COT } \\
\left(\mathrm{mgL}^{-1}\right)\end{array}$} & \multirow{2}{*}{$\begin{array}{c}\text { Desvio } \\
\text { padrão } \\
(\%)\end{array}$} \\
\hline & $\begin{array}{c}\mathrm{COT} \\
\left(\mathrm{mgL}^{-1}\right)\end{array}$ & COT (\%) & $\begin{array}{c}\mathrm{COT} \\
\left(\mathrm{mgL}^{-1}\right)\end{array}$ & COT (\%) & $\begin{array}{c}\mathrm{COT} \\
\left(\mathrm{mgL}^{-1}\right)\end{array}$ & COT (\%) & & & \\
\hline 0 & 39934,88 & 100,00000 & 40116,56 & 100,00000 & 39693,4 & 100,00000 & 100,00000 & 39914,953 & 0,000000 \\
\hline 30 & 38876,08 & 68 & 38852,14 & 96,8 & 39081,2 & 98 , & & 3893 & 0,82 \\
\hline 60 & 38702,35 & & 37996,29 & 94,7 & 38649,3 & & & 3844 & 1,41 \\
\hline 90 & 8503,54 & & 37876,68 & 94,4 & 38009,9 & & & 381 & \\
\hline 120 & 7326,41 & & 38468,6 & 95,8 & 38027,8 & & & 379 & 1,37 \\
\hline 150 & 37753,07 & 4,53658 & 37874,78 & 94,4 & 37941,5 & & & 3785 & 5146 \\
\hline 180 & 37637,50 & 94,24719 & 37106,13 & 92,49579 & 37589,3 & 94,69916 & 93,8 & 37444,323 & 1,163795 \\
\hline 210 & 36447,48 & 91,26727 & 37101,27 & 92,48368 & 37179,1 & 93,66576 & 224 & 36909,297 & 1,199285 \\
\hline 240 & 36999,94 & 92,65067 & 37144,11 & 92,59046 & 37041,4 & 93,31885 & 92,85333 & 37061,83 & 0,404277 \\
\hline 27 & 6701,27 & & 36719,54 & 91,53 & 36853,4 & & & 36758,08 & 0,676959 \\
\hline 300 & 36811,45 & 92,17869 & 36810,5 & 91,75887 & 37173,8 & 93,6522 & 92,52992 & 36931,903 & 0,994332 \\
\hline
\end{tabular}


Foto-Fenton 300 minutos

\begin{tabular}{|c|c|c|c|c|c|c|c|c|c|}
\hline \multicolumn{10}{|c|}{ Foto-Fenton 300 minutos } \\
\hline \multirow{2}{*}{$\begin{array}{l}\text { Tempo } \\
\text { (min) }\end{array}$} & \multicolumn{2}{|c|}{ Replicata 1} & \multicolumn{2}{|c|}{ Replicata 2} & \multicolumn{2}{|c|}{ Replicata 3} & \multirow{2}{*}{$\begin{array}{l}\text { Média do } \\
\text { COT (\%) }\end{array}$} & \multirow{2}{*}{$\begin{array}{c}\text { Desvio } \\
\text { padrão } \\
(\%)\end{array}$} & \multirow{2}{*}{$\begin{array}{c}\text { Média do } \\
\text { TOC } \\
\left(\mathrm{mgL}^{-1}\right)\end{array}$} \\
\hline & $\begin{array}{c}\mathrm{COT} \\
\left(\mathrm{mgL}^{-1}\right)\end{array}$ & COT (\%) & $\begin{array}{c}\text { COT } \\
\left(\mathrm{mgL}^{-1}\right)\end{array}$ & $\operatorname{COT}(\%)$ & $\begin{array}{c}\text { COT } \\
\left(\mathrm{mgL}^{-1}\right)\end{array}$ & COT (\%) & & & \\
\hline 0 & 46434,39 & 100,00000 & 46422,32 & 100,00000 & 45811,78 & 100,00000 & 100,000000 & 0,000000 & 46222,83 \\
\hline 30 & 38261,76 & 82,39963 & 37971,61 & 81,79601 & 38334,31 & 83,67784 & 82,624493 & 0,960855 & 38189,23 \\
\hline 60 & 33806,7 & 72,80530 & 33093,43 & 71,28775 & 33437,98 & 72,98991 & 72,360987 & 0,934022 & 33446,04 \\
\hline 90 & 28565,81 & 61,51865 & 28221,27 & 60,79246 & 27967,39 & 61,04847 & 61,119860 & 0,368321 & 28251,49 \\
\hline 120 & 23143,57 & 49,84145 & 22913,89 & 49,35964 & 22774,86 & 49,71397 & 49,638353 & 0,249647 & 22944,10 \\
\hline 150 & 19565,02 & 42,13477 & 19329,29 & 41,63792 & 19305,11 & 42,14006 & 41,970917 & 0,288396 & 19399,80 \\
\hline 180 & 16935,53 & 36,47195 & 17249,86 & 37,15854 & 17255,89 & 37,66693 & 37,099140 & 0,599700 & 17147,10 \\
\hline 210 & 14312,03 & 30,82205 & 14281,80 & 30,76495 & 13907,03 & 30,35688 & 30,647960 & 0,253694 & 14166,95 \\
\hline 240 & 12202,36 & 26,27870 & 12160,04 & 26,19438 & 12051,23 & 26,30597 & 26,259683 & 0,058174 & 12137,90 \\
\hline 270 & 11017,58 & 23,72720 & 10775,81 & 23,21255 & 10824,16 & 23,62747 & 23,522407 & 0,272937 & 10872,52 \\
\hline 300 & 10437,17 & 22,47724 & 10328,36 & 22,24869 & 10467,39 & 22,8487 & 22,524877 & 0,302828 & 10410,97 \\
\hline
\end{tabular}


Foto-Fenton 480 minutos

\begin{tabular}{|c|c|c|c|c|c|c|c|c|c|}
\hline \multicolumn{10}{|c|}{ Foto-Fenton 480 minutos } \\
\hline \multirow{2}{*}{$\begin{array}{l}\text { Tempo } \\
\text { (min) }\end{array}$} & \multicolumn{2}{|c|}{ Replicata 1} & \multicolumn{2}{|c|}{ Replicata 2} & \multicolumn{2}{|c|}{ Replicata 3} & \multirow{2}{*}{$\begin{array}{l}\text { Média do } \\
\text { COT (\%) }\end{array}$} & \multirow{2}{*}{$\begin{array}{l}\text { Desvio } \\
\text { padrão }\end{array}$} & \multirow{2}{*}{$\begin{array}{c}\text { Média do } \\
\text { COT } \\
\left(\mathrm{mgL}^{-1}\right)\end{array}$} \\
\hline & $\begin{array}{c}\mathrm{COT} \\
\left(\mathrm{mgL}^{-1}\right)\end{array}$ & COT (\%) & $\begin{array}{c}\text { COT } \\
\left(\mathrm{mgL}^{-1}\right)\end{array}$ & COT (\%) & $\begin{array}{c}\mathrm{COT} \\
\left(\mathrm{mgL}^{-1}\right)\end{array}$ & COT (\%) & & & \\
\hline 0 & 40345,54 & 100,00000 & 41361,08 & 100,00000 & 40399,94 & 100,00000 & 100,000000 & 0,000000 & 40702,19 \\
\hline 30 & 35836,07 & 88,82286 & 34832,64 & 84,21599 & 35491,53 & 87,85045 & 86,963100 & 2,428241 & 35386,75 \\
\hline 60 & 29416,42 & 72,91121 & 29398,29 & 71,07718 & 28745,45 & 71,15220 & 71,713530 & 1,037899 & 29186,72 \\
\hline 90 & 23583,15 & 58,45291 & 23093,53 & 55,83396 & 23256,74 & 57,56628 & 57,284383 & 1,332037 & 23311,14 \\
\hline 120 & 18275,77 & 45,29811 & 17876,82 & 43,22136 & 17876,82 & 44,24963 & 44,256367 & 1,038391 & 18009,80 \\
\hline 150 & 14080,64 & 34,90010 & 13941,63 & 33,70711 & 13796,55 & 34,14992 & 34,252377 & 0,603058 & 13939,60 \\
\hline 180 & 11638,54 & 28,84715 & 11759,44 & 28,43118 & 11396,75 & 28,20981 & 28,49 & 583 & 11598,24 \\
\hline 210 & 9172,206 & 22,73412 & 8948,571 & 21,63524 & 8755,128 & 21,67114 & 22,0 & 333 & 8958,63 \\
\hline 240 & 8047,861 & 19,94734 & 7800,041 & 18,85841 & 7860,488 & 19,45668 & 19,42 & 0,545350 & 7902,80 \\
\hline 270 & 6234,416 & 15,45255 & 6016,798 & 14,54700 & 6053,064 & 14,98285 & 14,994133 & 0,452880 & 6101,42 \\
\hline 300 & 5182,604 & 12,84554 & 5061,704 & 12,23784 & 5001,265 & 12,37939 & 12,487590 & 0,317970 & 5081,86 \\
\hline 330 & 4233,531 & 10,49318 & 4148,318 & 10,02952 & 4209,374 & 10,41926 & 10,313987 & 0,249112 & 4197,07 \\
\hline 360 & 3594,615 & 8,90957 & 3419,915 & 8,268438 & 3462,826 & 8,571364 & 8,583124 & 0,320727 & 3492,45 \\
\hline 390 & 3199,866 & 7,93115 & 3175,707 & 7,678009 & 3092,895 & 7,655692 & 7,754950 & 0,153000 & 3156,15 \\
\hline 420 & 3028,784 & 7,50710 & 2935,106 & 7,096299 & 2930,27 & 7,253153 & 7,285520 & 0,207308 & 2964,72 \\
\hline 450 & 2172,201 & 5,38399 & 2128,099 & 5,145172 & 2098,473 & 5,194247 & 5,241137 & 0,126125 & 2132,92 \\
\hline 480 & 2592,887 & 6,42670 & 2488,337 & 6,016131 & 2494,987 & 6,175719 & 6,206183 & 0,206973 & 2525,40 \\
\hline
\end{tabular}




\begin{tabular}{|c|c|c|c|c|c|c|c|c|c|}
\hline \multicolumn{10}{|c|}{ Fotólise 300 minutos } \\
\hline \multirow{2}{*}{$\begin{array}{c}\text { Tempo } \\
\text { (min) }\end{array}$} & \multicolumn{2}{|c|}{ Replicata 1} & \multicolumn{2}{|c|}{ Replicata 2} & \multicolumn{2}{|c|}{ Replicata 3} & \multirow{2}{*}{$\begin{array}{l}\text { Média do } \\
\text { COT (\%) }\end{array}$} & \multirow{2}{*}{$\begin{array}{c}\text { Desvio } \\
\text { padrão } \\
(\%)\end{array}$} & \multirow{2}{*}{$\begin{array}{c}\text { Média do } \\
\text { COT } \\
\left(\mathrm{mgL}^{-1}\right)\end{array}$} \\
\hline & $\begin{array}{c}\text { COT } \\
\left(\mathrm{mgL}^{-1}\right)\end{array}$ & COT (\%) & $\begin{array}{c}\text { COT } \\
\left(\mathrm{mgL}^{-1}\right)\end{array}$ & COT (\%) & $\begin{array}{c}\mathrm{COT} \\
\left(\mathrm{mgL}^{-1}\right)\end{array}$ & COT (\%) & & & \\
\hline 0 & 35916,993 & 100,0000 & 35759,827 & 100,00000 & 35705,423 & 100,0000 & 100,00000 & 0,000000 & 35794,081 \\
\hline 60 & 30500,805 & 84,920263 & 30361,773 & 84,904699 & 30331,549 & 84,949418 & 84,924793 & 0,022701 & 30398,043 \\
\hline 120 & 26251,274 & 73,088728 & 25296,187 & 70,73912 & 25791,865 & 72,235146 & 72,020998 & 1,1893527 & 25779,775 \\
\hline 180 & 21101,059 & 58,749514 & 21493,974 & 60,106483 & 21173,597 & 59,300787 & 59,385595 & 0,6824482 & 21256,21 \\
\hline 240 & 17776,39 & 49,492979 & 17268,622 & 48,290564 & 17365,34 & 48,63502 & 48,806188 & 0,6192124 & 17470,117 \\
\hline 300 & 14911,13 & 41,515529 & 14645,156 & 40,954214 & 14633,066 & 40,982756 & 41,150833 & 0,3161582 & 14729,784 \\
\hline
\end{tabular}

\begin{tabular}{|c|c|c|c|c|c|c|c|c|c|}
\hline \multicolumn{10}{|c|}{ Fotólise 480 minutos } \\
\hline \multirow{2}{*}{$\begin{array}{c}\text { Tempo } \\
\text { (min) }\end{array}$} & \multicolumn{2}{|c|}{ Replicata 1} & \multicolumn{2}{|c|}{ Replicata 2} & \multicolumn{2}{|c|}{ Replicata 3} & \multirow{2}{*}{$\begin{array}{l}\text { Média do } \\
\text { COT (\%) }\end{array}$} & \multirow{2}{*}{$\begin{array}{c}\text { Desvio } \\
\text { padrão } \\
(\%)\end{array}$} & \multirow{2}{*}{$\begin{array}{l}\text { Média do } \\
\text { COT } \\
\left(\mathrm{mgL}^{-1}\right)\end{array}$} \\
\hline & $\begin{array}{c}\mathrm{COT} \\
\left(\mathrm{mgL}^{-1}\right)\end{array}$ & COT (\%) & $\begin{array}{c}\text { COT } \\
\left(\mathrm{mgL}^{-1}\right)\end{array}$ & COT (\%) & $\begin{array}{c}\mathrm{COT} \\
\left(\mathrm{mgL}^{-1}\right)\end{array}$ & COT (\%) & & & \\
\hline 0 & 36146,09 & 100,00000 & 37010,503 & 100,00000 & 36309,298 & 100,00000 & 100,00000 & 0,000000 & 36488,63 \\
\hline 60 & 31400,845 & 86,872039 & 31062,351 & 83,928477 & 31068,396 & 85,565949 & 85,455488 & 1,4748863 & 31177,198 \\
\hline 120 & 24455,299 & 67,656831 & 23887,094 & 64,541393 & 23881,047 & 65,771161 & 65,989795 & 1,5691841 & 24074,48 \\
\hline 180 & 20640,992 & 57,104358 & 20501,947 & 55,394942 & 20338,742 & 56,015243 & 56,171514 & 0,8653561 & 20493,894 \\
\hline 240 & 16941,517 & 46,86957 & 17183,33 & 46,428255 & 16862,943 & 46,442493 & 46,580106 & 0,2507844 & 16995,93 \\
\hline 300 & 14058,093 & 38,89243 & 13913,039 & 37,592138 & 14100,429 & 38,834209 & 38,439592 & 0,7344938 & 14023,854 \\
\hline 360 & 11640,164 & 32,203107 & 11555,544 & 31,222338 & 11313,752 & 31,159379 & 31,528274 & 0,5852689 & 11503,153 \\
\hline 420 & 9965,7481 & 27,57075 & 9971,7982 & 26,943158 & 9790,4598 & 26,964057 & 27,159322 & 0,3564609 & 9909,3354 \\
\hline 480 & 9119,4502 & 25,229424 & 8980,439 & 24,264569 & 9004,6184 & 24,799759 & 24,764584 & 0,4833882 & 9034,8359 \\
\hline
\end{tabular}




\begin{tabular}{|c|c|c|c|c|c|c|c|c|c|}
\hline \multicolumn{10}{|c|}{ Fotólise $/ \mathrm{H}_{2} \mathrm{O}_{2} 480$ minutos } \\
\hline \multirow[b]{2}{*}{ Tempo (min) } & \multicolumn{2}{|c|}{ Replicata 1} & \multicolumn{2}{|c|}{ Replicata 2} & \multicolumn{2}{|c|}{ Replicata 3} & \multirow{2}{*}{$\begin{array}{l}\text { Média do } \\
\text { COT (\%) }\end{array}$} & \multirow{2}{*}{\begin{tabular}{|c|} 
Desvio \\
padrão \\
$(\%)$
\end{tabular}} & \multirow{2}{*}{$\begin{array}{c}\text { Média } \\
\text { do COT } \\
\left(\mathrm{mgL}^{-1}\right)\end{array}$} \\
\hline & $\begin{array}{c}\mathrm{COT} \\
\left(\mathrm{mgL}^{-1}\right)\end{array}$ & COT (\%) & $\begin{array}{c}\mathrm{COT} \\
\left(\mathrm{mgL}^{-1}\right)\end{array}$ & COT (\%) & $\begin{array}{c}\mathrm{COT} \\
\left(\mathrm{mgL}^{-1}\right)\end{array}$ & COT (\%) & & & \\
\hline 0 & 46862 & 100,0000 & 48379,5 & 100,0000 & 47787,6 & 100,0000 & 100,0000 & 0,00000 & 47676,4 \\
\hline 60 & 31376,5 & 66,9551 & 32060,3 & 66,2683 & 31795,2 & 66,5345 & 66,5859 & 0,34627 & 31744,0 \\
\hline 120 & 24749,2 & 52,8129 & 24133,7 & 49,8841 & 24683,6 & 51,6527 & 51,4499 & 1,47492 & 24522,2 \\
\hline 180 & 16370,6 & 34,9336 & 16879,3 & 34,8893 & 16487,9 & 34,5025 & 34,7751 & 0,23717 & 16579,3 \\
\hline 240 & 13996,7 & 29,8678 & 13971,1 & 28,8781 & \begin{tabular}{|l|}
13898,1 \\
\end{tabular} & 29,083 & 29,2763 & 0,52238 & 13955,3 \\
\hline 300 & 10803,7 & 23,0542 & 10875,8 & 22,4801 & 10713,3 & 22,4186 & 22,651 & 0,3506 & 10797,6 \\
\hline 360 & 9681,02 & 20,6585 & 10000,2 & 20,6703 & 9614,0 & 20,1182 & 20,4823 & 0,31542 & 9765,07 \\
\hline 420 & 7729,86 & 16,4949 & 7611,72 & 15,7333 & \begin{tabular}{|l|}
7551,42 \\
\end{tabular} & 15,8020 & 16,0101 & 0,42127 & 7631,00 \\
\hline 480 & 6945,49 & 14,8211 & 6941,46 & 14,3479 & 6819,3 & 14,2700 & 14,4797 & 0,29826 & 6902,08 \\
\hline
\end{tabular}


Toxicidade

\begin{tabular}{|c|c|c|c|c|c|}
\hline \multicolumn{6}{|c|}{ FET - Taxas dia 4 - Efluente bruto $\mathrm{pH} 1,4$} \\
\hline $\begin{array}{l}\text { Concentração } \\
\text { do efluente } \\
(\%)\end{array}$ & $\begin{array}{c}\text { Coagulados } \\
(\%)\end{array}$ & $\begin{array}{l}\text { Embriões } \\
\text { vivos (\%) }\end{array}$ & $\begin{array}{l}\text { Eclodidos } \\
\text { vivos (\%) }\end{array}$ & $\begin{array}{l}\text { Eclodidos } \\
\text { mortos (\%) }\end{array}$ & $\begin{array}{c}\text { Mortalidade } \\
\text { total }(\%)\end{array}$ \\
\hline 0,00 & 0,05 & 0,00 & 0,90 & 0,05 & 0,10 \\
\hline 0,00 & 0,05 & 0,00 & 0,90 & 0,05 & 0,10 \\
\hline 0,00 & 0,00 & 0,00 & 1,00 & 0,00 & 0,00 \\
\hline 0,01 & 0,10 & 0,00 & 0,90 & 0,00 & 0,10 \\
\hline 0,01 & 0,05 & 0,00 & 0,95 & 0,00 & 0,05 \\
\hline 0,01 & 0,05 & 0,00 & 0,95 & 0,00 & 0,05 \\
\hline 0,10 & 1,00 & 0,00 & 0,00 & 0,00 & 1,00 \\
\hline 0,10 & 1,00 & 0,00 & 0,00 & 0,00 & 1,00 \\
\hline 0,10 & 0,95 & 0,00 & 0,00 & 0,05 & 1,00 \\
\hline 1,00 & 1,00 & 0,00 & 0,00 & 0,00 & 1,00 \\
\hline 1,00 & 1,00 & 0,00 & 0,00 & 0,00 & 1,00 \\
\hline 1,00 & 1,00 & 0,00 & 0,00 & 0,00 & 1,00 \\
\hline 10,00 & 1,00 & 0,00 & 0,00 & 0,00 & 1,00 \\
\hline 10,00 & 1,00 & 0,00 & 0,00 & 0,00 & 1,00 \\
\hline 10,00 & 1,00 & 0,00 & 0,00 & 0,00 & 1,00 \\
\hline 25,00 & 1,00 & 0,00 & 0,00 & 0,00 & 1,00 \\
\hline 25,00 & 1,00 & 0,00 & 0,00 & 0,00 & 1,00 \\
\hline 25,00 & 1,00 & 0,00 & 0,00 & 0,00 & 1,00 \\
\hline 50,00 & 1,00 & 0,00 & 0,00 & 0,00 & 1,00 \\
\hline 50,00 & 1,00 & 0,00 & 0,00 & 0,00 & 1,00 \\
\hline 50,00 & 1,00 & 0,00 & 0,00 & 0,00 & 1,00 \\
\hline 75,00 & 1,00 & 0,00 & 0,00 & 0,00 & 1,00 \\
\hline 75,00 & 1,00 & 0,00 & 0,00 & 0,00 & 1,00 \\
\hline 75,00 & 1,00 & 0,00 & 0,00 & 0,00 & 1,00 \\
\hline 100,00 & 1,00 & 0,00 & 0,00 & 0,00 & 1,00 \\
\hline 100,00 & 1,00 & 0,00 & 0,00 & 0,00 & 1,00 \\
\hline 100,00 & 1,00 & 0,00 & 0,00 & 0,00 & 1,00 \\
\hline
\end{tabular}




\begin{tabular}{|c|c|c|c|c|c|}
\hline \multicolumn{6}{|c|}{ FET - Taxas dia 4 - pH 4 } \\
\hline $\begin{array}{c}\text { Concentração } \\
\text { do efluente (\%) }\end{array}$ & $\begin{array}{c}\text { Coagulados } \\
(\%)\end{array}$ & $\begin{array}{c}\text { Embriões } \\
\text { vivos (\%) }\end{array}$ & $\begin{array}{c}\text { Eclodidos } \\
\text { vivos (\%) }\end{array}$ & $\begin{array}{c}\text { Eclodidos } \\
\text { mortos (\%) }\end{array}$ & $\begin{array}{c}\text { Mortalidade } \\
\text { total (\%) }\end{array}$ \\
\hline 0,00 & 0,00 & 0,00 & 1,00 & 0,00 & 0,00 \\
\hline 0,00 & 0,00 & 0,00 & 1,00 & 0,00 & 0,00 \\
\hline 0,00 & 0,00 & 0,00 & 0,85 & 0,15 & 0,15 \\
\hline 0,01 & 0,10 & 0,00 & 0,85 & 0,05 & 0,15 \\
\hline 0,01 & 0,10 & 0,00 & 0,80 & 0,10 & 0,20 \\
\hline 0,01 & 0,10 & 0,00 & 0,85 & 0,05 & 0,15 \\
\hline 0,10 & 1,00 & 0,00 & 0,00 & 0,00 & 1,00 \\
\hline 0,10 & 0,55 & 0,05 & 0,35 & 0,05 & 0,60 \\
\hline 0,10 & 0,00 & 0,00 & 0,75 & 0,25 & 0,25 \\
\hline 1,00 & 1,00 & 0,00 & 0,00 & 0,00 & 1,00 \\
\hline 1,00 & 1,00 & 0,00 & 0,00 & 0,00 & 1,00 \\
\hline 1,00 & 1,00 & 0,00 & 0,00 & 0,00 & 1,00 \\
\hline 10,00 & 1,00 & 0,00 & 0,00 & 0,00 & 1,00 \\
\hline 10,00 & 1,00 & 0,00 & 0,00 & 0,00 & 1,00 \\
\hline 10,00 & 1,00 & 0,00 & 0,00 & 0,00 & 1,00 \\
\hline 25,00 & 1,00 & 0,00 & 0,00 & 0,00 & 1,00 \\
\hline 25,00 & 1,00 & 0,00 & 0,00 & 0,00 & 1,00 \\
\hline 25,00 & 1,00 & 0,00 & 0,00 & 0,00 & 1,00 \\
\hline 50,00 & 1,00 & 0,00 & 0,00 & 0,00 & 1,00 \\
\hline 50,00 & 1,00 & 0,00 & 0,00 & 0,00 & 1,00 \\
\hline 50,00 & 1,00 & 0,00 & 0,00 & 0,00 & 1,00 \\
\hline 75,00 & 1,00 & 0,00 & 0,00 & 0,00 & 1,00 \\
\hline 75,00 & 1,00 & 0,00 & 0,00 & 0,00 & 1,00 \\
\hline 75,00 & 1,00 & 0,00 & 0,00 & 0,00 & 1,00 \\
\hline 100,00 & 1,00 & 0,00 & 0,00 & 0,00 & 1,00 \\
\hline 100,00 & 1,00 & 0,00 & 0,00 & 0,00 & 1,00 \\
\hline 100,00 & 1,00 & 0,00 & 0,00 & 0,00 & 1,00 \\
\hline
\end{tabular}




\begin{tabular}{|c|c|c|c|c|c|}
\hline \multicolumn{5}{|c|}{ FET - Taxas dia 4 - pH 7,0 } & \\
\hline $\begin{array}{c}\text { Concentração } \\
\text { do efluente (\%) }\end{array}$ & $\begin{array}{c}\text { Coagulados } \\
(\%)\end{array}$ & $\begin{array}{c}\text { Embriões } \\
\text { vivos (\%) }\end{array}$ & $\begin{array}{c}\text { Eclodidos } \\
\text { vivos (\%) }\end{array}$ & $\begin{array}{c}\text { Eclodidos } \\
\text { mortos } \\
(\%)\end{array}$ & $\begin{array}{c}\text { Mortalidade } \\
\text { total (\%) }\end{array}$ \\
\hline 0,00 & 0,00 & 0,00 & 1,00 & 0,00 & 0,00 \\
\hline 0,00 & 0,00 & 0,00 & 1,00 & 0,00 & 0,00 \\
\hline 0,00 & 0,00 & 0,00 & 0,85 & 0,15 & 0,15 \\
\hline 0,01 & 0,10 & 0,00 & 0,90 & 0,00 & 0,1 \\
\hline 0,01 & 0,00 & 0,00 & 0,95 & 0,05 & 0,05 \\
\hline 0,01 & 0,10 & 0,00 & 0,90 & 0,00 & 0,1 \\
\hline 0,10 & 0,05 & 0,00 & 0,25 & 0,70 & 0,75 \\
\hline 0,10 & 0,10 & 0,00 & 0,65 & 0,25 & 0,35 \\
\hline 0,10 & 0,20 & 0,00 & 0,75 & 0,05 & 0,25 \\
\hline 1,00 & 1,00 & 0,00 & 0,00 & 0,00 & 1,00 \\
\hline 1,00 & 1,00 & 0,00 & 0,00 & 0,00 & 1,00 \\
\hline 1,00 & 1,00 & 0,00 & 0,00 & 0,00 & 1,00 \\
\hline 10,00 & 1,00 & 0,00 & 0,00 & 0,00 & 1,00 \\
\hline 10,00 & 1,00 & 0,00 & 0,00 & 0,00 & 1,00 \\
\hline 10,00 & 1,00 & 0,00 & 0,00 & 0,00 & 1,00 \\
\hline 25,00 & 1,00 & 0,00 & 0,00 & 0,00 & 1,00 \\
\hline 25,00 & 1,00 & 0,00 & 0,00 & 0,00 & 1,00 \\
\hline 25,00 & 1,00 & 0,00 & 0,00 & 0,00 & 1,00 \\
\hline 50,00 & 1,00 & 0,00 & 0,00 & 0,00 & 1,00 \\
\hline 50,00 & 1,00 & 0,00 & 0,00 & 0,00 & 1,00 \\
\hline 50,00 & 1,00 & 0,00 & 0,00 & 0,00 & 1,00 \\
\hline 75,00 & 1,00 & 0,00 & 0,00 & 0,00 & 1,00 \\
\hline 75,00 & 1,00 & 0,00 & 0,00 & 0,00 & 1,00 \\
\hline 75,00 & 1,00 & 0,00 & 0,00 & 0,00 & 1,00 \\
\hline 100,00 & 1,00 & 0,00 & 0,00 & 0,00 & 1,00 \\
\hline 100,00 & 1,00 & 0,00 & 0,00 & 0,00 & 1,00 \\
\hline 100,00 & 1,00 & 0,00 & 0,00 & 0,00 & 1,00 \\
\hline
\end{tabular}




\begin{tabular}{|c|c|c|c|c|c|}
\hline \multicolumn{6}{|c|}{ FET - Taxas dia 4 - Tratado $(\mathrm{pH} 7,01)$} \\
\hline $\begin{array}{l}\text { Concentração do } \\
\text { efluente (\%) }\end{array}$ & $\begin{array}{c}\text { Coagulados } \\
(\%)\end{array}$ & $\begin{array}{l}\text { Embriões } \\
\text { vivos (\%) }\end{array}$ & $\begin{array}{l}\text { Eclodidos } \\
\text { vivos (\%) }\end{array}$ & $\begin{array}{l}\text { Eclodidos } \\
\text { mortos (\%) }\end{array}$ & $\begin{array}{c}\text { Mortalidade } \\
\text { total (\%) }\end{array}$ \\
\hline 0,00 & 0,00 & 0,00 & 1,00 & 0,00 & 0,00 \\
\hline 0,00 & 0,00 & 0,00 & 1,00 & 0,00 & 0,00 \\
\hline 0,00 & 0,00 & 0,00 & 1,00 & 0,00 & 0,00 \\
\hline 0,01 & 0,00 & 0,00 & 1,00 & 0,00 & 0,00 \\
\hline 0,01 & 0,00 & 0,00 & 1,00 & 0,00 & 0,00 \\
\hline 0,01 & 0,00 & 0,00 & 1,00 & 0,00 & 0,00 \\
\hline 0,10 & 1,00 & 0,00 & 0,00 & 0,00 & 1,00 \\
\hline 0,10 & 1,00 & 0,00 & 0,00 & 0,00 & 1,00 \\
\hline 0,10 & 1,00 & 0,00 & 0,00 & 0,00 & 1,00 \\
\hline 1,00 & 1,00 & 0,00 & 0,00 & 0,00 & 1,00 \\
\hline 1,00 & 1,00 & 0,00 & 0,00 & 0,00 & 1,00 \\
\hline 1,00 & 1,00 & 0,00 & 0,00 & 0,00 & 1,00 \\
\hline 10,00 & 1,00 & 0,00 & 0,00 & 0,00 & 1,00 \\
\hline 10,00 & 1,00 & 0,00 & 0,00 & 0,00 & 1,00 \\
\hline 10,00 & 1,00 & 0,00 & 0,00 & 0,00 & 1,00 \\
\hline 25,00 & 1,00 & 0,00 & 0,00 & 0,00 & 1,00 \\
\hline 25,00 & 1,00 & 0,00 & 0,00 & 0,00 & 1,00 \\
\hline 25,00 & 1,00 & 0,00 & 0,00 & 0,00 & 1,00 \\
\hline 50,00 & 1,00 & 0,00 & 0,00 & 0,00 & 1,00 \\
\hline 50,00 & 1,00 & 0,00 & 0,00 & 0,00 & 1,00 \\
\hline 50,00 & 1,00 & 0,00 & 0,00 & 0,00 & 1,00 \\
\hline 75,00 & 1,00 & 1,00 & 1,00 & 0,00 & 1,00 \\
\hline 75,00 & 1,00 & 0,00 & 0,00 & 0,00 & 1,00 \\
\hline 75,00 & 1,00 & 0,00 & 0,00 & 0,00 & 1,00 \\
\hline 100,00 & 1,00 & 0,00 & 0,00 & 0,00 & 1,00 \\
\hline 100,00 & 1,00 & 0,00 & 0,00 & 0,00 & 1,00 \\
\hline 100,00 & 1,00 & 0,00 & 0,00 & 0,00 & 1,00 \\
\hline
\end{tabular}

